\title{
Frequency of compound hot-dry weather extremes has significantly increased in Australia since 1889
}

\author{
Brian Collins
}

The University of Queensland, The Queensland Alliance for Agriculture and Food Innovation (QAAFI), Toowoomba, QLD 4350, Australia. Email: brcollins2020@gmail.com.

\begin{abstract}
There is high confidence that climate change has increased the probability of concurrent temperatureprecipitation extremes, changed their spatial-temporal variations, and affected the relationships between drivers of such natural hazards. However, the extent of such changes has been less investigated in Australia. Daily weather data (131 years, 1889-2019) at 700 grid cells $(1 \circ \times 1 \circ)$ across Australia was obtained to calculate annual and seasonal mean daily maximum temperature (MMT) and total precipitation (TPR). A nonparametric multivariate copula framework was adopted to estimate the return period of compound hotdry (CHD) events based on an 'And' hazard scenario (hotter than a threshold 'And' drier than a threshold). CHD extremes were defined as years with joint return periods of larger than 25 years. Mann-Kendall nonparametric tests was used to analyse trends in MMT and TPR as well as in the frequency of univariate and CHD extremes. A general cooling-wetting trend was observed over 1889-1989. Significant increasing trends were detected over 1990-2019 in the frequency and severity of hot extremes across the country while trends in dry extremes were mostly insignificant (and decreasing). Results showed a significant increase in the association between temperature and precipitation at various temporal scales. The frequency of CHD extremes was mostly stable over 1889-1989, but significantly increased between 1990 and 2019 at 44\% of studied grid cells, mostly located in the north, south-east and south-west. Spatial homogeneity (i.e. connectedness) and propagation of extreme events from one grid cell to its neighbouring cells was investigated across Australia. It can be concluded that this connectedness has not significantly changed since 1889.
\end{abstract}

Keywords: Climate change; Mann-Kendall test; Moran's I statistic; Nonparametric copula; Spatial homogeneity; Trend analysis.

\section{INTRODUCTION}

Great many climate risk studies have analysed the univariate hydroclimatic extremes. It has been shown that heatwave magnitudes, frequencies, intensities, and spatial extents are increasing in Australia (Ababaei and Chenu, 2020) and other regions of the world (Pai et al., 2013; Cheng et al., 2014; Sun et al., 2014; Christidis et al., 2015; Ramezani Etedali et al., 2018; Ababaei and Ramezani Etedali, 2019; Ababaei, 2020), a trend that is projected to continue in a warming climate (Lobell et al., 2015; Murari et al., 2015; Alexander and Arblaster, 2017; Zscheischler et al., 2018; Trancoso et al., 2020). Moreover, analyses of historical precipitation, streamflow, and soil moisture indices show an increasing trend of aridity over many regions across the world (Hennessy et al., 1999; Vicente-Serrano et al., 2010; Wang et al., 2011; Mishra and Liu, 2014; Mallya et al., 2015; Araghi et al., 2018; Ababaei and Ramezani Etedali, 2019; Ababaei, 2020). 
Australia's climate has warmed by $1.44^{\circ} \mathrm{C}$ since 1910 , leading to an increase in the frequency of extreme heat events, while a 16\% decline in April-October rainfall in the southwest of Australia has been detected since 1970 (BOM and CSIRO, 2020). Heatwaves have become more intense across Australia between 1950 and 2016, with major increases in the 2000s (Trancoso et al., 2020). Significant decreasing trends in annual precipitation have been reported in the south of SA since 1961 (Rashid and Beecham, 2019) and in summer rainfall in northeast Australia over 1948-2007 (Li et al., 2012) while an increasing trend was observed in northern Australia between 1900 and 2010 (Rogers and Beringer, 2017) and northwest Australia (Lin and $\mathrm{Li}, 2012)$. Hajani et al. (2017) found that increasing trends in annual maximum rainfall intensity were more frequent than decreasing trends in New South Wales. A multi-index study over 1911-2010 across Australia (Alexander and Arblaster, 2017) reported significant trends in temperature extremes associated with warming but few significant trends in precipitation extremes. Jakob and Walland (2016a) found significant long-term increases in extreme maximum temperatures but with substantial regional and seasonal variations. This univariate approach provides valuable information as to the anomalous state of each individual climatic driver; however, it may not accurately represent concurrent extremes and could lead to significant underrepresentation of such extremes (Gr̈aler et al., 2013).

While there is high confidence that human activities and climate change have increased the probability of concurrent precipitation-temperature extremes (Hao et al., 2013; Leonard et al., 2014; Sarhadi et al., 2018), and that the relationships between drivers of such natural hazards have been affected by climate change (AghaKouchak et al., 2014), the extent to which global warming has changed the spatial-temporal variations of such extremes has been less investigated in Australia. More frequent compound extreme events have been recorded in recent decades across the entire globe (Sarhadi et al., 2018). While these extreme events can individually cause significant adverse impacts, their concurrence can be even more impactful. For example, it is known that interactions between heat and drought stresses have major implications for crop production (e.g. Sadras et al., 2012; Tao et al., 2012; Lobell et al., 2013; Dreccer et al., 2018). Moreover, tree mortality can significantly increase due to the compounding effect of drought and hot temperatures and increased risk of wildfires (Williams et al., 2013).

Compound extremes are typically characterized by complex interdependent processes at different spatial and temporal scales (Alizadeh et al., 2020). Multivariate parametric and nonparametric copulas can be used for deriving occurrence probability and return period of dependent variables (Salvadori et al., 2013). Copulas explore the association between two or more variables regardless of their univariate distributions and provide a multivariate distribution (Nelsen, 2003).

It is also important to analyse spatial homogeneity of the area affected by CHD extremes. Large spatially homogenous CHD events can endanger natural and built system services (Fischer et al., 2013). Homogeneous CHD events might fragment the connectedness of natural systems and result in population collapse. As for built systems, such extremes can damage harvests from agricultural lands and lead to quick depletion of relief resources. Analysis of trends in the spatial homogeneity of CHD events has not received much attention in past studies.

Gridded daily precipitation and maximum temperature data (131 years, 1889-2019) were used to calculate annual and seasonal total precipitation (TPR) and mean maximum temperature (MMT), which were then used in an empirical (i.e. nonparametric) copula framework to estimate the return period of compound hotdry (CHD) events. The concept of return period provides critical information for risk assessment and decision-making (AghaKouchak et al., 2014). The joint return period was estimated using an 'And' hazard scenario (hotter than a threshold 'And' drier than a threshold) in a multivariate framework. CHD extremes were defined as years with joint return periods of precipitation deficit and heat excess of larger than 25 years. The trend in the time series of MMT and TPR as well as in the frequency of univariate and CHD extremes 
were analysed across Australia and in each state. The focus is on the comparison between trends and frequencies over the most recent 30-year period (1990-2019) and the previous 101-year period (1889-1989). Spatial homogeneity and propagation of extreme drought and heat events from one grid cell to its neighbouring cells, i.e., self-propagation, were also investigated across Australia. Further, many of the previous studies only analysed the occurrence and concurrence of droughts and heatwaves after the 1940s (e.g. Mueller and Seneviratne, 2012; Hajani et al., 2017; Sharma and Mujumdar, 2017; Sarhadi et al., 2018; Rashid and Beecham, 2019; Trancoso et al., 2020), which, for example, overlooks the widespread droughts in Australia between the 1890s and 1940s (Askarimarnani et al., 2020). The analysis covered 1889-2019 and provided a new perspective into the temporal trends of CHD events across the country. This information can help assess vulnerabilities of natural and built systems to climate change and inform strategies to mitigate the compounding impacts of multiple extremes.

\section{MATERIAL AND METHODS}

\subsection{Weather data}

Daily weather data were obtained from SILO gridded dataset (www.longpaddock.qld.gov.au/silo; Jeffrey et al., 2001) for the period between 1889 and 2019 for 700 grid cells locating on a $1 \circ \times 1 \circ$ grid across Australia (Figure 1). Mean daily maximum temperature (MMT; Figure S1A) and total precipitation (TPR; Figure S1B) were calculated annually as well as over summer (December-February; DJF), autumn (March-May; MAM), winter (June-August; JJA), spring (September-November; SON) and autumn-winter (April-October; A2O). The focus of the text will be on annual and autumn-winter analyses while the detailed data for individual seasons are presented in the Supplementary Material.

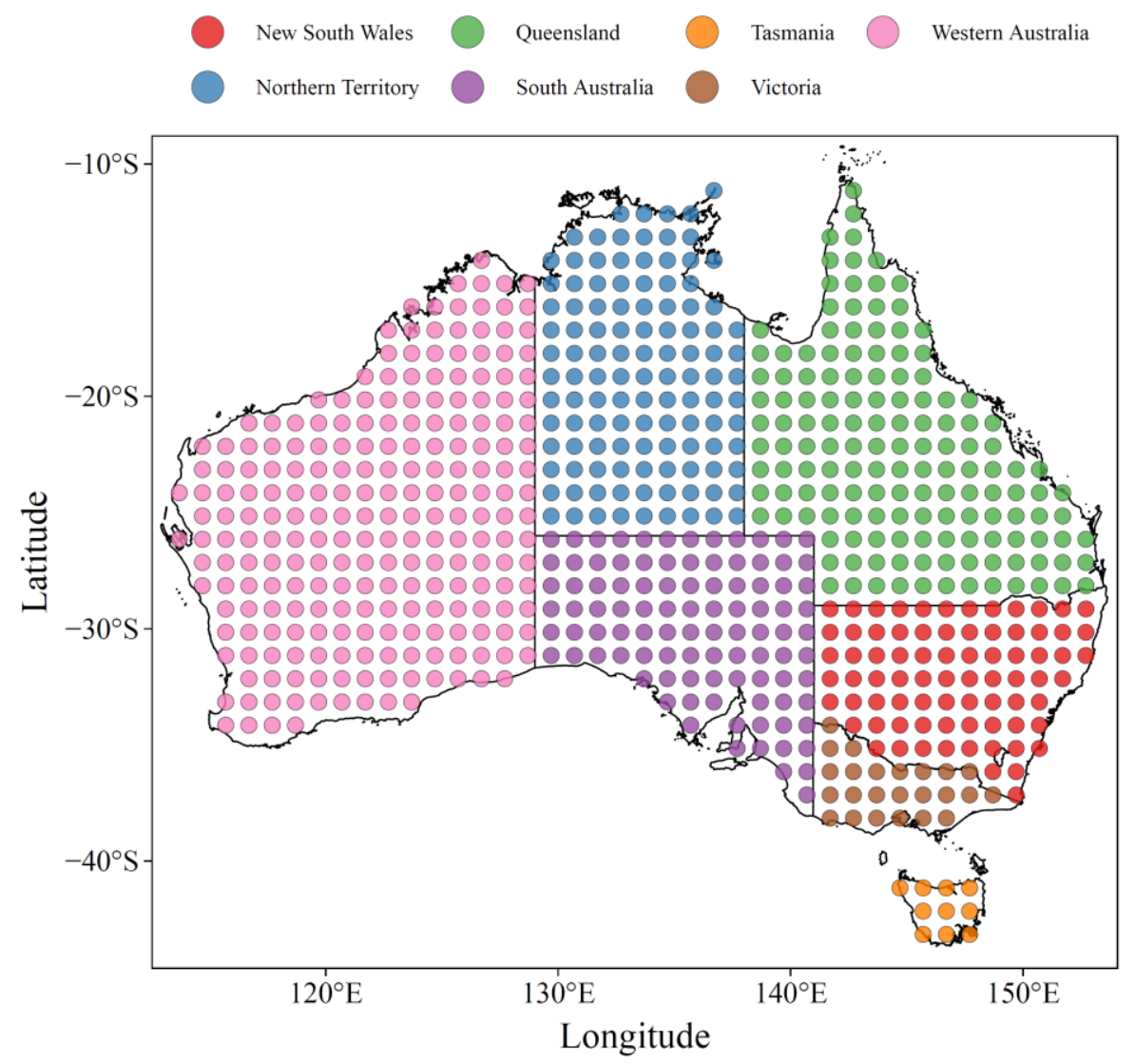

Figure 1. Selected grid cells across Australia. 


\subsection{Compound hot-dry extremes}

A nonparametric approach was adopted to calculate univariate and multivariate probabilities and associated return periods, following Salvadori et al. (2011, 2013), AghaKouchak et al. (2014) and Alizadeh et al. (2020). This way, parametric distributions, which are limited by their underlying assumptions, were not fitted. Having multiple parametric models across Australia would make spatial comparison of results difficult and add extra layer of complexity.

The bivariate return periods of CHD events were calculated using an empirical copula models and an 'And' hazard scenario. Assuming $\mathrm{X}$ and $\mathrm{Y}$ are continuous random variables with univariate distribution functions $\mathrm{F}(\mathrm{x})=\operatorname{Pr}(\mathrm{X} \leq \mathrm{x})$ and $\mathrm{G}(\mathrm{y})=\operatorname{Pr}(\mathrm{Y} \leq \mathrm{y})$, respectively, and a bivariate distribution function $\mathrm{H}(\mathrm{x}, \mathrm{y})=\operatorname{Pr}(\mathrm{X} \leq$ $\mathrm{x}, \mathrm{Y} \leq \mathrm{y})$ that describes their joint distribution. Then, there is a copula, $C$, so that $H(x, y)=C[F(x), G(y)]$. Therefore:

Eq (1) $\quad C(u, v)=H\left[F^{-1}(u), G^{-1}(v)\right]$

The bivariate exceedance probability $(\mathrm{Pr})$ and the return period $(\mathrm{RP})$ for the 'And' scenario can be defined by the following equations:

Eq (2) $\quad \operatorname{Pr}(X>x, Y>y)=1-F(x)-G(y)+C[F(x), G(y)]$

Eq (3) $\quad R P=\frac{1}{\operatorname{Pr}(X>x, Y>y)}$

A CHD extreme was defined as a hot 'And' dry year whose associated return period, based on the corresponding nonparametric bivariate distribution, was larger than 25 years. Similarly, a hot or dry extreme was defined as a year whose associated return period, based on corresponding nonparametric univariate distribution, was larger than 25 years.

\subsection{Spatial correlation}

The spatial autocorrelation of CHD extreme events over a time period was determined using Moran's I (Moran, 1950; hereafter denoted as 'Moran-I'), which is a cross-product statistic between a variable and its spatial lag. For an observation $\mathrm{x}$ at location $\mathrm{i}$, the deviation of observation from its mean $(\bar{X})$ can be expressed as $Z_{i}=x-\bar{X}$. Moran-I is calculated using the following equation:

Eq (4) $\quad$ Moran $-I=\frac{\sum_{i} \sum_{j} W_{i, j} z_{i} \cdot Z_{j} / S_{w}}{\sum_{i} Z_{i}^{2} /{ }_{N}}$

where $\mathrm{W}_{\mathrm{i}, \mathrm{j}}$ is the element $\mathrm{i}, \mathrm{j}$ of the matrix of spatial weights (i.e. the reciprocal of distances between all possible pairs), $\mathrm{N}$ is the number of observations, and $\mathrm{S}_{\mathrm{w}}$ is the sum of all spatial weights. Moran-I takes values between -1 and +1 . Positive and negative values show spatial clustering of similar and dissimilar values, respectively (1: perfect clustering, -1 : perfect dispersion), and a zero value specifies absence of spatial autocorrelation (i.e. perfect randomness). The 'ape' R package was used to calculate Moran-I at all temporal scales. 


\subsection{Temporal trend analysis}

The Mann-Kendall (MK) test (Mann, 1945; Kendall and Gobbons, 1990), a rank-based nonparametric test, was used for investigating the significance of trends. The test has been frequently adopted in hydrological and meteorological studies (e.g. Tabari and Hosseinzadeh Talaee, 2011; Gocic and Trajkovic, 2013; Khalili et al., 2016; Araghi et al., 2018; Ababaei and Chenu, 2019; Ababaei and Ramezani Etedali, 2019; Ababaei, 2020; Alizadeh et al., 2020) and its calculation procedure can be found in Ababaei and Chenu (2020). The accuracy of the test is affected by the presence of serial correlation. In this study, temporal trends were investigated using the method proposed by Yue et al. (2002), which applies a pre-whitening procedure to remove the effect of the lag- 1 autocorrelation. The removal of a positive autocorrelation in time series could lead to inaccurate estimations of trend magnitude. They suggested the Trend Free Pre-whitening (TFPW) procedure in which a trend is removed prior to the estimation of the lag- 1 autocorrelation. The slope is first estimated with the Theil-Sen approach. If it is almost equal to zero, it is not necessary to analyse the trend. Otherwise, the trend is assumed linear, the data is detrended by the estimated slope, and the lag-1 autocorrelation is computed and removed from the detrended series. The trend and residuals are then mixed, and the MK test is applied to the final series to assess the significance of the trend. The R package 'zyp' was used to perform the test (Bronaugh and Werner, 2015). A 95\% confidence level was used to identify significant increasing and decreasing (SI and SD, respectively) trends. The magnitude (i.e. slope) of trends was estimated with a linear regression fitted using the least-squares approach. The magnitude of significant trends are marked with a '*' throughout the text.

\subsection{Distribution test}

The two-sample Kolmogorov-Smirnov test was adopted to identify significant changes in probability distributions. The test is based on the maximum difference between two distribution functions (Massey, 1951). It measures the distance between two empirical distribution functions, $F_{n}$ and $F_{m}$. The test statistic is specified as:

Eq (5) $\quad D=\sup _{x}\left|F_{n}(x)-F_{m}(x)\right|$

where sup is the supremum (i.e. the smallest quantity that is greater than or equal to each of a given set or subset of quantities) of the set of distances. The null hypothesis, $\mathrm{H}_{0}$, is rejected if $\mathrm{D}$ is greater than the significance level at $\mathrm{P}=0.05$.

\section{RESULTS}

\subsection{A general cooling-wetting trend over 1889-1989}

Trend analysis showed SD trends in annual MMT between 1889 and 1989 (Figure 2A) in 49\% of grid cells across Australia while no significant trend was detected in $50 \%$ of grid cells (average rate of change in annual MMT across all grid cells was $-0.04{ }^{\circ} \mathrm{C}$ decade ${ }^{-1}$. Inland cells are more likely to have experienced a decreasing trend in annual MMT than grid cells closer to the shores. Nationally, annual MMT decreased at a rate of *$0.04{ }^{\circ} \mathrm{C}$ decade $^{-1}$. NSW $\left({ }^{*}-0.07\right)$ and TAS $(-0.01)$ had the slowest and fastest declines in annual MMT, respectively. A relatively similar spatial pattern was observed for autumn-winter MMT (Figure S2A), though with $37 \%$ of grid cells showing annual SD trends. Summer $\left(*_{-} 0.04{ }^{\circ} \mathrm{C}\right.$ decade $\left.{ }^{-1}\right)$, autumn $(-0.02)$, winter $(-$ $0.02)$ and spring $(*-0.07)$ all showed decreasing trends in MMT while the rate of decrease for autumn-winter MMT was $*-0.04{ }^{\circ} \mathrm{C}$ decade $^{-1}$ (Figure S7). 
Linear trend in average daily maximum temperature $\left({ }^{\circ} \mathrm{C} /\right.$ decade $)$

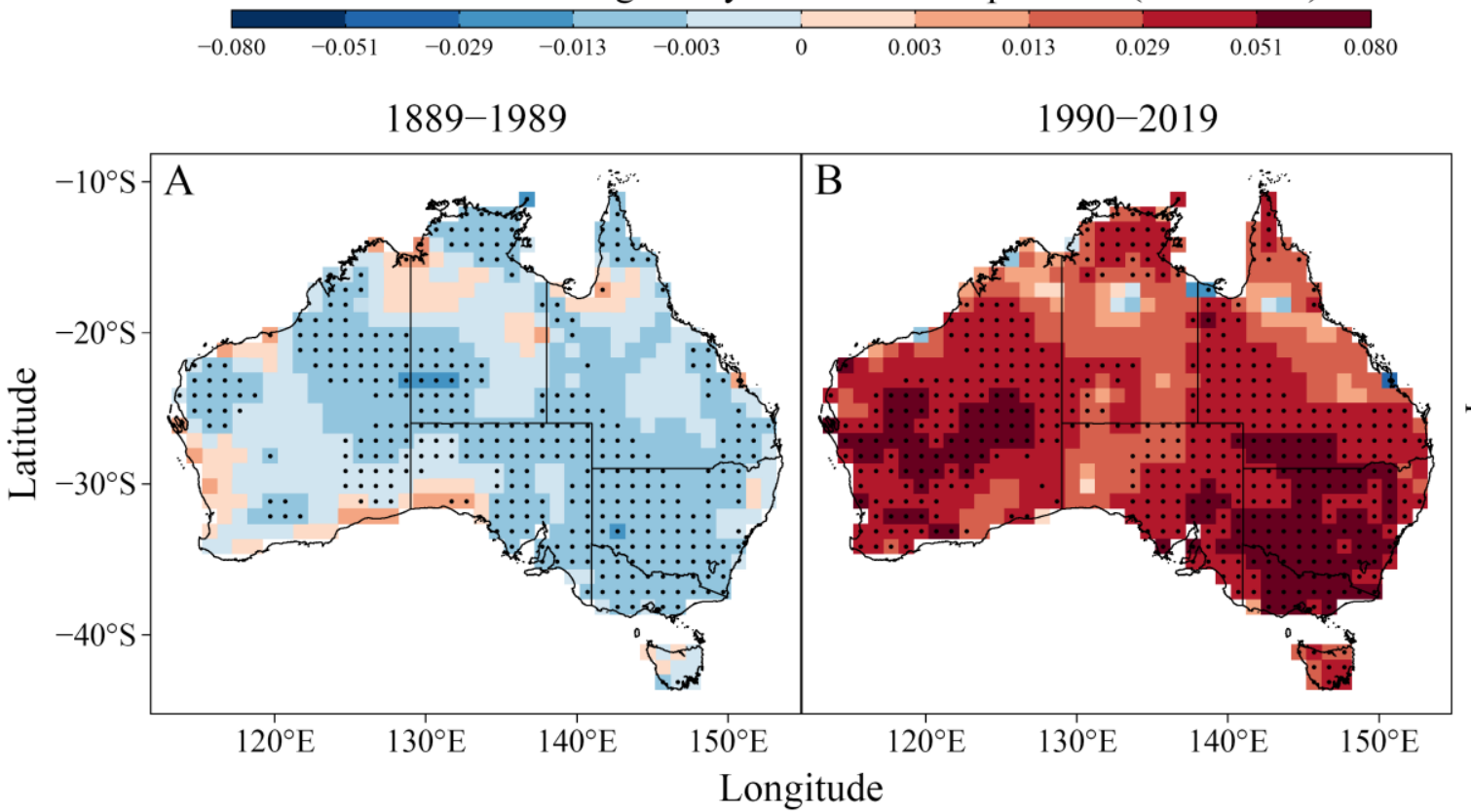

Linear trend in in average total precipitation ( $\mathrm{mm} /$ decade)

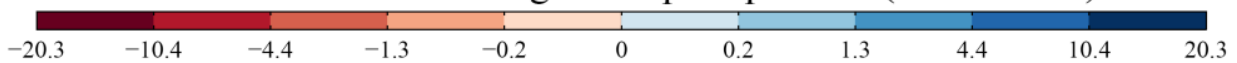

1889-1989

1990-2019

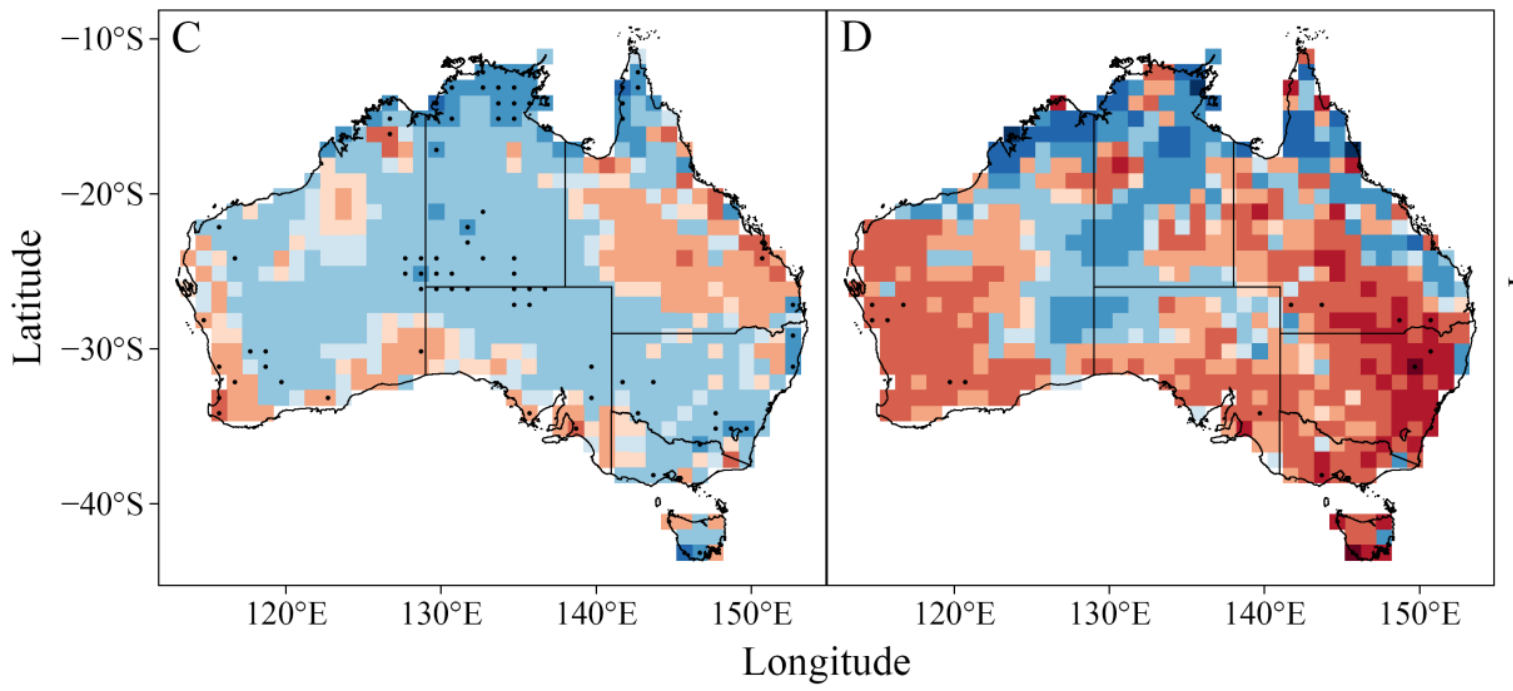

Figure 2. Trends in annual mean maximum daily temperature (MMT; A,B) and total precipitation (TPR; C,D) over 1889-1989 and 1990-2019. Dots show significant trends $(\mathrm{P}<0.05)$. See Figure S3-S6 for seasonal trends.

Over the same period, significant trends in annual TPR were much less pronounced and prevalent across the country (on average across all grid cells: $1.35 \mathrm{~mm}_{\text {decade }}{ }^{-1}$ increase) with only 2 and $9 \%$ of the grid cells experiencing SD and SI trends, respectively (Figure 1C). Most of the grid cells with SI trends were located in central Australia, north of NT, and southern VIC and TAS. Nationally, annual TPR increased at a rate of $3.35 \mathrm{~mm}$ decade ${ }^{-1}$ over $1889-1989$. NT $\left(* 10.03 \mathrm{~mm}\right.$ decade $\left.^{-1}\right)$ experienced the fastest increases in annual TPR while QLD was the only state that experienced a decline by $-0.44 \mathrm{~mm}$ decade ${ }^{-1}$. A relatively similar spatial pattern was observed for autumn-winter TPR (Figure S2C), though with 9 and $0 \%$ of grid cells showing SD and SI trends, respectively. At a national level, summer (2.16 mm decade-1), autumn (1.43) and 
spring (0.76) experienced increasing trends in TPR while winter was the only season with a reduction at $0.64 \mathrm{~mm}$ decade $^{-1}$. National autumn-winter TPR also had an insignificant increasing trend of $0.19 \mathrm{~mm}$ decade $^{-1}$.

\subsection{Enhanced reversed temporal trends over 1990-2019}

Climate change has substantially affected temporal changes of both MMT and TPR in Australia as compared with previous 100 years. Two-sample Kolmogorov-Smirnov tests confirmed that the cumulative distribution of annual MMT has significantly $(\mathrm{P}<0.05)$ changed in $89 \%$ of the country's land (Figure $3 \mathrm{~A}$ ). Instead of a declining pattern for annual MMT, 67\% of grid cells experienced SI trends since 1990 (Figure 2B) and none showed a SD trend. TAS (100\%), NSW (96\%), VIC (96), WA (66) and QLD (60) had the largest shares of grid cells with SI trends while only $40 \%$ of grid cells in NT experienced such trends in MMT. Grid cells with sharpest rises in MMT were mostly found in the whole VIC and NSW, southern QLD, eastern SA, and central WA. Autumn-winter MMT had a similar spatial pattern to that of the annual time series with 53\% of grid cells experiencing SI trends between 1990 and 2019. Over this period and at a national scale, annual MMT increased at a rate of $* 0.37{ }^{\circ} \mathrm{C}$ decade ${ }^{-1}$. VIC $(* 0.59)$ and NT $(* 0.23)$ had the fastest and slowest rises in annual MMT, respectively. Nationally, summer $\left(* 0.36{ }^{\circ} \mathrm{C}\right.$ decade $\left.^{-1}\right)$, autumn $(0.27)$, winter $(* 0.23)$ and spring $(* 0.51)$ all showed increasing trends in MMT while autumn-winter MMT has increased by $* 0.34{ }^{\circ} \mathrm{C}$ decade $^{-1}$ (Figure S7).

\section{Change in distribution}

Insignificant change $\square$ Significant change

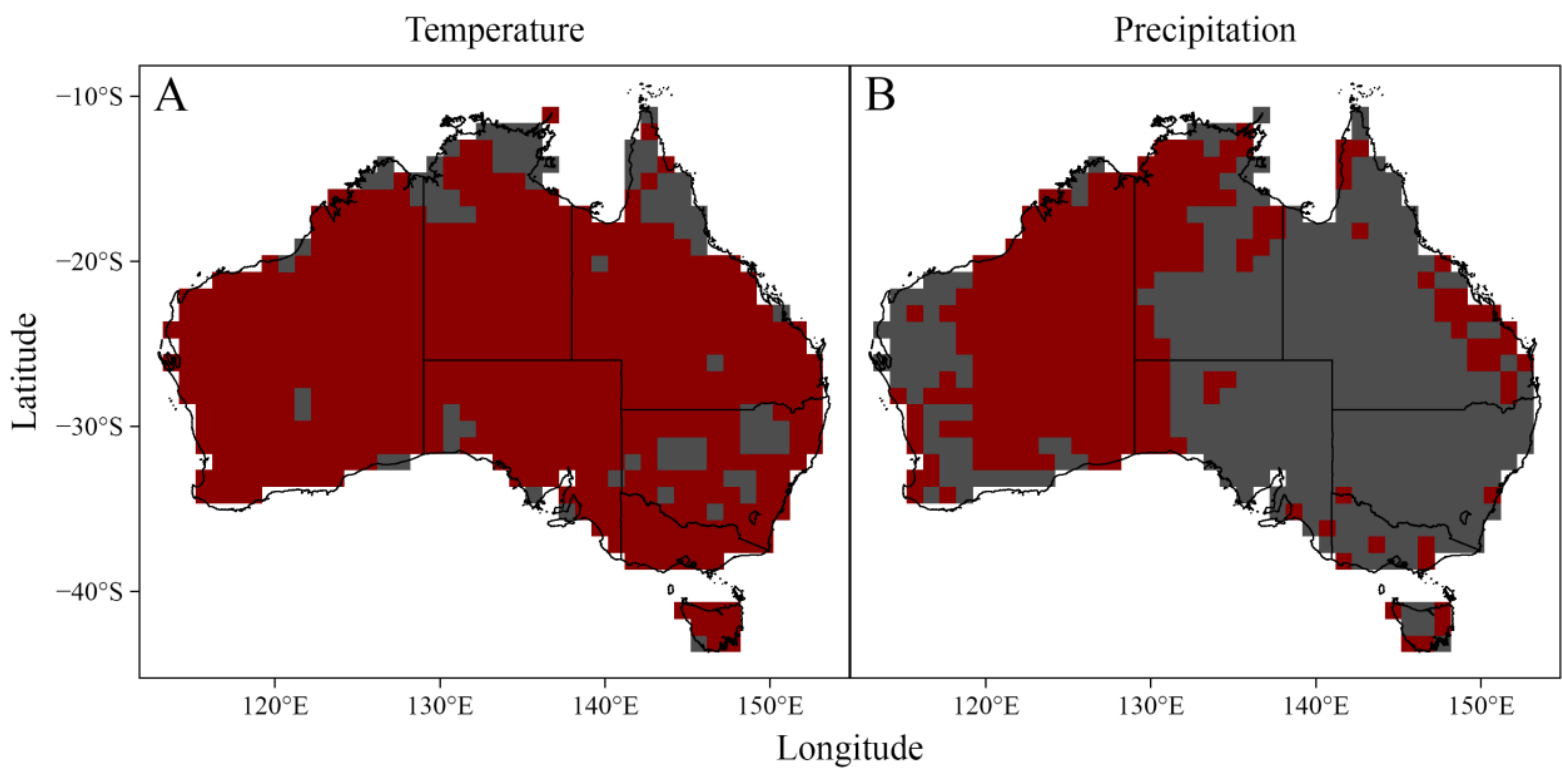

Figure 3. Grid cells with different cumulative distributions for annual mean maximum daily temperature (MMT; A) and annual total precipitation (TPR; B) over 1889-1989 and 1990-2019. Based on Kolmogorov-Smirnov tests.

The impact of climate change on precipitation has been less profound than on temperature. Nearly $98 \%$ of grid cells did not experience significant trends in annual TPR over 1990-2019 while 2\% showed SD trends (Figure 2D), though two-sample Kolmogorov-Smirnov tests showed that $40 \%$ of grid cells had different cumulative distributions for annual TPR over 1889-1989 and 1990-2019 (Figure 3B). Autumn-winter TPR decreased in $9 \%$ of grid cells, mostly located in west of WA, south-east of NSW and southern VIC. At a national scale, annual TPR decreased by $-6.24 \mathrm{~mm}$ decade $^{-1}$ while also no state experienced a significant decline (Figure S7). Summer and autumn were identified to have experienced insignificant increasing trends 
(1.97 and $\left.2.84 \mathrm{~mm}^{\text {decade }}{ }^{-1}\right)$. On the other hand, winter and spring TPR have insignificantly decreased by 4.32 and $1.84 \mathrm{~mm} \mathrm{decade}^{-1}$, respectively, causing a decline in autumn-winter TPR at a statistically insignificant rate of $13.49 \mathrm{~mm}_{\text {decade }}{ }^{-1}$.

\subsection{Association between precipitation and temperature}

Interdependence of precipitation and temperature can intensify the impacts of the anomalous state of each driver (Alizadeh et al., 2020). Linear correlation analysis over 1960-2019 showed significant negative association between TPR and MMT at seasonal and annual scales in majority of grid cells across Australia (Figure 4). The spatial pattern of correlation coefficients varies with seasons. In summer and autumn, a decreasing north-south gradient was observed while in winter, spring and autumn-winter the gradient was reversed. For autumn-winter, the linear correlation was not statistically significant in some grid cells located in the north shores of WA, NT and QLD and few grid cells in TAS.

Climate change has affected this dependence structure at various spatial-temporal scales. Analysis of linear correlation between TPR and MMT over last three 30-year periods showed that the association have escalated significantly over the last century at all temporal scales (Figure 5). For example, the national average of linear correlation coefficients was estimated to be $-0.51,-0.56$ and -0.67 across the country for the periods of 1930-1959, 1960-1989 and 1990-2019, respectively. Only in winter the average correlation did not change significantly across the periods $(-0.44,-0.45$ and -0.44$)$. These findings are in line with the expectation, according to the literature, for increased probability of concurrent hot-dry extremes throughout the year.

\subsection{Compound extremes are now more severe and frequent than in last century}

The frequency of CHD extremes has significantly increased only in parts of the country over the 1889-1989 period (Figure 6C). Over this period, SI trends in return periods of annual CHD extremes were detected in less than $3 \%$ of grid cells and SD trends could only be identified in VIC, south-western NSW, southern TAS, north and southwest of NT, and small parts of WA (i.e. 16\% of grid cells). On the other hand, over $44 \%$ of grid cells showed SI trends in 1990-2019, mostly in NSW, VIC and TAS, southern and western QLD, north of NT, and central and western WA (Figure 6F). Nearly 7\% of grid cells experienced SD trends in autumn-winter CHD extremes over 1889-1989 while in 1990-2019 the spatial pattern of autumn-winter SI trends was more similar to that at an annual scale (Figure S8).

While in 1930-1959 most of the grid cells across Australia observed only 1-2 annual CHD extreme events with some (specially located in central Australia) not observing any (Figure 7), the frequency of such extremes increased to an average of 5.3 events in 1990-2019 (Figure S13), with nearly 50\% of grid cells experiencing $>8$ compound extreme events over the 30 -year period. The increase was most pronounced in SA (average of 1.2 CHD extreme events in 1930-1959 vs 6.7 in 1990-2019), TAS (1.2 vs 7.4) and VIC (1.2 vs 6.6). The increase in the frequency of autumn-winter CHD extremes was larger than that observed at an annual scale, with the average frequency of such bivariate events increasing from 1.9 events in 1930-1959 to 6.8 events in 1990-2019 (Figure S13). Among seasons, summer (2.1 vs 4) had the smallest rise in the frequency of CHD extremes with autumn (2.9 vs 5.5) and winter (1.4 vs 4.3) following while spring (2.2 vs 6) experienced the largest rise. 

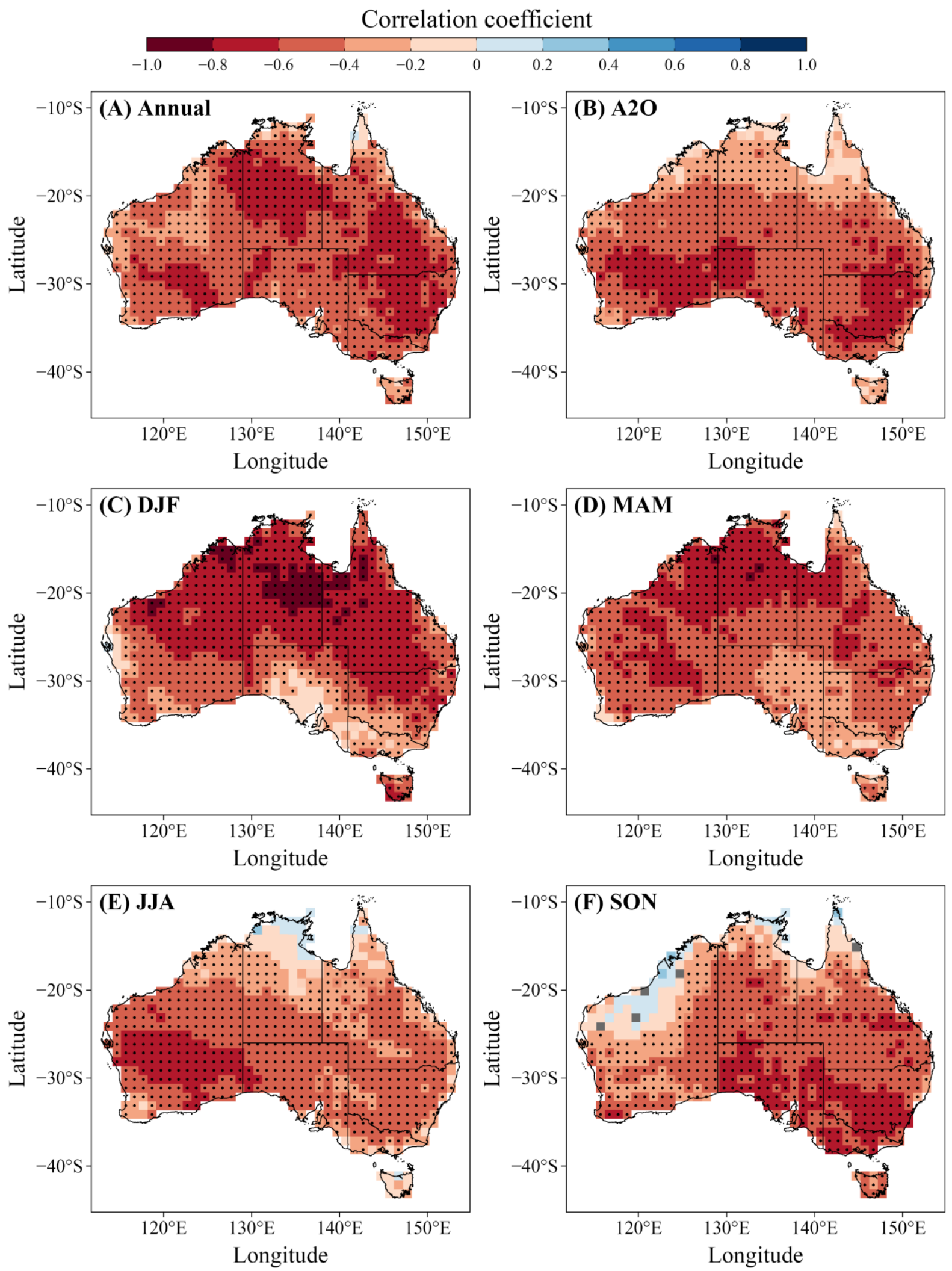

Figure 4. Linear correlation coefficient between mean maximum daily temperature (MMT) and total precipitation (TPR) over 1960-2019. A2O: autumn-winter, DJF: summer, MAM: autumn, JJA: winter, SON: spring. Dots show significant values $(\mathrm{P}<0.05)$.

The cumulative distribution of the return period of CHD extremes over 1990-2019 diverges from that of 1889-1989 in 49 and 85\% of the grid cells for annual and autumn-winter time series (Figures 8-9), based on two-sample Kolmogorov-Smirnov tests. This shift was more marked for hot years with 90 and $95 \%$ of grid 
cells having different cumulative distributions $(\mathrm{P}<0.05)$ over 1889-1989 and 1990-2019, but the shift was less marked for dry years (39 and 19\%). A relatively similar pattern was observed at a state level. At an annual scale, NSW (25\%), NT (46\%), QLD (37\%), SA (76\%), TAS (90\%), VIC (83\%) and WA (50\%) were shown to have high number of grid cells with different cumulative distributions in 1990-2019 than in 18891989. The number of such grid cells were significantly higher for hot years (NSW: 75\%, NT: 85\%, QLD: 88\%, SA: 94\%, TAS: 90\%, VIC: 100\%, and WA: 95\%) and lower for dry years (NSW: 1\%, NT: 40\%, QLD: 15\%, SA: 18\%, TAS: 50\%, VIC: $21 \%$, and WA: $75 \%$ ).

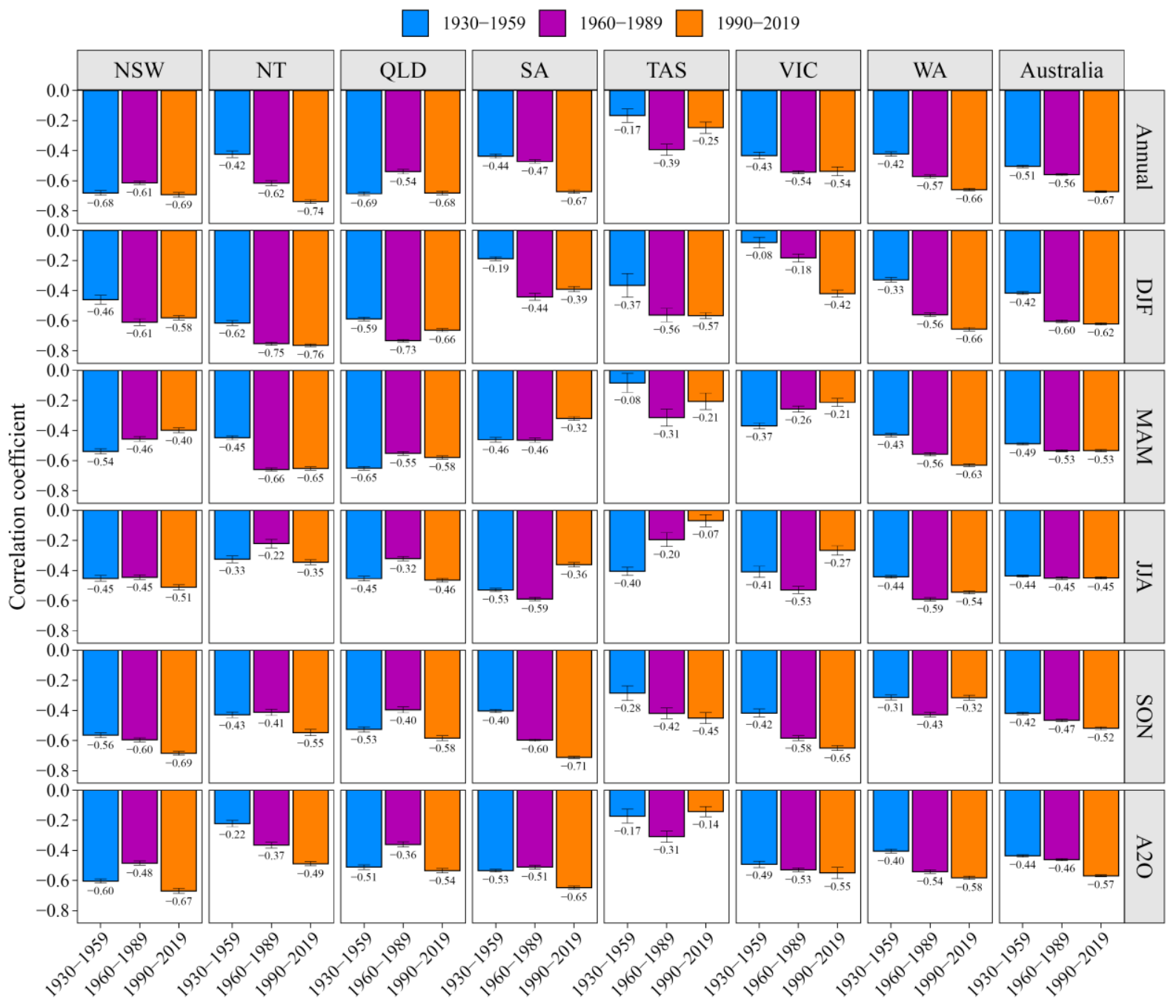

Figure 5. Average linear correlation coefficient between mean maximum daily temperature (MMT) and total precipitation (TPR) over three consecutive 30-year periods between 1930 and 2019. DJF: summer, MAM: autumn, JJA: winter, SON: spring, A2O: autumn-winter.

\subsection{Increasingly larger area is affected by compound hot-dry extremes}

The share of state area affected by annual CHD extremes over 1889-1989 showed a statistically insignificant (except in WA) increasing trend across all states except NSW and QLD (Figure S19). The highest increase rate over this period was associated with SA $\left(0.6 \%\right.$ decade $\left.^{-1}\right)$ and TAS $(0.4 \%)$ while at a national level the rate was estimated to be $0.11 \%$ decade $^{-1}$ though Only WA experienced a SI trend $\left(* 0.38 \%\right.$ decade $\left.^{-1}\right)$. Among the seasons, winter witnessed the fastest rise in the area affected by CHD extremes $\left(* 0.61 \%\right.$ decade $\left.{ }^{-1}\right)$ followed by autumn and spring $\left(0.25 \%\right.$ decade $\left.^{-1}\right)$. 


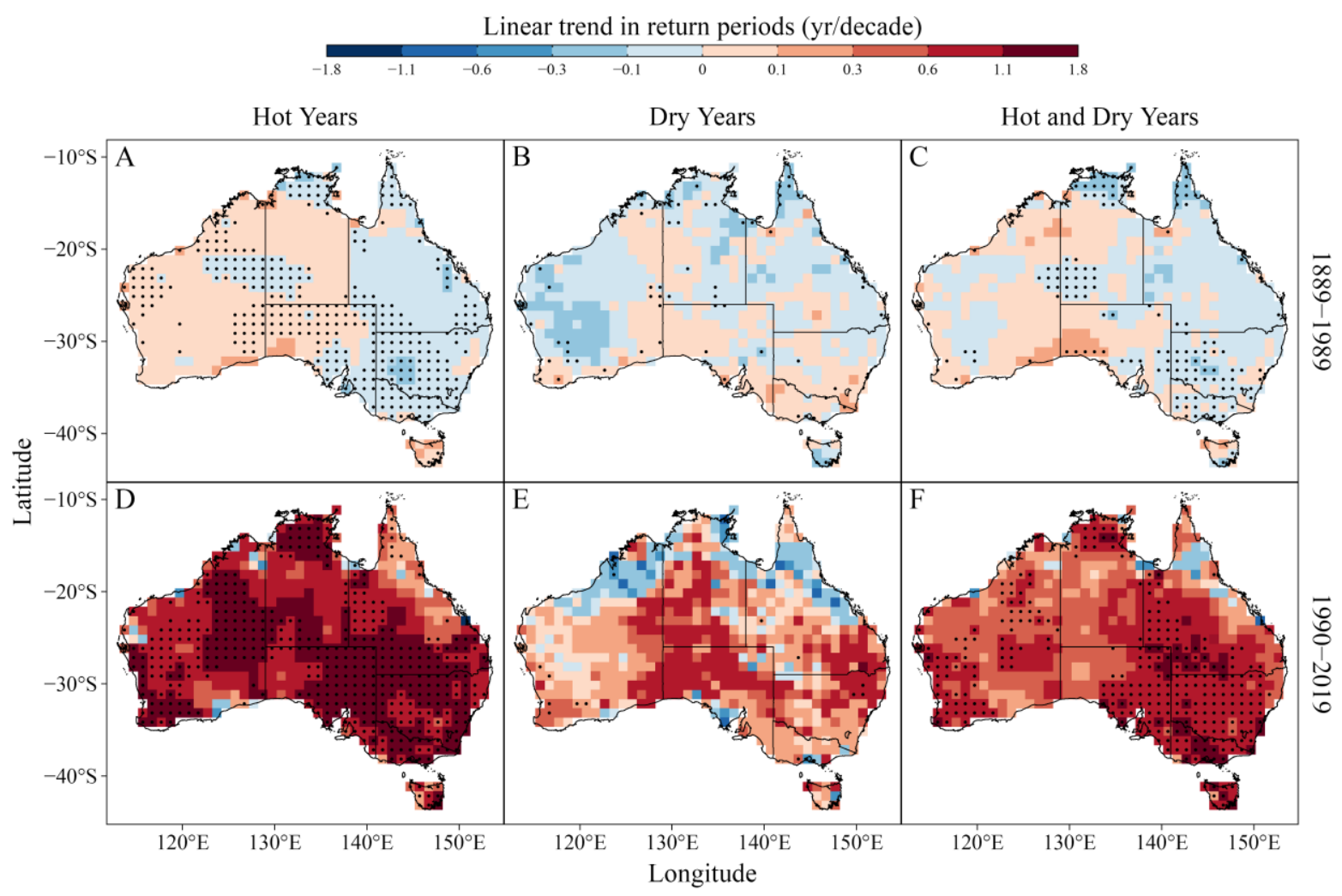

Figure 6. Trends in return periods of annual hot $(\mathbf{A}, \mathbf{D})$, dry $(\mathbf{B}, \mathbf{E})$ and compound hot-and-dry (CHD; $\mathbf{C , F})$ extreme events over 1889-1989 and 1990-2019. Dots show significant trends $(\mathrm{P}<0.05)$. See Figure S8-S12 for seasonal trends.

Propagation of affected area significantly enhanced over 1990-2019 as compared with previous 100 years. At an annual scale, in excess of $* 10 \%$ of country's area was added to the affected area in each decade with an outstanding spike over the last few years (Figure 10$)$. QLD $\left(* 10.6 \%\right.$ decade $\left.{ }^{-1}\right)$, SA $(* 12.5 \%)$, TAS $(* 13.5 \%)$, VIC $(* 17.1 \%)$ also experienced the same propagating pattern while the trend was not significant in NSW (14.1\% decade $\left.{ }^{-1}\right)$, NT (9.7\%) and WA (6.4\%). Nationally, the increasing trend in the affected area was only significant for spring $\left(* 12.3 \%\right.$ decade $\left.^{-1}\right)$ and autumn-winter $(* 11 \%$; Figure S19).

\subsection{Dominant driver of compound hot-dry extremes has changed}

Analysis of correlation between return period of hot extremes and dry extremes with that of CHD extremes showed a shift in the nature of the dominant driver for CHD events in most regions of the country (Figure 11). While the association between CHD and dry extremes declined in 1990-2019 compared with 1930-1959 (e.g. 0.86 in 1930-1959 vs 0.70 in 1990-2019 for annual dry extremes), the association of compound and hot extremes enhanced significantly across Australia (e.g. 0.69 in 1930-1959 vs 0.86 in 1990-2019 for annual hot extremes).

Up to the 1980s, severe dry extremes were mostly the dominant driver of the joint probability of compound extremes (Figure 7, Figure 10). For example, lack of precipitation was the main driver in five out of six years with over $20 \%$ of the country's land affected by CHD extremes before 1980 . However, between the 1980s and 2000s both precipitation deficit and heat excess contributed to the compound events across the country and since 2010, temperature extremes became the main driver of compound extreme events. This pattern was more visible at the state level. For example, NSW $\mid$ NT experienced $11 \mid 10$ outstanding peaks in the affected area by CHD extremes before 1980, of which $9 / 9$ events were mostly driven by precipitation extremes (Figure 10A-B). However, temperature extremes were the main driver of $5 \mid 7$ out of $7 \mid 8$ widespread CHD extremes across NSW|NT since 2000. This implies that the dominant triggering driver 
of the land-atmosphere feedback has shifted from dryness in the first 100 years of the study to temperature extremes in recent decades.

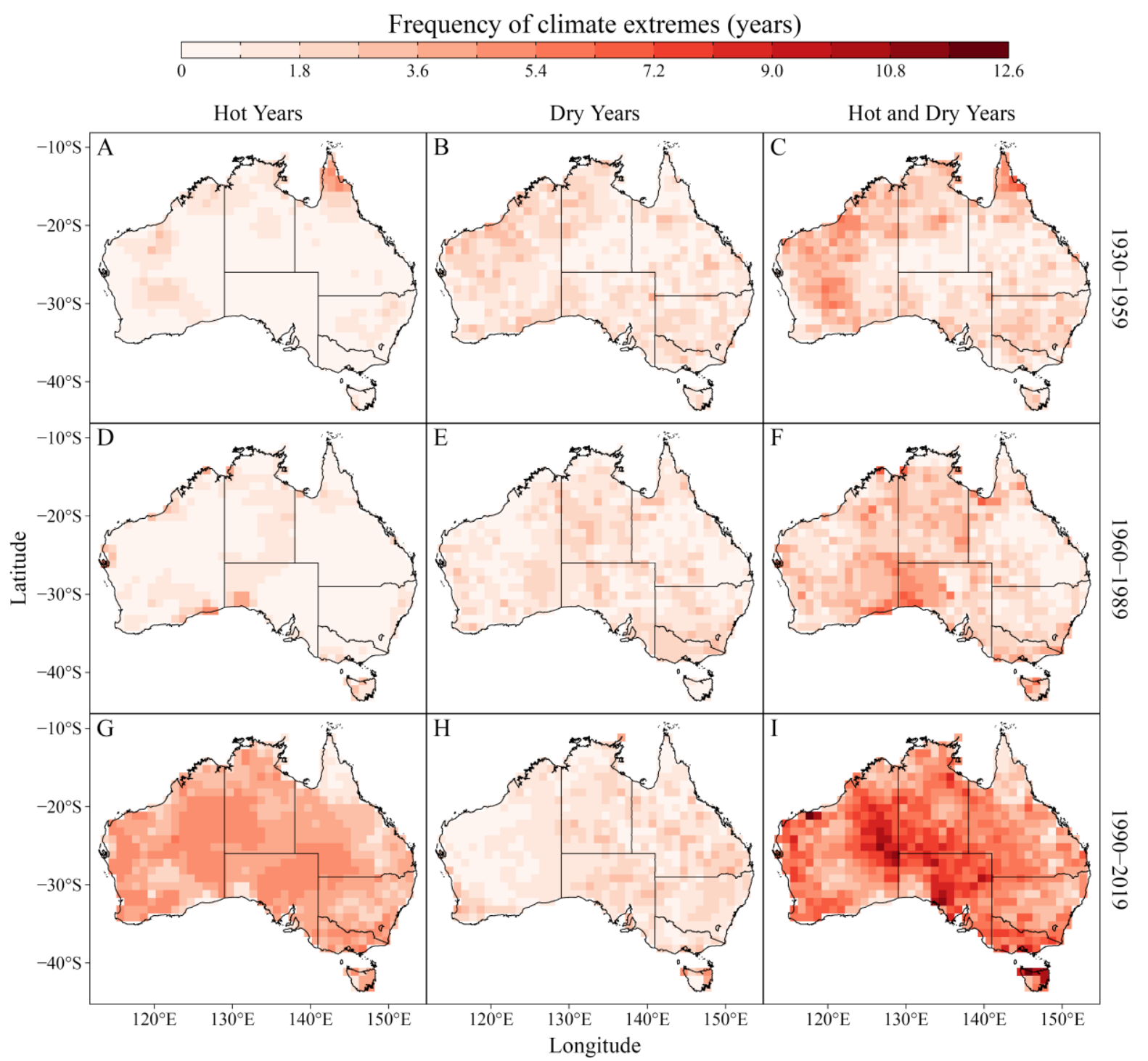

Figure 7. Average frequency of annual hot $(\mathbf{A}, \mathbf{D}, \mathbf{G})$, dry $(\mathbf{B}, \mathbf{E}, \mathbf{H})$ and compound hot-and-dry (CHD; $\mathbf{C , F}, \mathbf{I})$ extreme events over three consecutive 30-year periods between 1930 and 2019. See Figure S14-S18 for seasonal averages.

\subsection{Insignificant changes in spatial homogeneity of compound hot-dry extremes}

The connectedness of grid cells that experience CHD extremes were assessed. At an annual scale and over 1889-1989, spatial homogeneity (the value of Moran-I) of temperature extreme events changed at a rate of -0.057 decade $^{-1}$ across the country, while states also experienced insignificant decreasing trends (Figure 12A). For dry years and $\mathrm{CHD}$ events, slopes were more variable across states though no significant trend was detected (Figure 12C,E). Nationally, spatial homogeneity of CHD events decreased by -0.006 decade $^{-1}$. As expected, the slope of Moran-I significantly increased in all states over 1990-2019 compared with previous 100 years (Figure 12B,D,F). Nationally, Moran-I insignificantly decreased by -0.045 and -0.110 decade $^{-1}$ for hot and dry years, respectively. For CHD years, only SA showed a SD trend $\left(*-0.172\right.$ decade $^{-1}$; Figure $\left.12 \mathrm{~F}\right)$ while other states mostly experienced insignificant decreases. Between 1990 and 2019, the spatial homogeneity of CHD events across Australia decreased at an insignificant rate of -0.02 decade $^{-1}$. 
Change in distribution

Insignificant change $\square$ Significant change

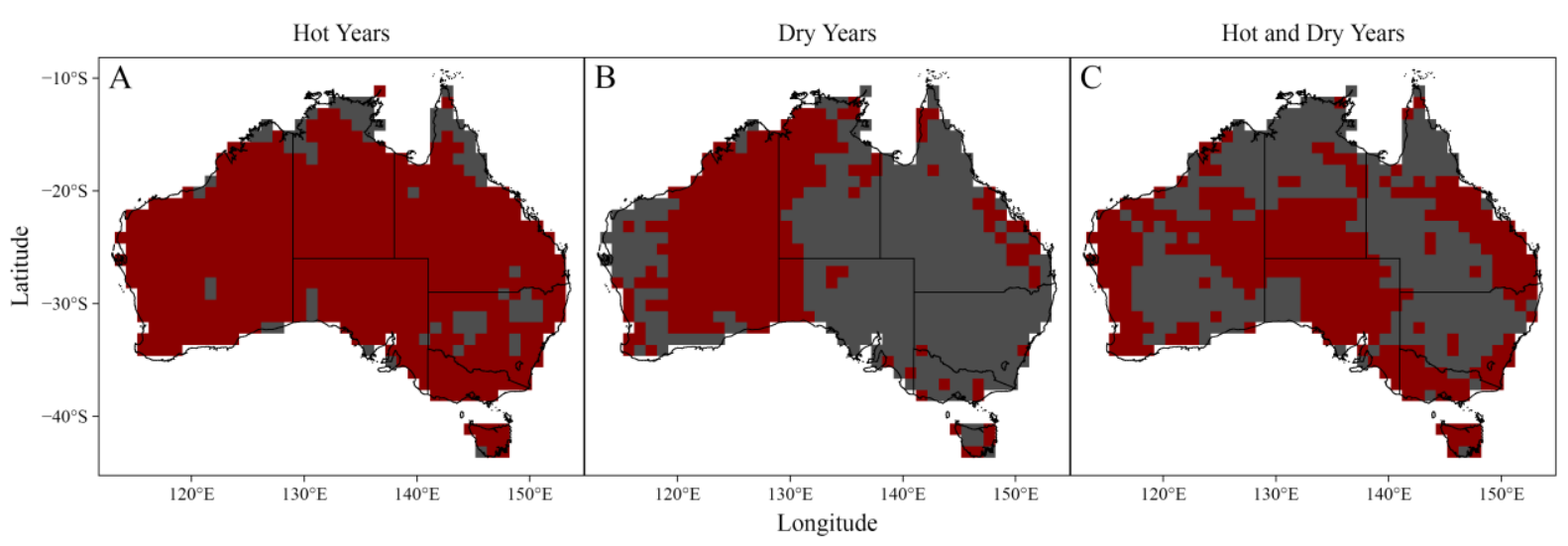

Figure 8. Grid cells with significantly $(\mathrm{P}<0.05)$ different cumulative distributions for return periods of annual hot $(\mathbf{A})$, dry $(\mathbf{B})$ and compound hot-and-dry (CHD; C) extreme events over 1889-1989 and 1990-2019. Based on Kolmogorov-Smirnov tests.

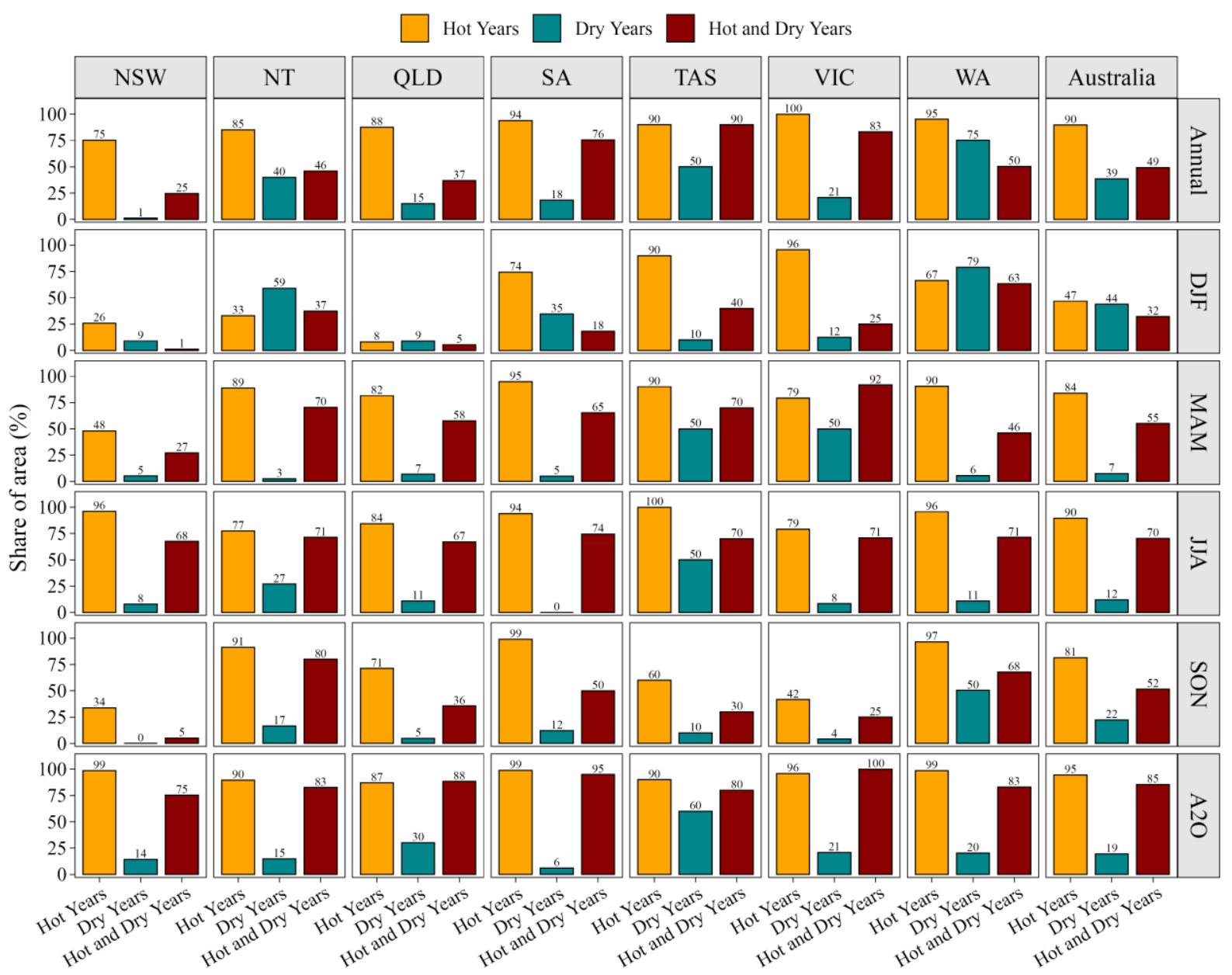

Figure 9. Share of area of states and whole Australia with significantly $(\mathrm{P}<0.05)$ different cumulative distributions for return periods of hot, dry and compound hot-and-dry (CHD) extreme events over 1889-1989 and 1990-2019. Based on KolmogorovSmirnov tests. 


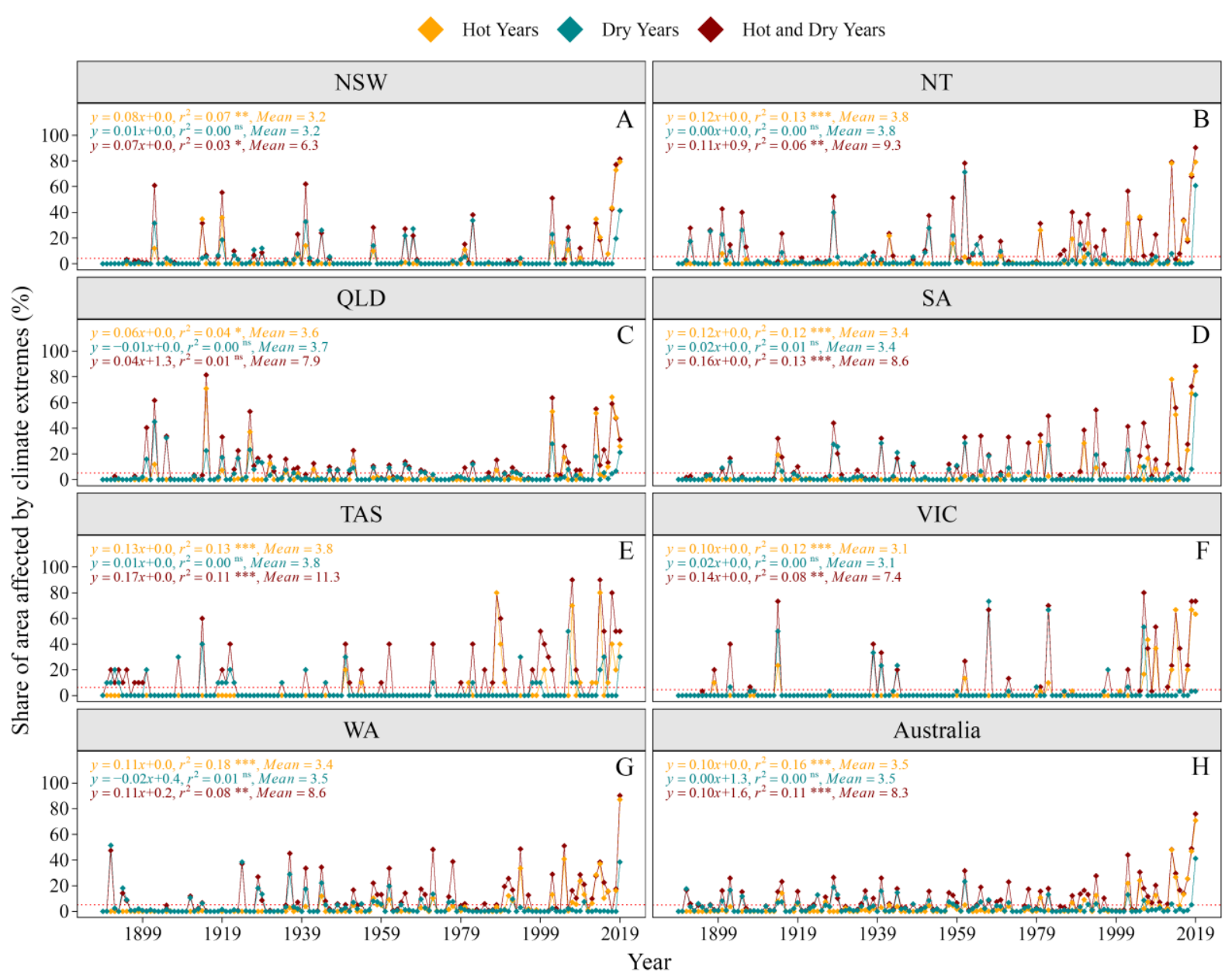

Figure 10. Area affected by annual hot, dry and compound hot-and-dry (CHD) extreme events over 1889-2019. See Figure S20S24 for seasonal trends.

\section{DISCUSSION}

Australia's average temperature has risen by $1.44 \pm 0.24{ }^{\circ} \mathrm{C}$ since 1910 (BOM and CSIRO, 2020), leading to an increase in the frequency of extreme heat events (Jakob and Walland, 2016a; Ababaei and Chenu, 2020). Most of the change has occurred after 1950 (Collins and Della-Marta, 1999; Suppiah et al., 2001) and the warmest years were recorded in the last decade (BOM and CSIRO, 2020). The duration, frequency and intensity of extremely hot events have increased across large parts of Australia with considerable regional and seasonal variations (CSIRO and Bureau of Meteorology, 2016; Jakob and Walland, 2016b; Ababaei and Chenu, 2020).

While there has already been a detectable historical change in some of the rainfall drivers across Australia, changes in its characteristics have been small and not statistically significant in most regions (Figure 2; Dey et al., 2019). There has been a $16 \%$ decline in April to October precipitation in the southwest since 1970 and $12 \%$ in the southeast since 1990 (BOM and CSIRO, 2020), which confirm our findings for the same regions (Figure 2B). Our findings about precipitation historical trends were in agreement with those by Dey et al. (2019). The general consensus into Australia's future precipitation points to lower mean precipitation in southwest Australia and uncertain changes in the north and east (Dey et al., 2019). 


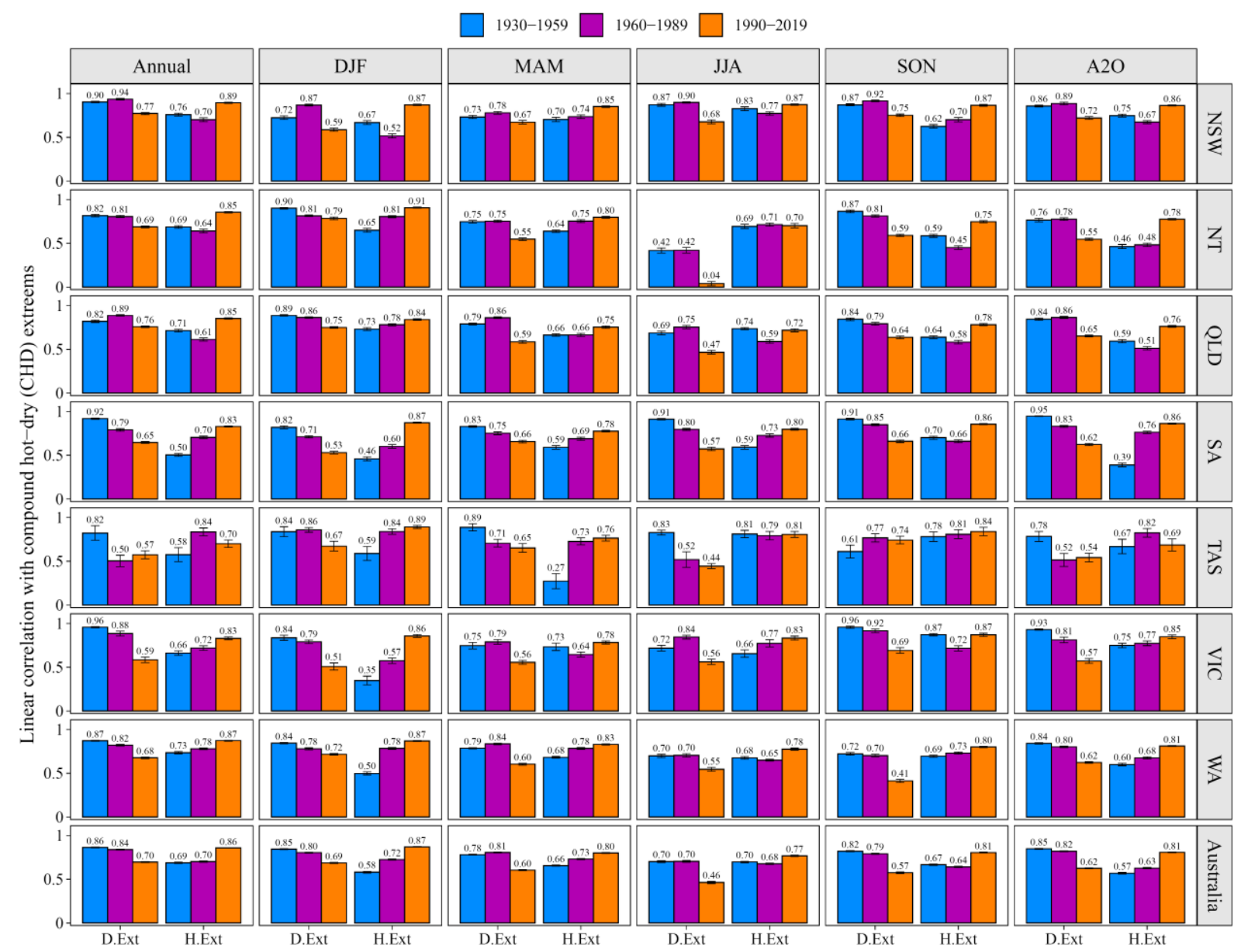

Figure 11. Average linear correlation coefficient between return period of compound hot-dry (CHD) extremes and return period of univariate hot (H.Ext) and dry (D.Ext) extremes over three consecutive 30-year periods between 1930 and 2019. DJF: summer, MAM: autumn, JJA: winter, SON: spring, A2O: autumn-winter.

Changes in temperature may aid in understanding the changes to precipitation as temperatures rises (Wasko and Nathan, 2019). Rising temperatures would naturally lead to higher chance of co-occurrence of hot extremes and dry extremes. Our results demonstrated that enhanced association between temperature and precipitation (Figure 4) has further exacerbated the increase in co-occurrence of such univariate extremes in many parts of Australia. These findings suggest that systems will be hit by hot 'And' dry extremes more frequently and hence need to adapt to them as well as to change in mean climate. This also implies that quantification of the disproportionate impact of compound extremes is crucial in any impact assessment study (Williams et al., 2013).

Land-atmosphere feedbacks can also intensify and propagate large-scale anomalous climatic conditions. For example, higher temperatures and stronger radiative forcing can potentially cause earlier drying of the soil in summer and therefore reduce evaporative cooling (Seneviratne et al., 2010). This could, at least partly, explain the significant enhancement of correlation between temperature and precipitation in spring and summer (Figure 4; Nicholls, 2003). Moreover, land-atmosphere feedbacks increase the occurrence probability of mega heatwaves (Fischer, 2014). Dry soil and partitioning of solar radiation into latent heat decrease evaporation and lead to a larger fraction of the incoming radiation translated into sensible heat which, in turn, warms the environment (Fischer et al., 2007). This cycle restrains local convective precipitation and leads to more severe droughts (Schumacher et al., 2019). 


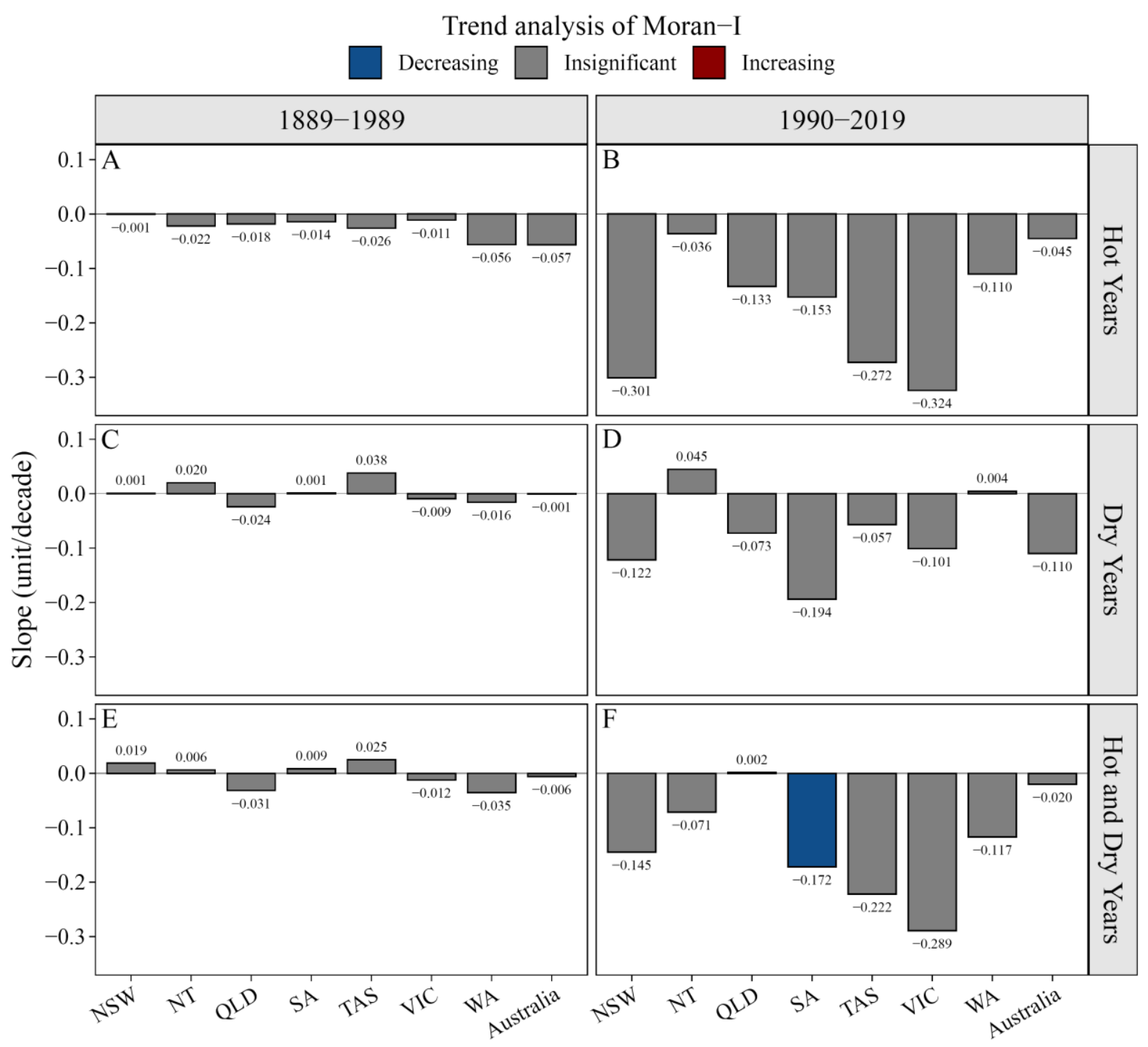

Figure 12. Trends in Moran-I values for annual hot $(\mathbf{A}, \mathbf{B})$, dry $(\mathbf{C}, \mathbf{D})$ and compound hot-and-dry (CHD; E,F) extreme events over 1889-1989 and 1990-2019. Blue and red colors show significant $(\mathrm{P}<0.05)$ decreasing and increasing trends. See Figure S25S29 for seasonal trends.

Atmospheric moisture deficit and heat can propagate from one location to downwind regions (HerreraEstrada et al., 2019; Alizadeh et al., 2020). The tele-connected land-atmosphere feedbacks, i.e. withincontinent transport of terrestrially sourced moisture, are believed to enhance this propagation (Miralles et al., 2019). The propagation of droughts is more important for regions that depend on terrestrially sourced precipitation. Our analysis, however, showed that connectedness between areas impacted by univariate and CHD extremes have not increased since 1889 (Figure 12), except in autumn (Figure S10) and autumn-winter over 1990-2019 (Figure S25). On the contrary, the connectedness has reduced over the last 30 years, though the trend was shown to be statistically insignificant. Connected spatial growth of CHD events can have significant repercussions for societies and natural systems. For example, drought and heatwave in summer of 2010 in Russia caused an estimated $\$ 15$ billion economic loss (Barriopedro et al., 2011).

Our results show that the frequency of CHD extremes has substantially increased across Australia in the past 30 years (Figure 7). Although notable spatial variations was observed over different regions of Australia, there was no significant increasing trend in the frequency of univariate dry extremes (Figure 2; Figure 6); however, hot extremes are becoming more frequent (Figure 6) and more intense (Figure 2). There has been 
a shift in the dominant driver of CHD extremes from dry extremes over 1930-1959 to hot extremes in 19902019 (Figure 11).

If dry extremes of the extent and severity of those observed in the 1930s (Figure 10) occur during the hot years, which are increasingly common now across the country, their concurrence can have much deeper impact (Overpeck, 2013). Moreover, a hotter climate increases water demand, concurrence of which with dry years would adversely affect social and natural systems (Williams et al., 2013). Our findings contribute to a deeper understanding of the spatiotemporal patterns of compound extreme events in Australia. The consequences of the increased frequency, intensity, and spatial homogeneity of multivariate weather extremes are far more severe than the effect of each individual driver (Alizadeh et al., 2020). Therefore, risk assessment frameworks need to consider the compounding effects of multiple extremes rather than addressing drivers individually.

\section{CONCLUSION}

Univariate extreme events can individually cause significant adverse impacts, but their concurrence can be even more impactful. While many studies have been conducted to investigate temporal variations in temperature and precipitation, the extent to which global warming has changed the probability of concurrent precipitation-temperature extremes and their spatial-temporal variations has been less investigated in Australia. Current study was an effort to fill this gap.

Trends in daily maximum temperature and precipitation at seasonal and annual scales were analysed at 700 grid cells across Australia over 1889-2019. A general cooling-wetting trend existed over 1889-1989. However, significant increasing trends were detected in the frequency and severity of hot extremes across the country over 1990-2019 while the trends were mostly insignificant (and decreasing) for dry extremes.

A nonparametric bivariate approach was adopted to analyse trends in the frequency and severity of compound hot-dry extremes over the same period. Comparing the period 1990-2019 with 1930-1959, a significant increase in the association between temperature and precipitation was observed at various temporal scales. The findings showed that the frequency of bivariate extremes was mostly stable over 18891989, but it significantly increased between 1990 and 2019 at 44\% of studied grid cells, mostly located in the north, south-east and south-west.

Large homogenous extreme events can endanger natural and built system services. However, analysis of trends in the spatial homogeneity of univariate and compound extreme events has not received much attention in past studies. The Moran's I statistic was used to analyse the spatial connectedness between impacted areas and found that it has not significantly changed since 1889.

\section{REFERENCES}

Ababaei, B., 2020. SPATIO-TEMPORAL VARIATIONS OF SEVEN WEATHER VARIABLES IN IRAN: APPLICATION OF CRU TS AND GPCC DATA SETS. Irrig. Drain. ird.2399. https://doi.org/10.1002/ird.2399

Ababaei, B., Chenu, K., 2020. Heat shocks increasingly impede grain filling but have little effect on grain setting across the Australian wheatbelt. Agric. For. Meteorol. 284, 107889. https://doi.org/10.1016/j.agrformet.2019.107889

Ababaei, B., Chenu, K., 2019. Recent Trends in Drought, Heat and Frost-Induced Yield Losses Across the Australian Wheatbelt. Proceedings 36, 5. https://doi.org/10.3390/proceedings2019036005

Ababaei, B., Ramezani Etedali, H., 2019. Investigating climate change over 1957-2016 in an arid environment with three drought indexes. Theor. Appl. Climatol. 137, 2977-2992. https://doi.org/10.1007/s00704-019-02793-0

AghaKouchak, A., Cheng, L., Mazdiyasni, O., Farahmand, A., 2014. Global warming and changes in risk of concurrent climate extremes: Insights from the 2014 California drought. Geophys. Res. Lett. 41, 8847-8852. https://doi.org/10.1002/2014GL062308

Alexander, L. V., Arblaster, J.M., 2017. Historical and projected trends in temperature and precipitation extremes in Australia in observations and CMIP5. Weather Clim. Extrem. 15, 34-56. https://doi.org/10.1016/j.wace.2017.02.001

Alizadeh, M.R., Adamowski, J., Nikoo, M.R., AghaKouchak, A., Dennison, P., Sadegh, M., 2020. A century of observations reveals increasing likelihood of continental-scale compound dry-hot extremes. Sci. Adv. 6, eaaz4571. https://doi.org/10.1126/sciadv.aaz4571 
Araghi, A., Martinez, C.J., Adamowski, J., Olesen, J.E., 2018. Spatiotemporal variations of aridity in Iran using high-resolution gridded data. Int. J. Climatol. 38, 2701-2717. https://doi.org/10.1002/joc.5454

Askarimarnani, S.S., Kiem, A.S., Twomey, C.R., 2020. Comparing the performance of drought indicators in Australia from 1900 to 2018. Int. J. Climatol. joc.6737. https://doi.org/10.1002/joc.6737

Barriopedro, D., Fischer, E.M., Luterbacher, J., Trigo, R.M., García-Herrera, R., 2011. The hot summer of 2010: Redrawing the temperature record map of Europe. Science (80-. ). https://doi.org/10.1126/science.1201224

BOM and CSIRO, 2020. State of the climate 2020.

Bronaugh, D., Werner, A., 2015. Package 'zyp.' R Cran.

Cheng, L., AghaKouchak, A., Gilleland, E., Katz, R.W., 2014. Non-stationary extreme value analysis in a changing climate. Clim. Change. https://doi.org/10.1007/s10584-014-1254-5

Christidis, N., Jones, G.S., Stott, P.A., 2015. Dramatically increasing chance of extremely hot summers since the 2003 European heatwave. Nat. Clim. Chang. https://doi.org/10.1038/nclimate2468

Collins, D.A., Della-Marta, P.M., 1999. Annual climate summary 1998: Australia’s warmest year on record. Aust. Meteorol. Mag. 48, 273-283.

CSIRO and Bureau of Meteorology, 2016. State of the climate 2016.

Dey, R., Lewis, S.C., Arblaster, J.M., Abram, N.J., 2019. A review of past and projected changes in Australia's rainfall. Wiley Interdiscip. Rev. Clim. Chang. https://doi.org/10.1002/wcc.577

Dreccer, M.F., Fainges, J., Whish, J., Ogbonnaya, F.C., Sadras, V.O., 2018. Comparison of sensitive stages of wheat, barley, canola, chickpea and field pea to temperature and water stress across Australia. Agric. For. Meteorol. 248, 275-294. https://doi.org/10.1016/j.agrformet.2017.10.006

Fischer, E.M., 2014. Autopsy of two mega-heatwaves. Nat. Geosci. https://doi.org/10.1038/ngeo2148

Fischer, E.M., Beyerle, U., Knutti, R., 2013. Robust spatially aggregated projections of climate extremes. Nat. Clim. Chang. https://doi.org/10.1038/nclimate2051

Fischer, E.M., Seneviratne, S.I., Vidale, P.L., Lüthi, D., Schär, C., 2007. Soil moisture-atmosphere interactions during the 2003 European summer heat wave. J. Clim. https://doi.org/10.1175/JCLI4288.1

Gocic, M., Trajkovic, S., 2013. Analysis of changes in meteorological variables using Mann-Kendall and Sen's slope estimator statistical tests in Serbia. Glob. Planet. Change 100, 172-182. https://doi.org/10.1016/j.gloplacha.2012.10.014

Gäler, B., Van Den Berg, M.J., Vandenberghe, S., Petroselli, A., Grimaldi, S., De Baets, B., Verhoest, N.E.C., 2013. Multivariate return periods in hydrology: A critical and practical review focusing on synthetic design hydrograph estimation. Hydrol. Earth Syst. Sci. https://doi.org/10.5194/hess-17-1281-2013

Hajani, E., Rahman, A., Ishak, E., 2017. Trends in extreme rainfall in the state of New South Wales, Australia. Hydrol. Sci. J. 62, $2160-2174$. https://doi.org/10.1080/02626667.2017.1368520

Hao, Z., Aghakouchak, A., Phillips, T.J., 2013. Changes in concurrent monthly precipitation and temperature extremes. Environ. Res. Lett. https://doi.org/10.1088/1748-9326/8/3/034014

Hennessy, K.J., Suppiah, R., Page, C.M., 1999. Australian rainfall changes, 1910-1995. Aust. Meteorol. Mag.

Herrera-Estrada, J.E., Martinez, J.A., Dominguez, F., Findell, K.L., Wood, E.F., Sheffield, J., 2019. Reduced Moisture Transport Linked to Drought Propagation Across North America. Geophys. Res. Lett. https://doi.org/10.1029/2019GL082475

Jakob, D., Walland, D., 2016a. Variability and long-term change in Australian temperature and precipitation extremes. Weather Clim. Extrem. 14, 36-55. https://doi.org/10.1016/j.wace.2016.11.001

Jakob, D., Walland, D., 2016b. Variability and trends in temperature and precipitation extremes. Weather Clim. Extrem. 14, 1-19. https://doi.org/10.1016/j.wace.2016.11.001

Jeffrey, S.J., Carter, J.O., Moodie, K.B., Beswick, A.R., 2001. Using spatial interpolation to construct a comprehensive archive of Australian climate data. Environ. Model. Softw. 16, 309-330. https://doi.org/10.1016/S1364-8152(01)00008-1

Kendall, M.G., Gobbons, J.D., 1990. Rank Correlation Methods, Science Forum.

Khalili, K., Tahoudi, M.N., Mirabbasi, R., Ahmadi, F., 2016. Investigation of spatial and temporal variability of precipitation in Iran over the last half century. Stoch. Environ. Res. Risk Assess. 30, 1205-1221. https://doi.org/10.1007/s00477-015-1095-4

Leonard, M., Westra, S., Phatak, A., Lambert, M., van den Hurk, B., McInnes, K., Risbey, J., Schuster, S., Jakob, D., Stafford-Smith, M., 2014. A compound event framework for understanding extreme impacts. Wiley Interdiscip. Rev. Clim. Chang. 5, 113-128. https://doi.org/10.1002/wcc. 252

Li, J., Feng, J., Li, Y., 2012. A possible cause of decreasing summer rainfall in northeast Australia. Int. J. Climatol. 32, 995-1005. https://doi.org/10.1002/joc.2328

Lin, Z., Li, Y., 2012. Remote influence of the tropical Atlantic on the variability and trend in North West Australia summer rainfall. J. Clim. 25, 2408-2420. https://doi.org/10.1175/JCLI-D-11-00020.1

Lobell, D.B., Hammer, G.L., Chenu, K., Zheng, B., McLean, G., Chapman, S.C., 2015. The shifting influence of drought and heat stress for crops in northeast Australia. Glob. Chang. Biol. 21, 4115-4127. https://doi.org/10.1111/gcb.13022

Lobell, D.B., Hammer, G.L., McLean, G., Messina, C., Roberts, M.J., Schlenker, W., 2013. The critical role of extreme heat for maize production in the United States. Nat. Clim. Chang. 3, 497-501. https://doi.org/10.1038/nclimate1832

Mallya, G., Mishra, V., Niyogi, D., Tripathi, S., Govindaraju, R.S., 2015. Trends and variability of droughts over the Indian monsoon region. Weather Clim. Extrem. https://doi.org/10.1016/j.wace.2016.01.002

Mann, H.B., 1945. Nonparametric tests against trend. Econom. J. Econom. Soc. 245-259. https://doi.org/10.1017/CBO9781107415324.004

Massey, F.J., 1951. The Kolmogorov-Smirnov Test for Goodness of Fit. J. Am. Stat. Assoc. 46, 68-78. https://doi.org/10.1080/01621459.1951.10500769

Miralles, D.G., Gentine, P., Seneviratne, S.I., Teuling, A.J., 2019. Land-atmospheric feedbacks during droughts and heatwaves: state of the science and current challenges. Ann. N. Y. Acad. Sci. 1436, 19-35. https://doi.org/10.1111/nyas.13912

Mishra, A., Liu, S.C., 2014. Changes in precipitation pattern and risk of drought over India in the context of global warming. J. Geophys. Res. https://doi.org/10.1002/2014JD021471

Moran, P.A.P., 1950. NOTES ON CONTINUOUS STOCHASTIC PHENOMENA. Biometrika $37, \quad 17-23$. 
https://doi.org/10.1093/biomet/37.1-2.17

Mueller, B., Seneviratne, S.I., 2012. Hot days induced by precipitation deficits at the global scale. Proc. Natl. Acad. Sci. 109, $12398-12403$. https://doi.org/10.1073/pnas.1204330109

Murari, K.K., Ghosh, S., Patwardhan, A., Daly, E., Salvi, K., 2015. Intensification of future severe heat waves in India and their effect on heat stress and mortality. Reg. Environ. Chang. https://doi.org/10.1007/s10113-014-0660-6

Nelsen, R.B., 2003. Properties and applications of copulas: A brief survey. First Brazilian Conf. Stat. Model. Insur. Financ.

Nicholls, N., 2003. Continued anomalous warming in Australia. Geophys. Res. Lett. 30. https://doi.org/10.1029/2003GL017037

Overpeck, J.T., 2013. The challenge of hot drought. Nature. https://doi.org/10.1038/503350a

Pai, D.S., Nair, S.A., Ramanathan, A.N., 2013. Long term climatology and trends of heat waves over India during the recent 50 years (1961-2010). Mausam.

Ramezani Etedali, H., Ababaei, B., Kaviani, A., 2018. Analysis of long-term impact of climate change on temperature over Iran using the CRU dataset. [in Persian]. J. Water Soil Resour. Conserv. 8, 25-48.

Rashid, M.M., Beecham, S., 2019. Development of a non-stationary Standardized Precipitation Index and its application to a South Australian climate. Sci. Total Environ. 657, 882-892. https://doi.org/10.1016/j.scitotenv.2018.12.052

Rogers, C.D.W., Beringer, J., 2017. Describing rainfall in northern Australia using multiple climate indices. Biogeosciences 14, 597-615. https://doi.org/10.5194/bg-14-597-2017

Sadras, V.O., Lake, L., Chenu, K., McMurray, L.S., Leonforte, A., 2012. Water and thermal regimes for field pea in Australia and their implications for breeding. Crop Pasture Sci. 63, 33-44. https:// doi.org/10.1071/CP11321

Salvadori, G., De Michele, C., Durante, F., 2011. On the return period and design in a multivariate framework. Hydrol. Earth Syst. Sci. https://doi.org/10.5194/hess-15-3293-2011

Salvadori, G., Durante, F., De Michele, C., 2013. Multivariate return period calculation via survival functions. Water Resour. Res. https://doi.org/10.1002/wrcr.20204

Sarhadi, A., Ausín, M.C., Wiper, M.P., Touma, D., Diffenbaugh, N.S., 2018. Multidimensional risk in a nonstationary climate: Joint probability of increasingly severe warm and dry conditions. Sci. Adv. 4, eaau3487. https://doi.org/10.1126/sciadv.aau3487

Schumacher, D.L., Keune, J., van Heerwaarden, C.C., Vilà-Guerau de Arellano, J., Teuling, A.J., Miralles, D.G., 2019. Amplification of megaheatwaves through heat torrents fuelled by upwind drought. Nat. Geosci. https://doi.org/10.1038/s41561-019-0431-6

Seneviratne, S.I., Corti, T., Davin, E.L., Hirschi, M., Jaeger, E.B., Lehner, I., Orlowsky, B., Teuling, A.J., 2010. Investigating soil moisture-climate interactions in a changing climate: A review. Earth-Science Rev. https://doi.org/10.1016/j.earscirev.2010.02.004

Sharma, S., Mujumdar, P., 2017. Increasing frequency and spatial extent of concurrent meteorological droughts and heatwaves in India. Sci. Rep. https://doi.org/10.1038/s41598-017-15896-3

Sun, Y., Zhang, X., Zwiers, F.W., Song, L., Wan, H., Hu, T., Yin, H., Ren, G., 2014. Rapid increase in the risk of extreme summer heat in Eastern China. Nat. Clim. Chang. https://doi.org/10.1038/nclimate2410

Suppiah, R., Suppiah, R., Collins, D., Collins, D., Della-marta, P., Della-marta, P., 2001. Observed changes in australian climate. Atmos. Res. 1-6.

Tabari, H., Hosseinzadeh Talaee, P., 2011. Analysis of trends in temperature data in arid and semi-arid regions of Iran. Glob. Planet. Change 79, $1-$ 10. https://doi.org/10.1016/j.gloplacha.2011.07.008

Tao, F., Zhang, S., Zhang, Z., 2012. Spatiotemporal changes of wheat phenology in China under the effects of temperature, day length and cultivar thermal characteristics. Eur. J. Agron. 43, 201-212. https://doi.org/10.1016/j.eja.2012.07.005

Trancoso, R., Syktus, J., Toombs, N., Ahrens, D., Wong, K.K.H., Pozza, R.D., 2020. Heatwaves intensification in Australia: A consistent trajectory across past, present and future. Sci. Total Environ. 742, 140521. https://doi.org/10.1016/j.scitotenv.2020.140521

Vicente-Serrano, S.M., Beguería, S., López-Moreno, J.I., 2010. A Multiscalar Drought Index Sensitive to Global Warming: The Standardized Precipitation Evapotranspiration Index. J. Clim. 23, 1696-1718. https://doi.org/10.1175/2009JCLI2909.1

Wang, A., Lettenmaier, D.P., Sheffield, J., 2011. Soil moisture drought in China, 1950-2006. J. Clim. 24, $3257-3271$. https://doi.org/10.1175/2011JCLI3733.1

Wasko, C., Nathan, R., 2019. The local dependency of precipitation on historical changes in temperature. Clim. Change 156, 105-120. https://doi.org/10.1007/s10584-019-02523-5

Williams, A.P., Allen, C.D., Macalady, A.K., Griffin, D., Woodhouse, C.A., Meko, D.M., Swetnam, T.W., Rauscher, S.A., Seager, R., Grissino-Mayer, H.D., Dean, J.S., Cook, E.R., Gangodagamage, C., Cai, M., Mcdowell, N.G., 2013. Temperature as a potent driver of regional forest drought stress and tree mortality. Nat. Clim. Chang. 3, 292-297. https://doi.org/10.1038/nclimate1693

Yue, S., Pilon, P., Phinney, B., Cavadias, G., 2002. The influence of autocorrelation on the ability to detect trend in hydrological series. Hydrol. Process. 16, 1807-1829. https://doi.org/10.1002/hyp.1095

Zscheischler, J., Westra, S., Van Den Hurk, B.J.J.M., Seneviratne, S.I., Ward, P.J., Pitman, A., Aghakouchak, A., Bresch, D.N., Leonard, M., Wahl, T., Zhang, X., 2018. Future climate risk from compound events. Nat. Clim. Chang. https://doi.org/10.1038/s41558-018-0156-3 


\title{
Frequency of compound hot-dry weather extremes has significantly increased in Australia since 1889
}

\author{
Brian Collins
}

The University of Queensland, The Queensland Alliance for Agriculture and Food Innovation (QAAFI), Toowoomba, QLD 4350, Australia. Email: brcollins2020@gmail.com.

\section{Supplementary Material}




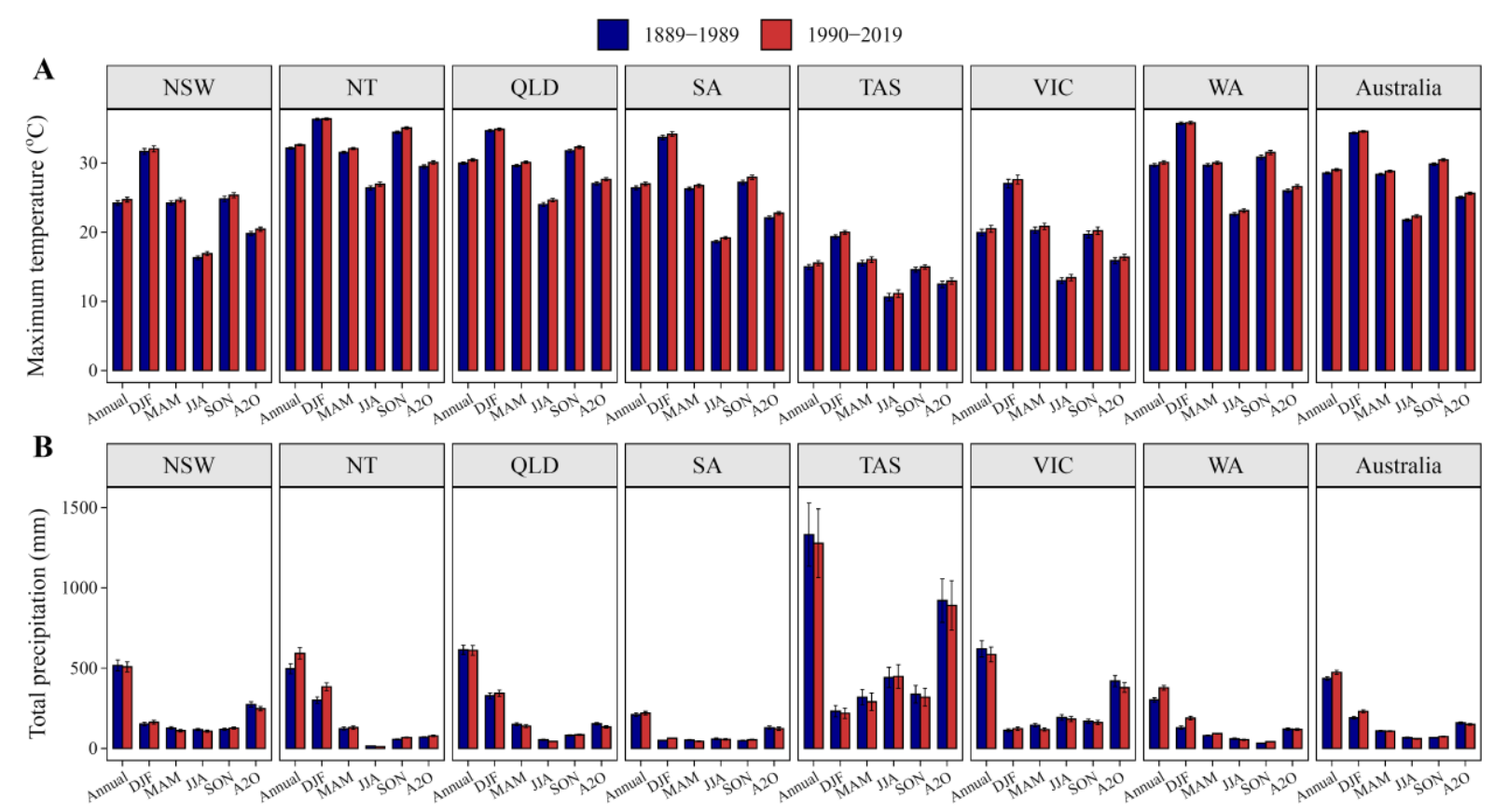

Figure S1. Annual and seasonal averages of daily maximum temperature $(\mathbf{A})$ and total daily precipitation $(\mathbf{B})$ across states and whole Australia. A2O: autumn-winter, DJF: summer, MAM: autumn, JJA: winter, SON: spring. NSW: New South Wales, NT:

Northern Territory, QLD: Queensland, SA: South Australia, TAS: Tasmania, VIC: Victoria, WA: Western Australia. 
Linear trend in average daily maximum temperature $\left({ }^{\circ} \mathrm{C} /\right.$ decade $)$
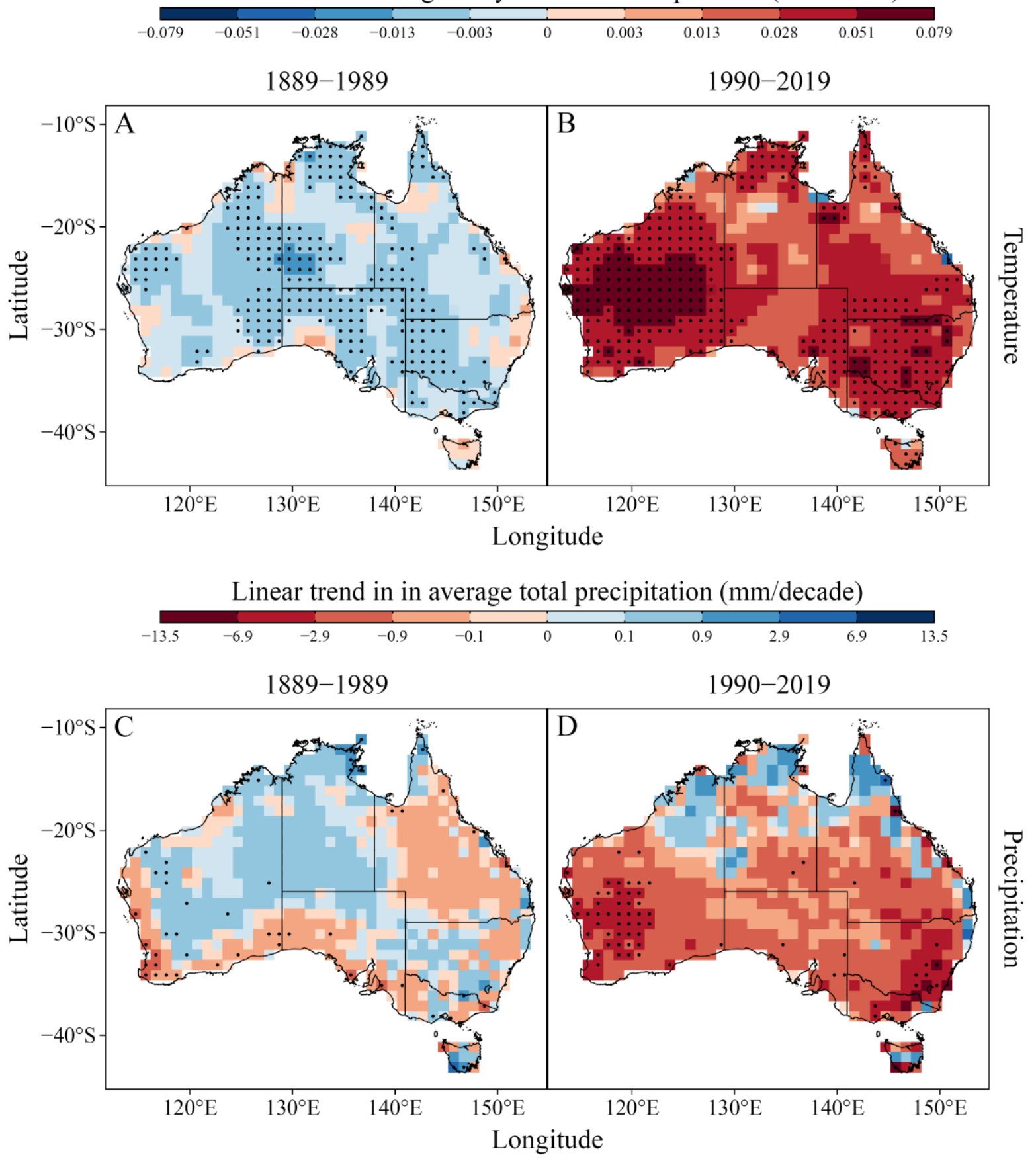

Figure S2. Trends in autumn-winter mean maximum daily temperature (MMT; A,B) and total precipitation (TPR; C,D) over 1889-1989 and 1990-2019. Dots show significant trends $(\mathrm{P}<0.05)$. 
Linear trend in average daily maximum temperature $\left({ }^{\circ} \mathrm{C} /\right.$ decade $)$

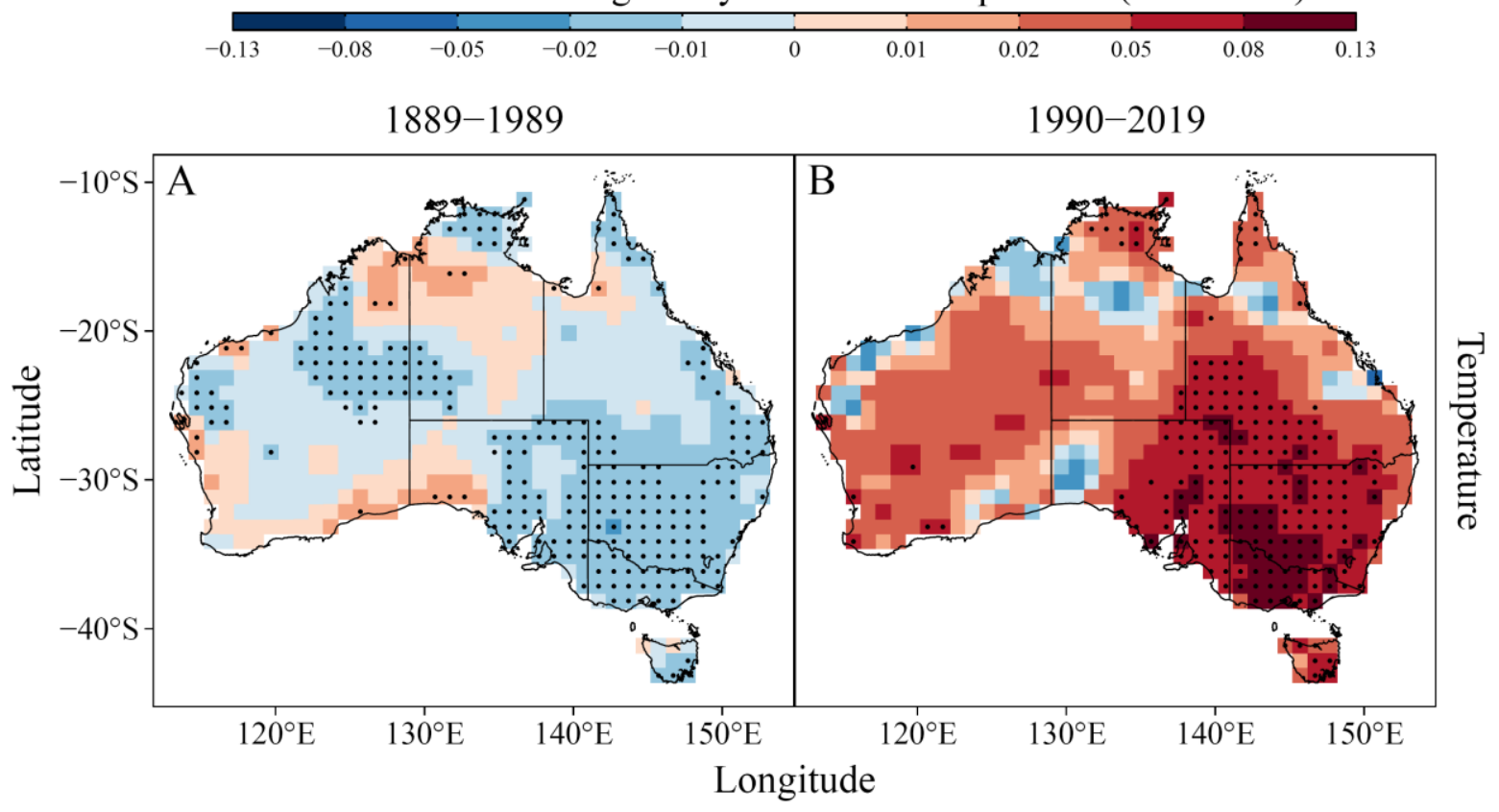

Linear trend in in average total precipitation (mm/decade)

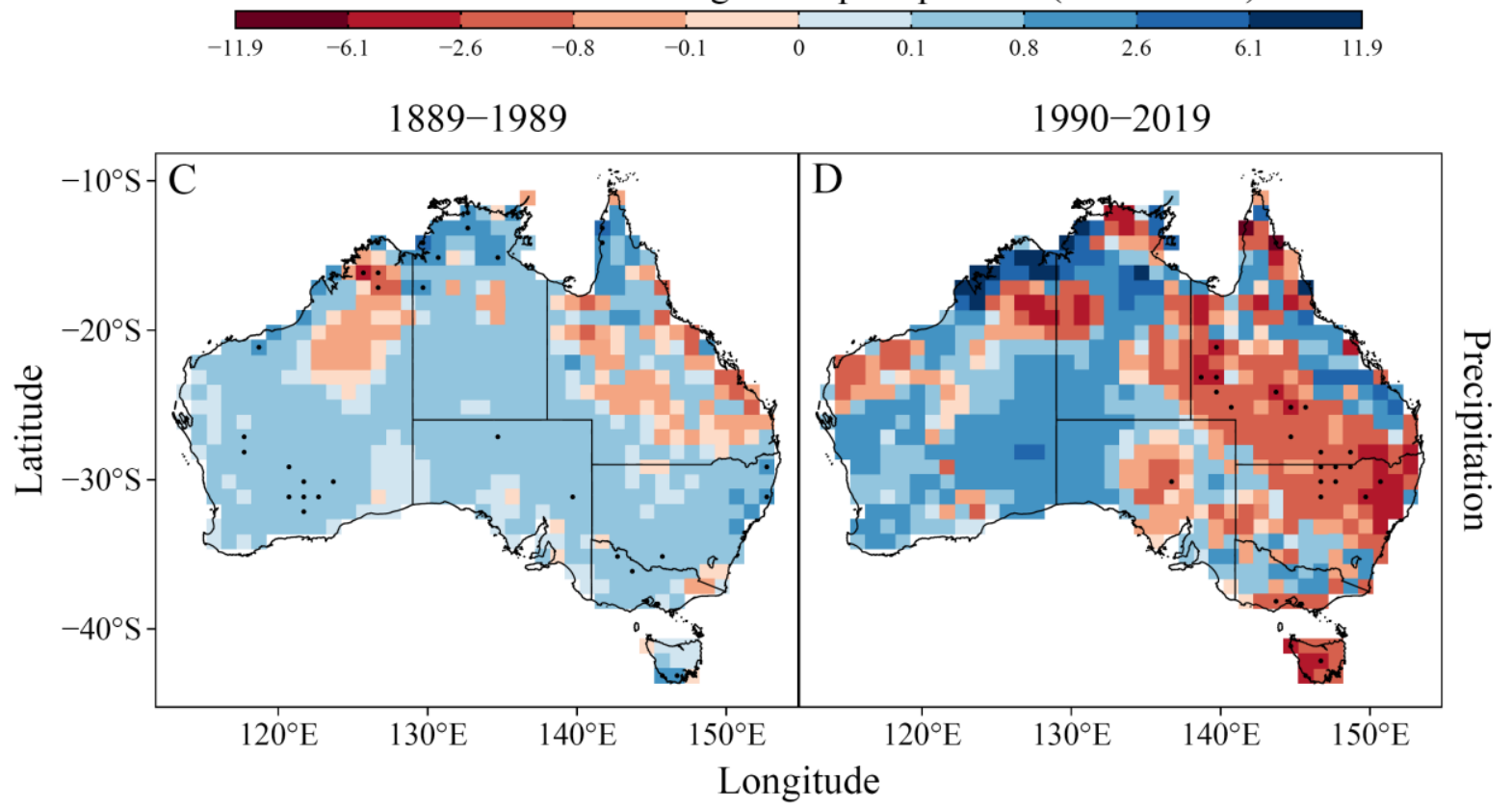

Figure S3. Trends in summer mean maximum daily temperature (MMT; A,B) and total precipitation (TPR; C,D) over 1889-1989 and 1990-2019. Dots show significant trends $(\mathrm{P}<0.05)$. 
Linear trend in average daily maximum temperature $\left({ }^{\circ} \mathrm{C} /\right.$ decade $)$
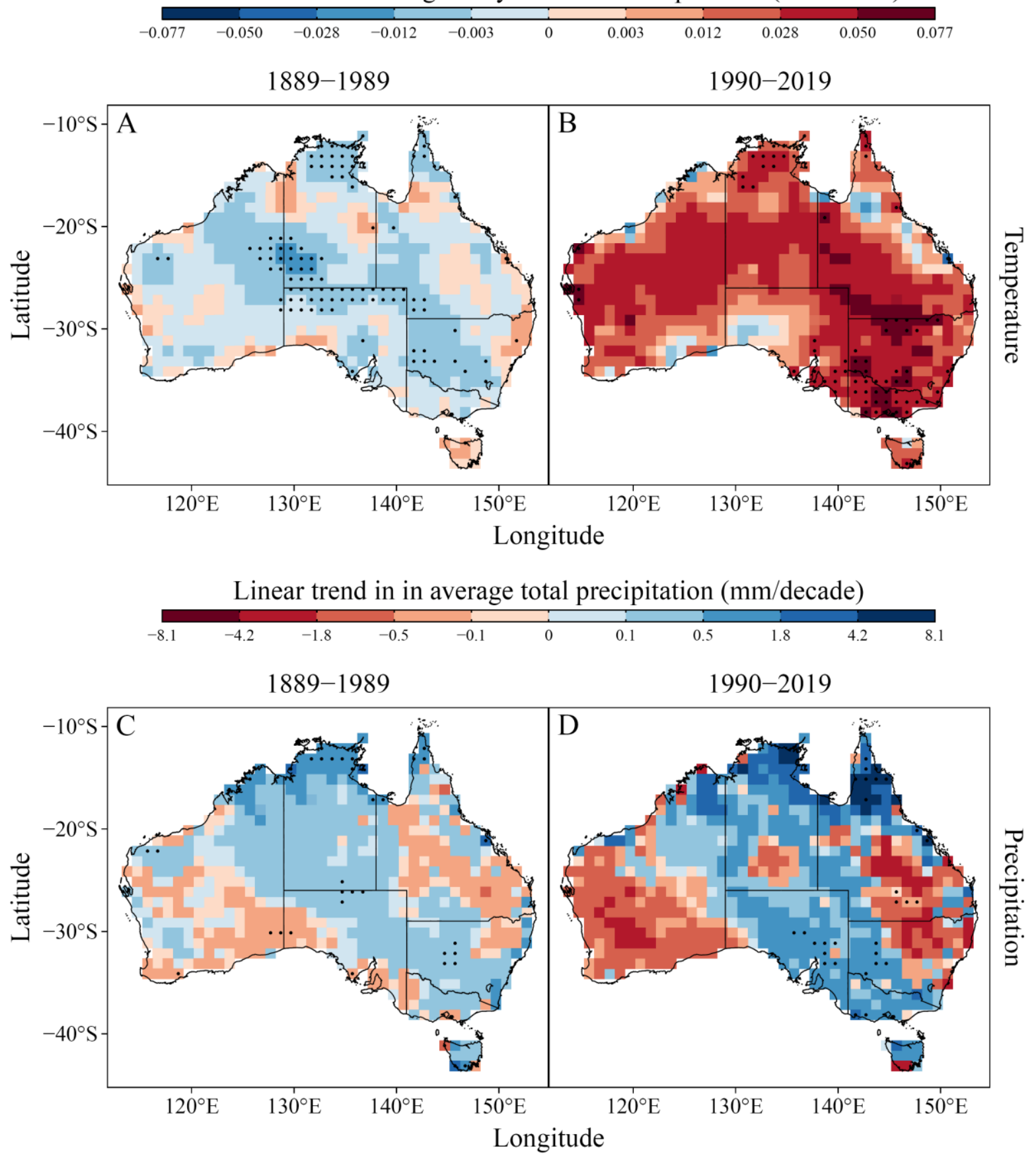

Figure S4. Trends in autumn mean maximum daily temperature (MMT; A,B) and total precipitation (TPR; C,D) over 1889-1989 and 1990-2019. Dots show significant trends $(\mathrm{P}<0.05)$. 
Linear trend in average daily maximum temperature $\left({ }^{\circ} \mathrm{C} /\right.$ decade $)$
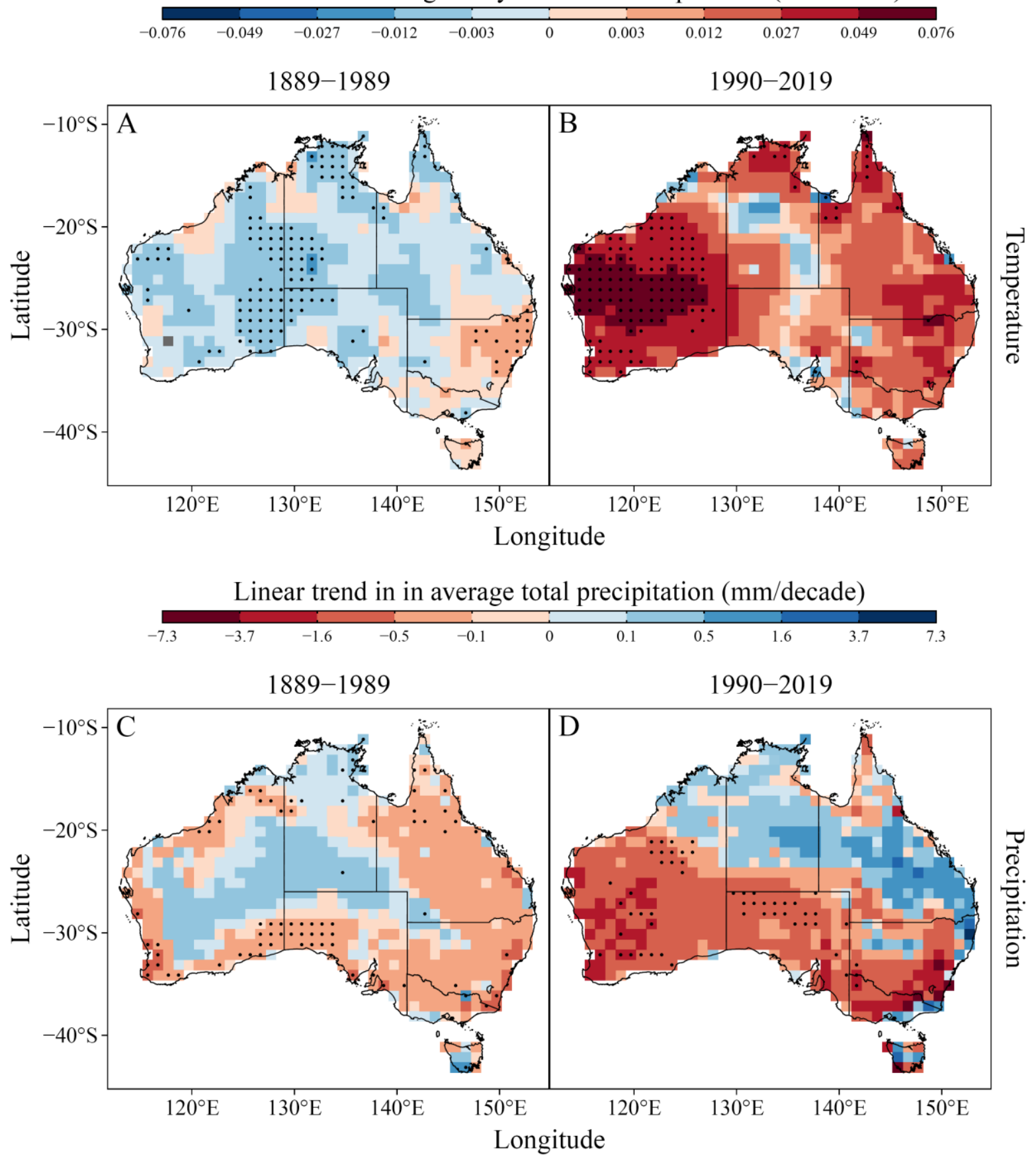

Figure S5. Trends in winter mean maximum daily temperature (MMT; A,B) and total precipitation (TPR; C,D) over 1889-1989 and 1990-2019. Dots show significant trends $(\mathrm{P}<0.05)$. 
Linear trend in average daily maximum temperature $\left({ }^{\circ} \mathrm{C} /\right.$ decade $)$
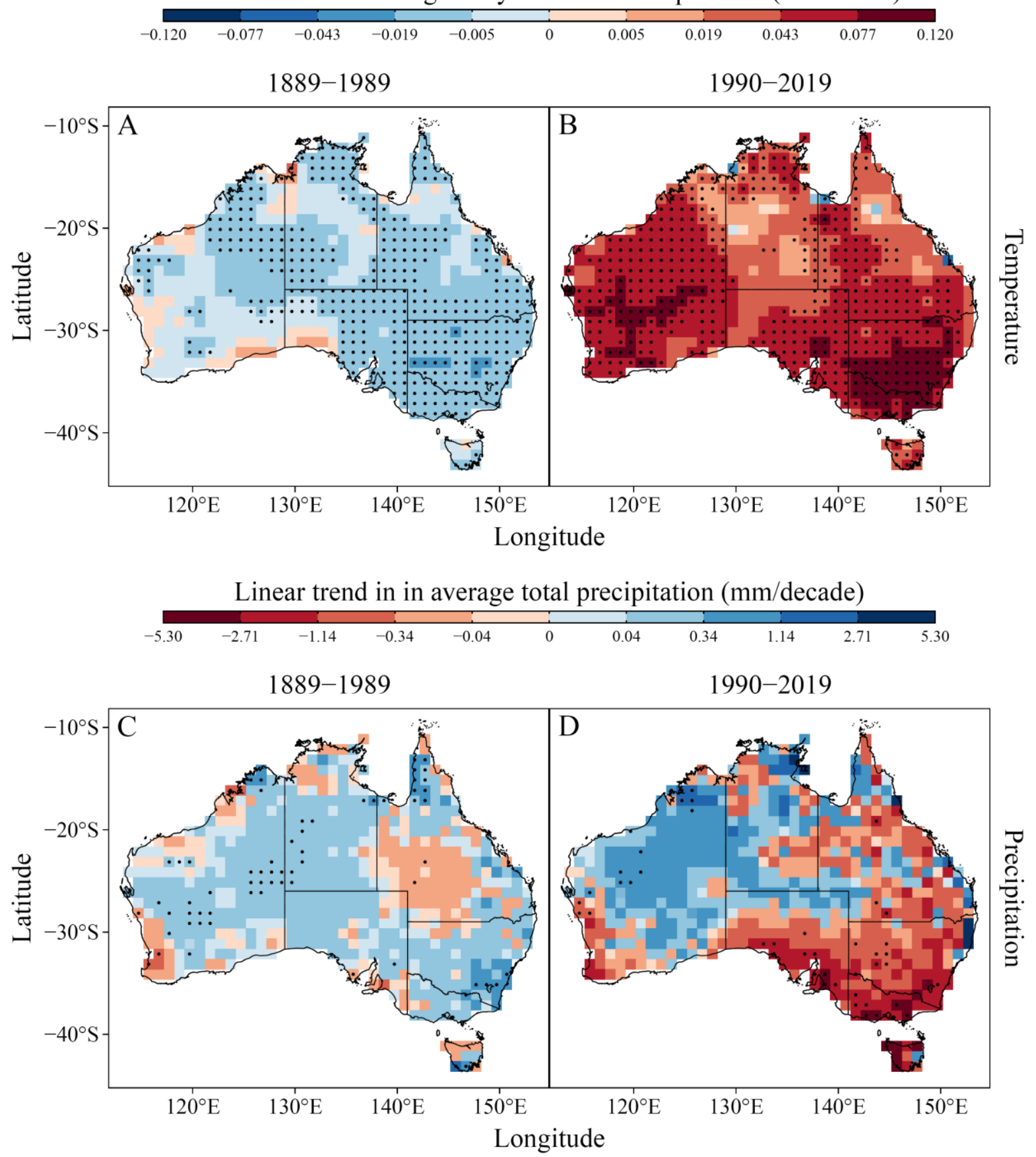

Figure S6. Trends in spring mean maximum daily temperature (MMT; A,B) and total precipitation (TPR; C,D) over 1889-1989 and 1990-2019. Dots show significant trends $(\mathrm{P}<0.05)$. 


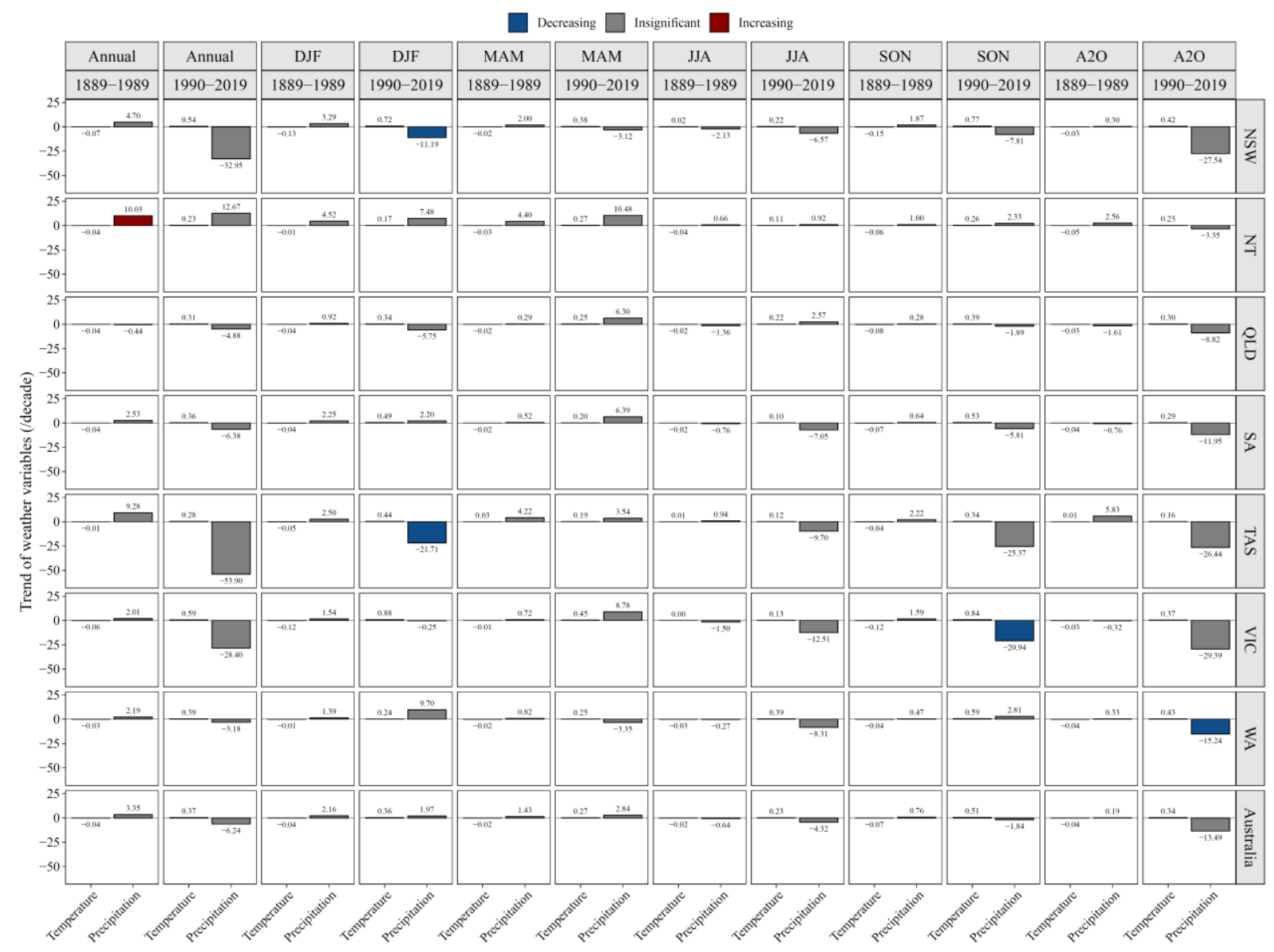

Figure S7. Trends in daily maximum temperature and precipitation averaged across states and whole Australia. A2O: autumnwinter, DJF: summer, MAM: autumn, JJA: winter, SON: spring. NSW: New South Wales, NT: Northern Territory, QLD: Queensland, SA: South Australia, TAS: Tasmania, VIC: Victoria, WA: Western Australia. 


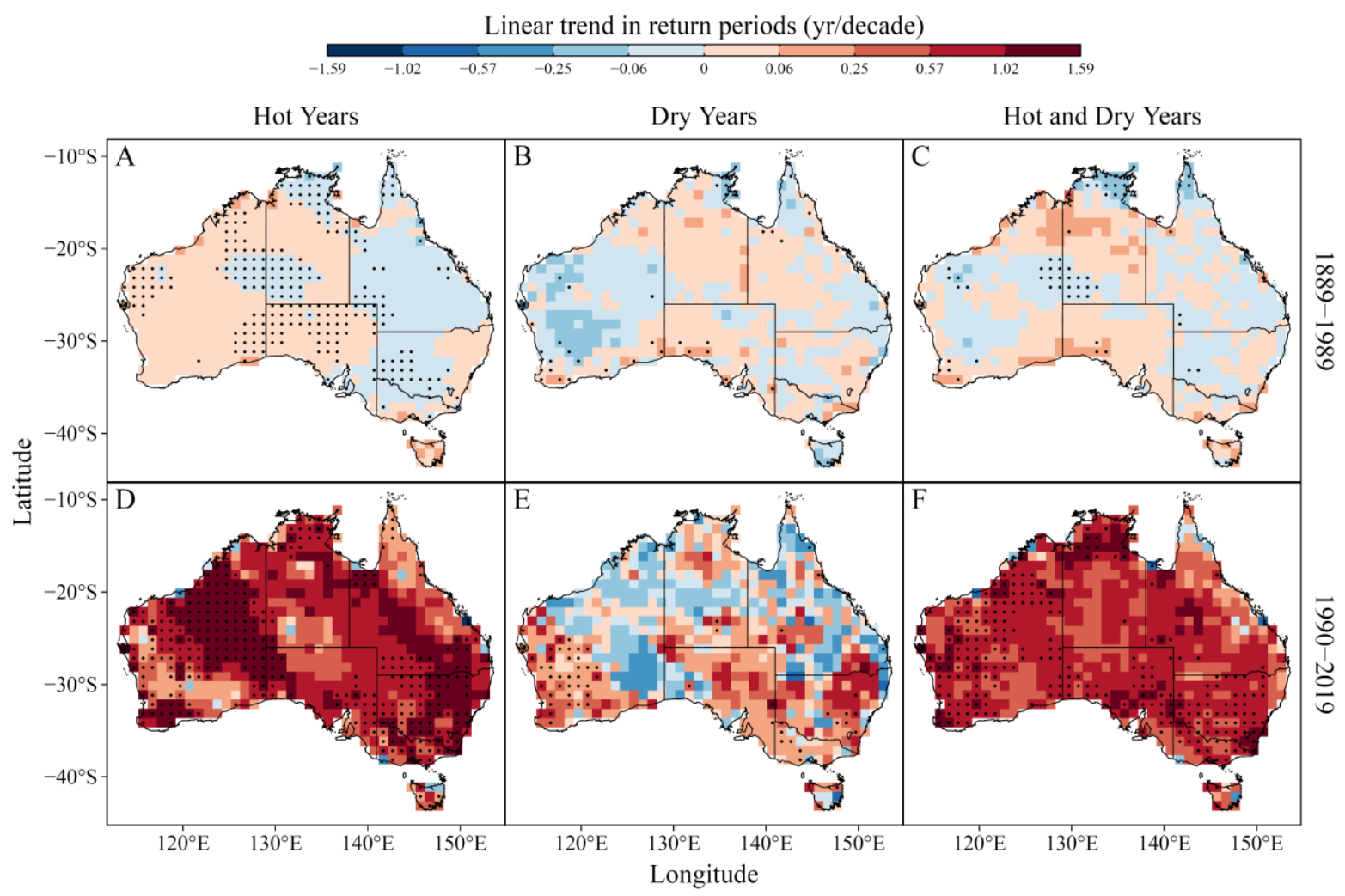

Figure S8. Trends in return periods of autumn-winter hot (A,D), dry (B,E) and compound hot-and-dry (CHD; C,F) extreme events over 1889-1989 and 1990-2019. Dots show significant trends $(\mathrm{P}<0.05)$. 


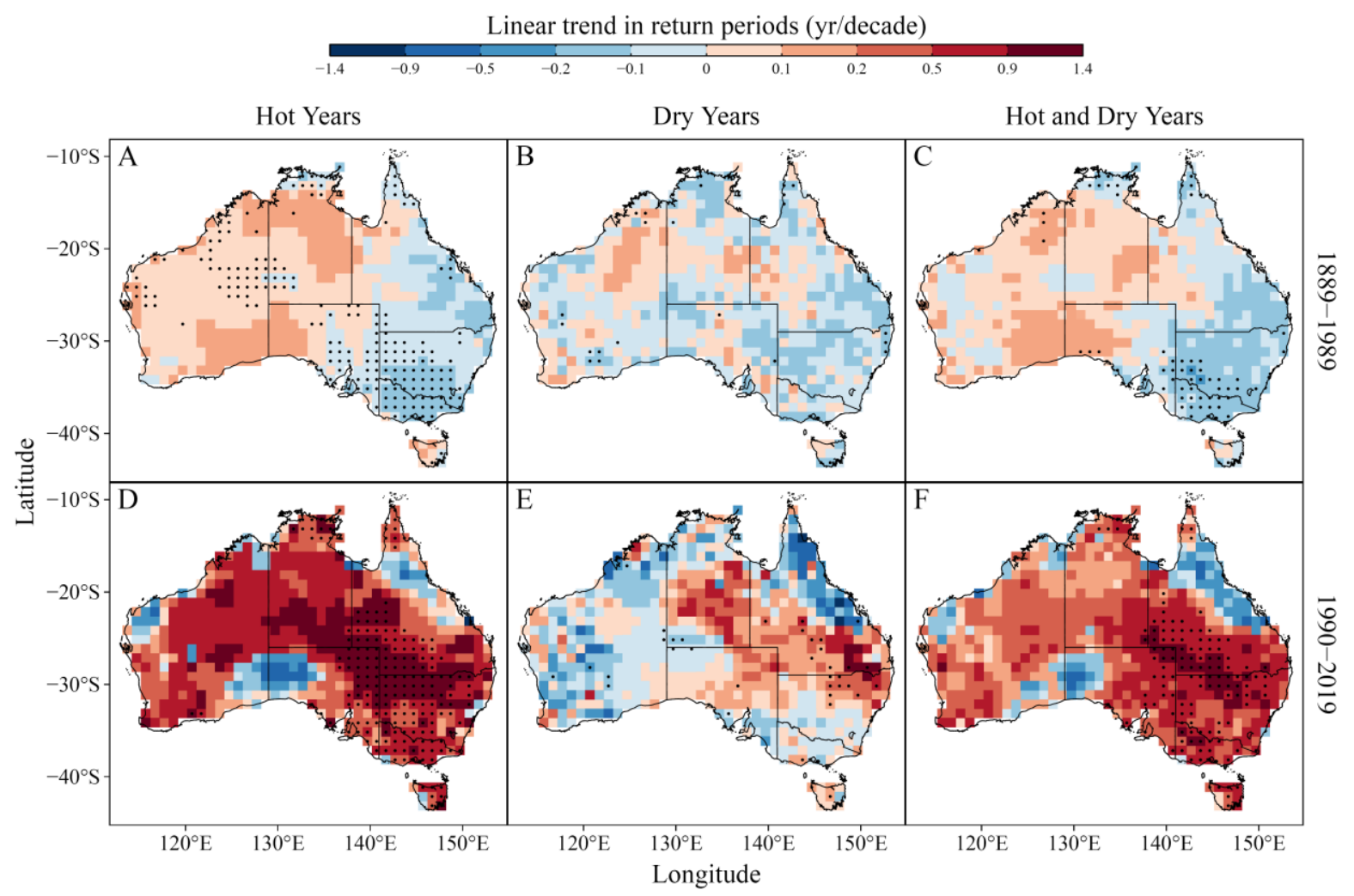

Figure S9. Trends in return periods of summer hot $(\mathbf{A}, \mathbf{D})$, dry $(\mathbf{B}, \mathbf{E})$ and compound hot-and-dry (CHD; $\mathbf{C}, \mathbf{F})$ extreme events over 1889-1989 and 1990-2019. Dots show significant trends $(\mathrm{P}<0.05)$. 


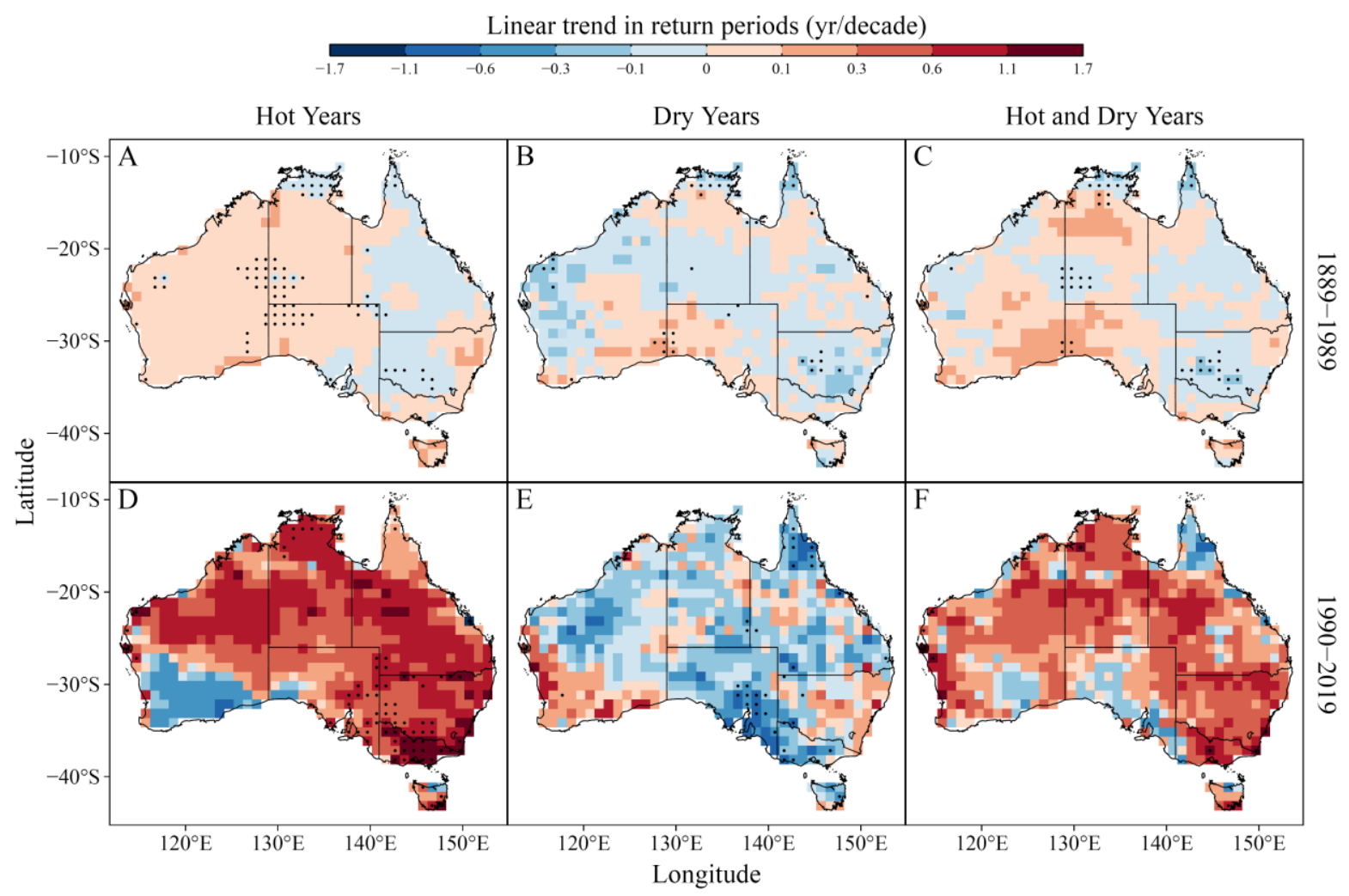

Figure S10. Trends in return periods of autumn hot $(\mathbf{A}, \mathbf{D})$, dry $(\mathbf{B}, \mathbf{E})$ and compound hot-and-dry (CHD; C,F $)$ extreme events over 1889-1989 and 1990-2019. Dots show significant trends $(\mathrm{P}<0.05)$. 


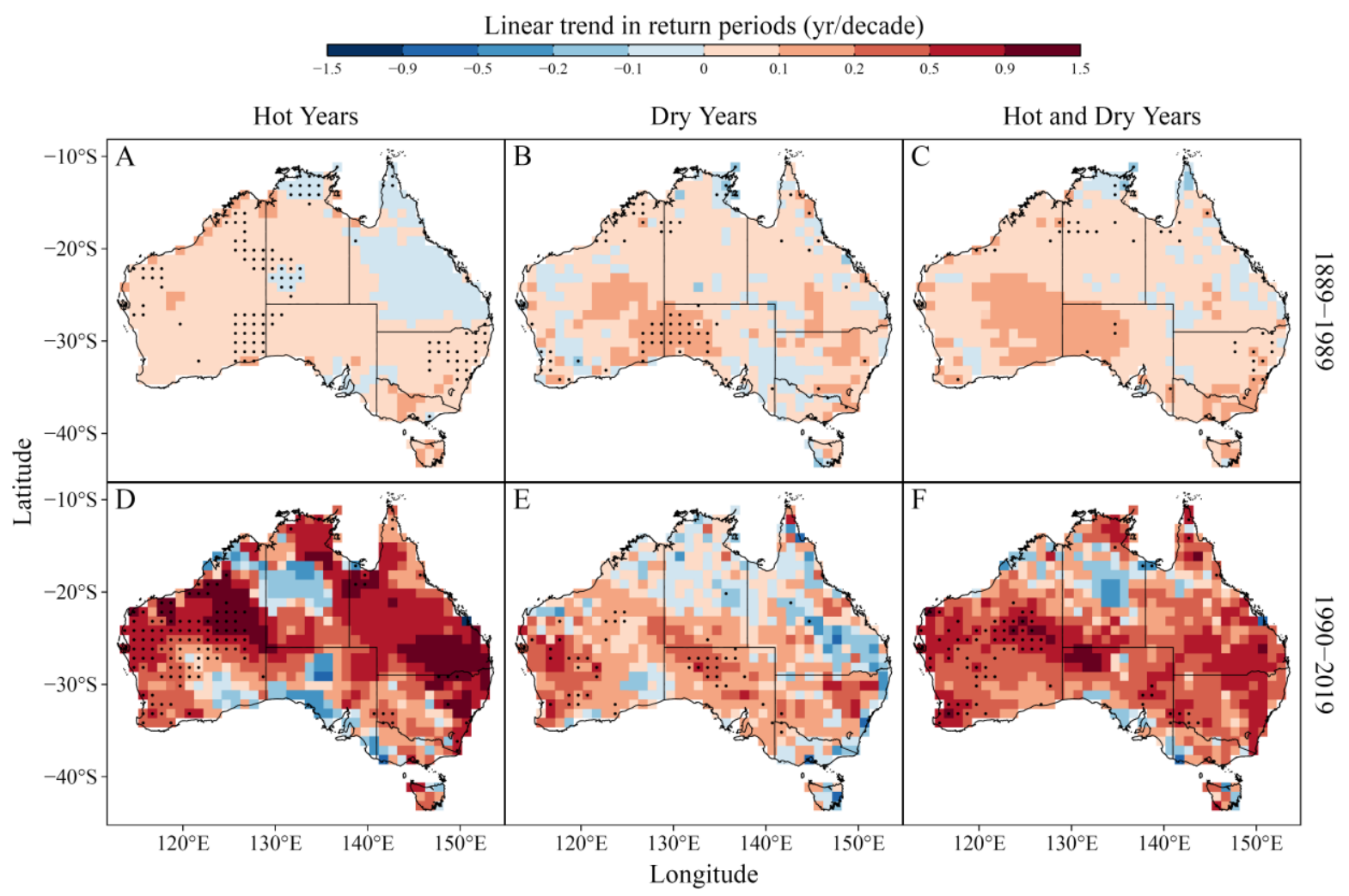

Figure S11. Trends in return periods of winter hot (A,D), dry (B,E) and compound hot-and-dry (CHD; C,F) extreme events over 1889-1989 and 1990-2019. Dots show significant trends $(\mathrm{P}<0.05)$. 


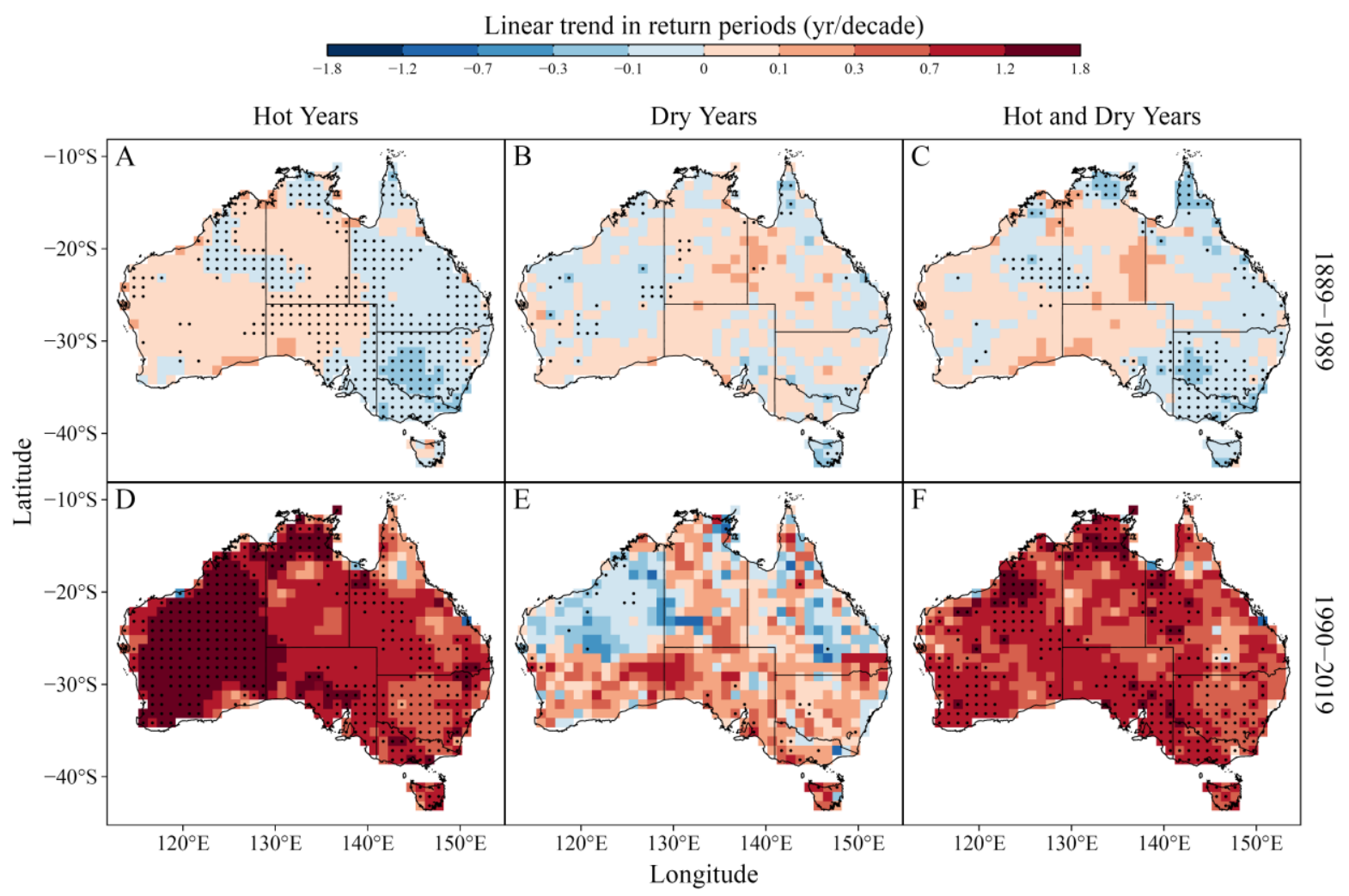

Figure S12. Trends in return periods of spring hot (A,D), dry (B,E) and compound hot-and-dry (CHD; C,F) extreme events over 1889-1989 and 1990-2019. Dots show significant trends $(\mathrm{P}<0.05)$. 


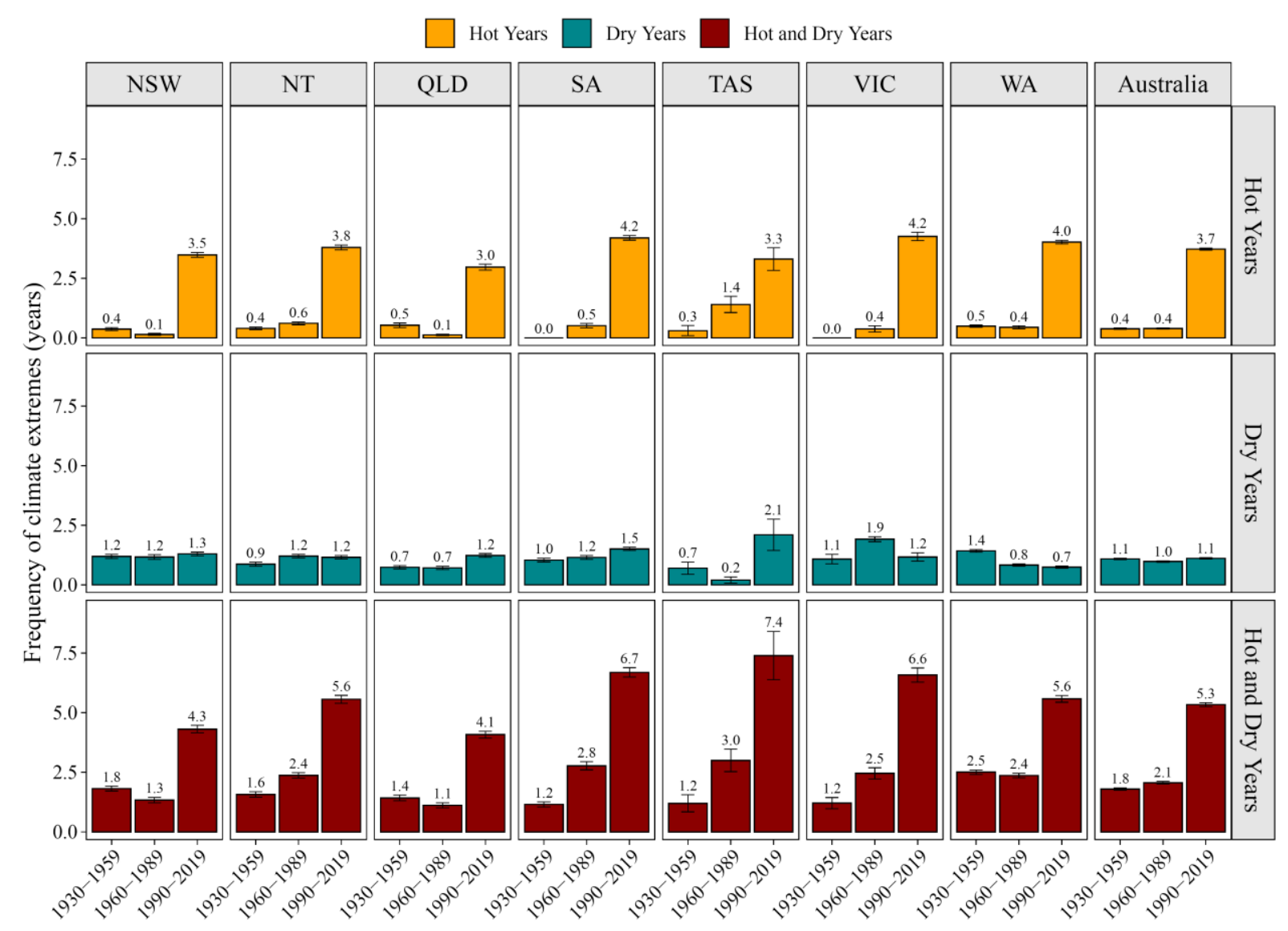

Figure S13. Average frequency of annual CHD events across states and whole Australia. NSW: New South Wales, NT: Northern Territory, QLD: Queensland, SA: South Australia, TAS: Tasmania, VIC: Victoria, WA: Western Australia. 


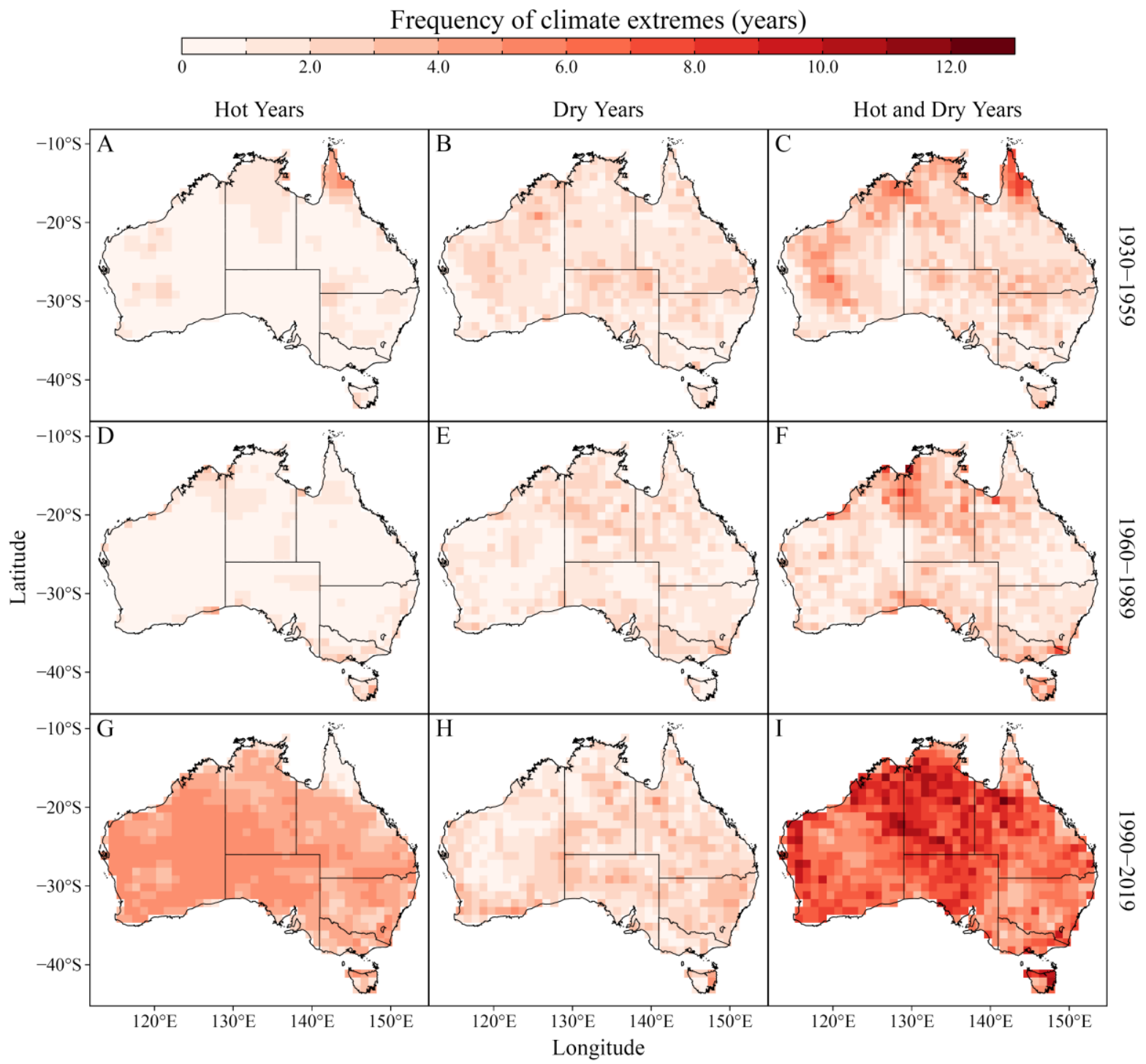

Figure S14. Average frequency of autumn-winter hot $(\mathbf{A}, \mathbf{D}, \mathbf{G})$, dry $(\mathbf{B}, \mathbf{E}, \mathbf{H})$ and compound hot-and-dry $(\mathbf{C H D} ; \mathbf{C}, \mathbf{F}, \mathbf{B})$ extreme events over three consecutive 30-year periods between 1930 and 2019. 


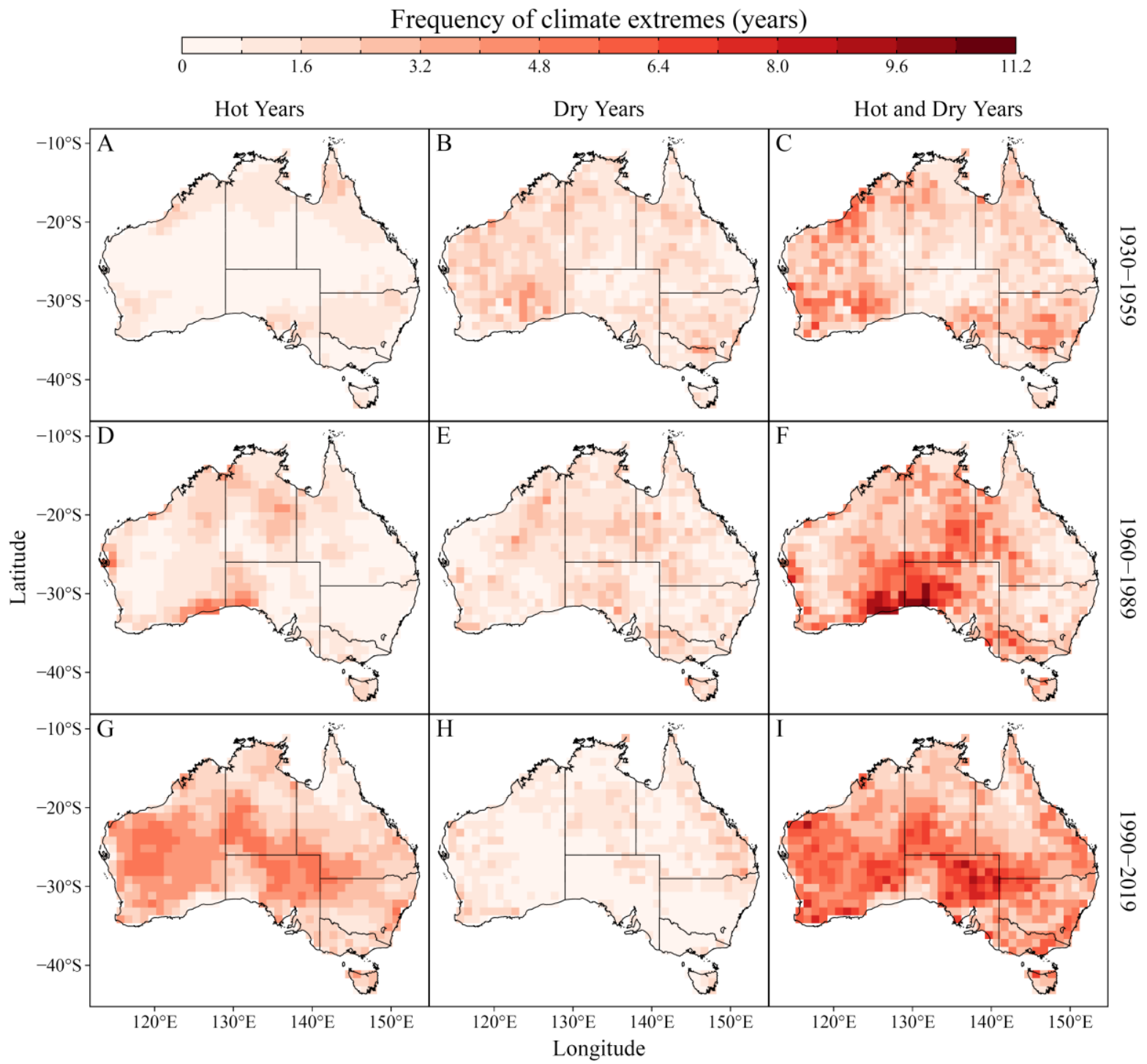

Figure S15. Average frequency of summer hot $(\mathbf{A}, \mathbf{D}, \mathbf{G})$, dry $(\mathbf{B}, \mathbf{E}, \mathbf{H})$ and compound hot-and-dry $(\mathbf{C H D} ; \mathbf{C}, \mathbf{F}, \mathbf{B})$ extreme events over three consecutive 30-year periods between 1930 and 2019. 


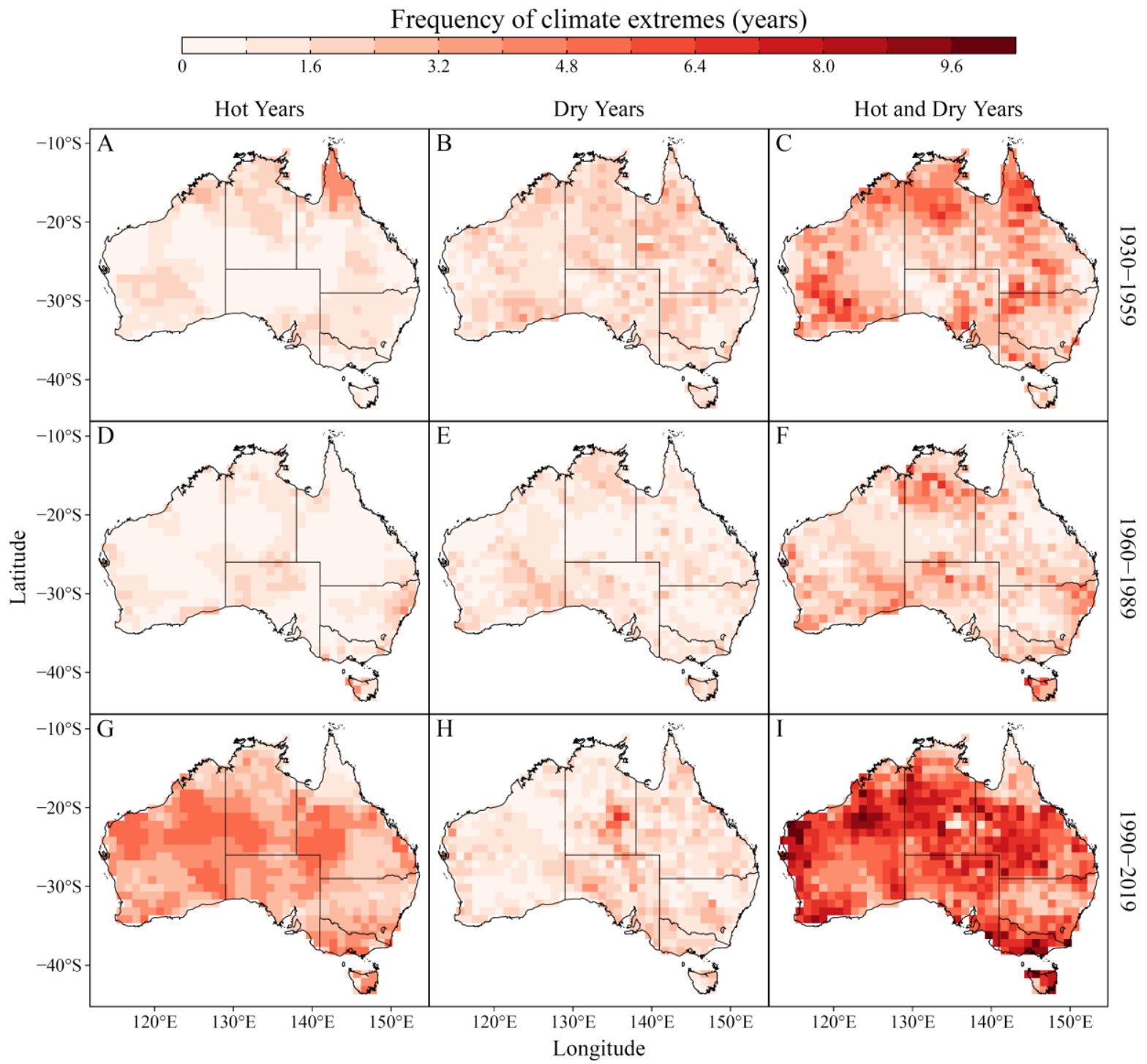

Figure S16. Average frequency of autumn hot $(\mathbf{A}, \mathbf{D}, \mathbf{G})$, dry $(\mathbf{B}, \mathbf{E}, \mathbf{H})$ and compound hot-and-dry $(\mathrm{CHD} ; \mathbf{C}, \mathbf{F}, \mathbf{B})$ extreme events over three consecutive 30-year periods between 1930 and 2019. 


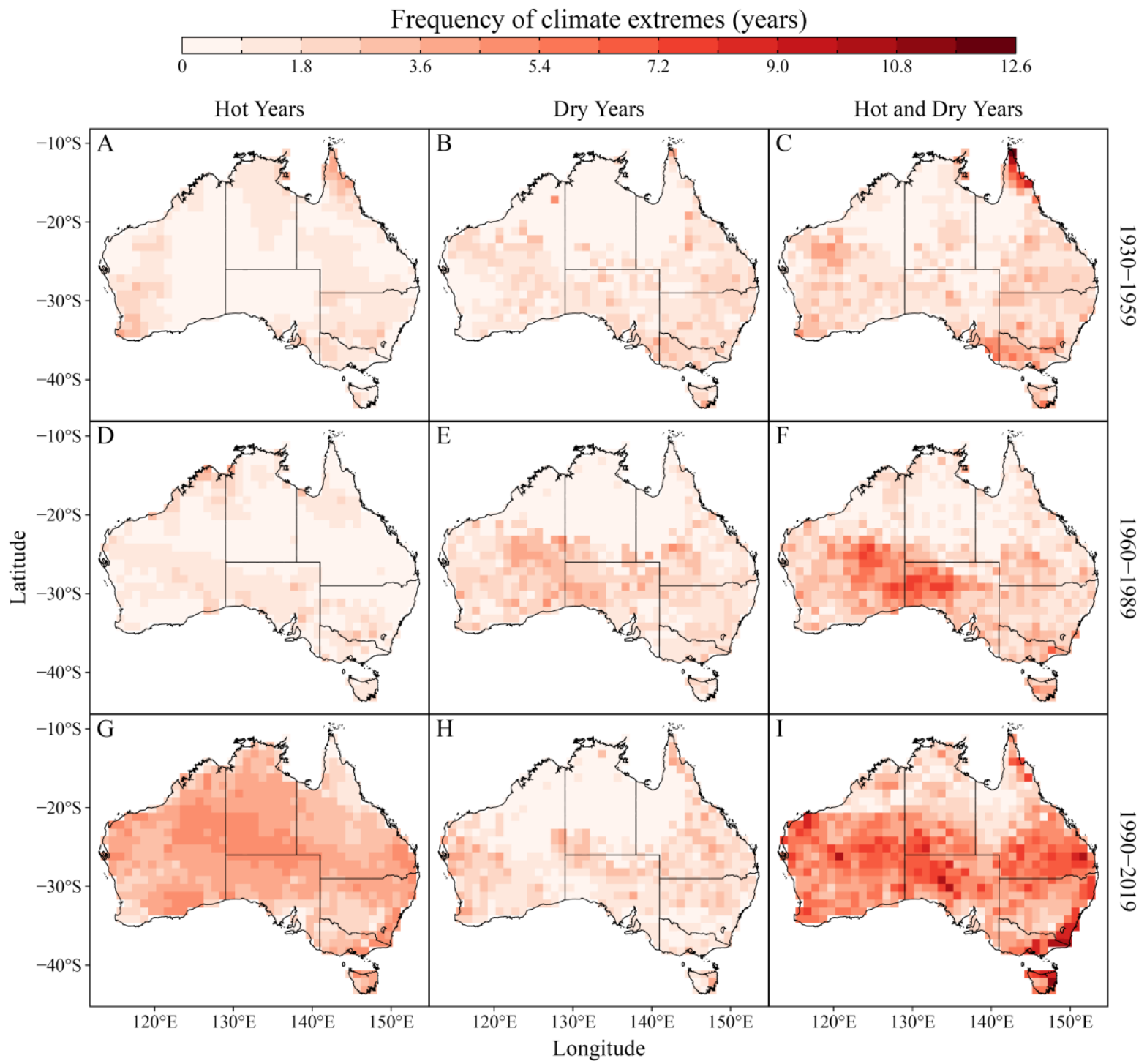

Figure S17. Average frequency of winter hot $(\mathbf{A}, \mathbf{D}, \mathbf{G})$, dry $(\mathbf{B}, \mathbf{E}, \mathbf{H})$ and compound hot-and-dry $(\mathbf{C H D} ; \mathbf{C}, \mathbf{F}, \mathbf{B})$ extreme events over three consecutive 30-year periods between 1930 and 2019. 


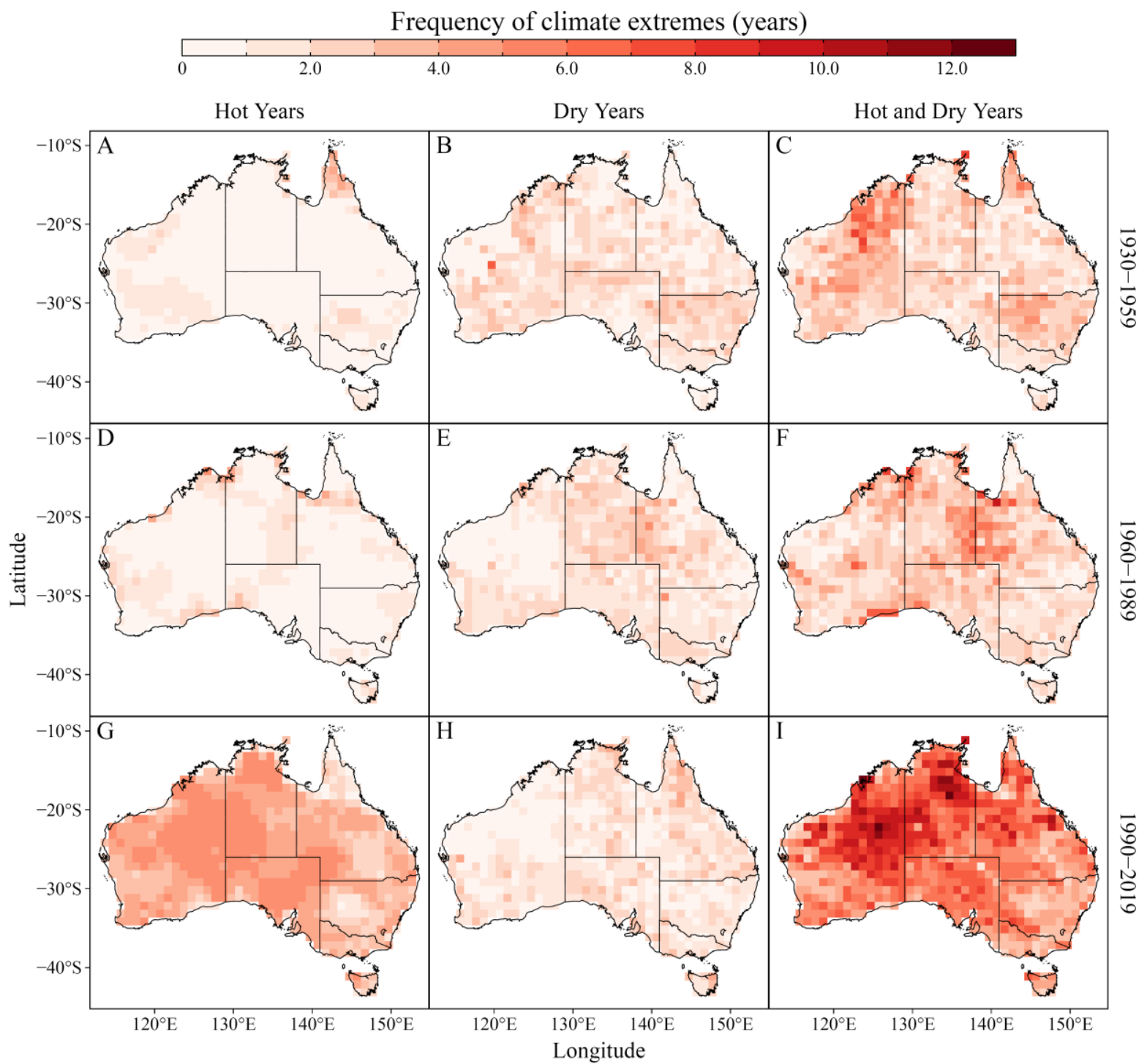

Figure S18. Average frequency of spring hot $(\mathbf{A}, \mathbf{D}, \mathbf{G})$, dry $(\mathbf{B}, \mathbf{E}, \mathbf{H})$ and compound hot-and-dry $(\mathbf{C H D} ; \mathbf{C}, \mathbf{F}, \mathbf{B})$ extreme events over three consecutive 30-year periods between 1930 and 2019. 
Insignificant $\square$ Significant

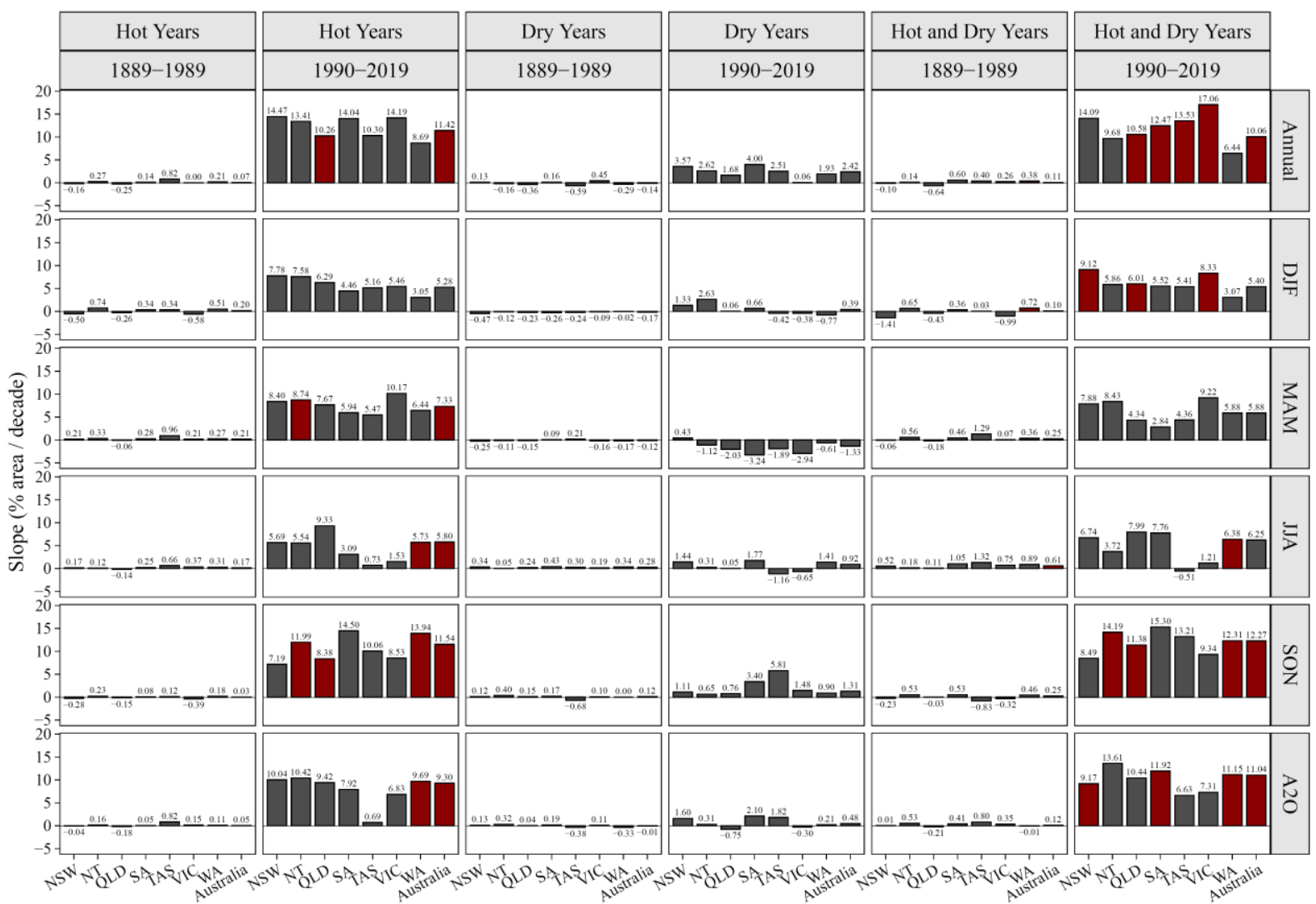

Figure S19. Trend in area affected by hot, dry and compound hot-and-dry (CHD) extreme events over 1889-1989 and 1990-2019. A2O: autumn-winter, DJF: summer, MAM: autumn, JJA: winter, SON: spring. NSW: New South Wales, NT: Northern Territory, QLD: Queensland, SA: South Australia, TAS: Tasmania, VIC: Victoria, WA: Western Australia. 
Hot and Dry Years

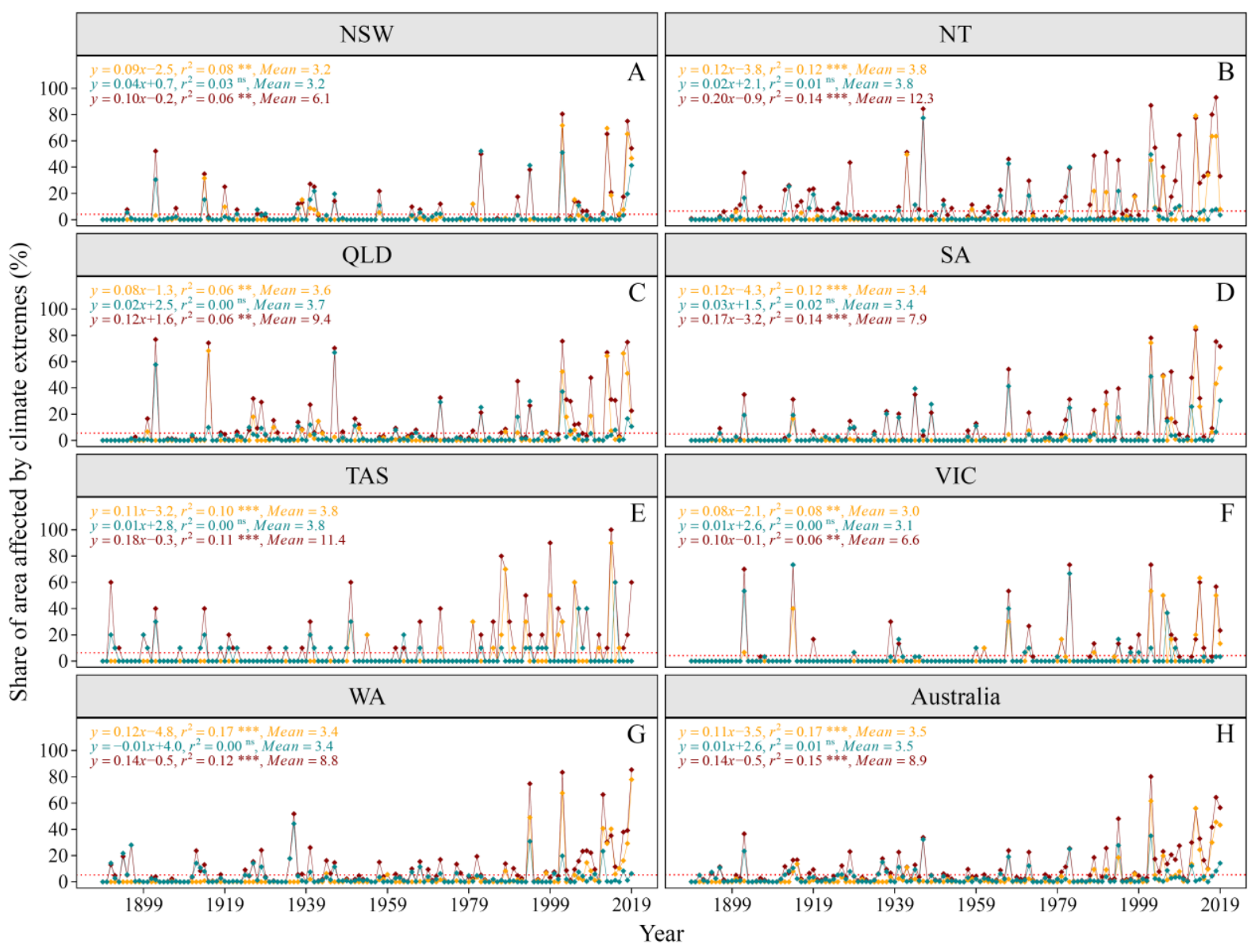

Figure S20. Area affected by autumn-winter hot, dry and compound hot-and-dry (CHD) extreme events over 1889-2019. NSW: New South Wales, NT: Northern Territory, QLD: Queensland, SA: South Australia, TAS: Tasmania, VIC: Victoria, WA: Western Australia. 
Hot and Dry Years

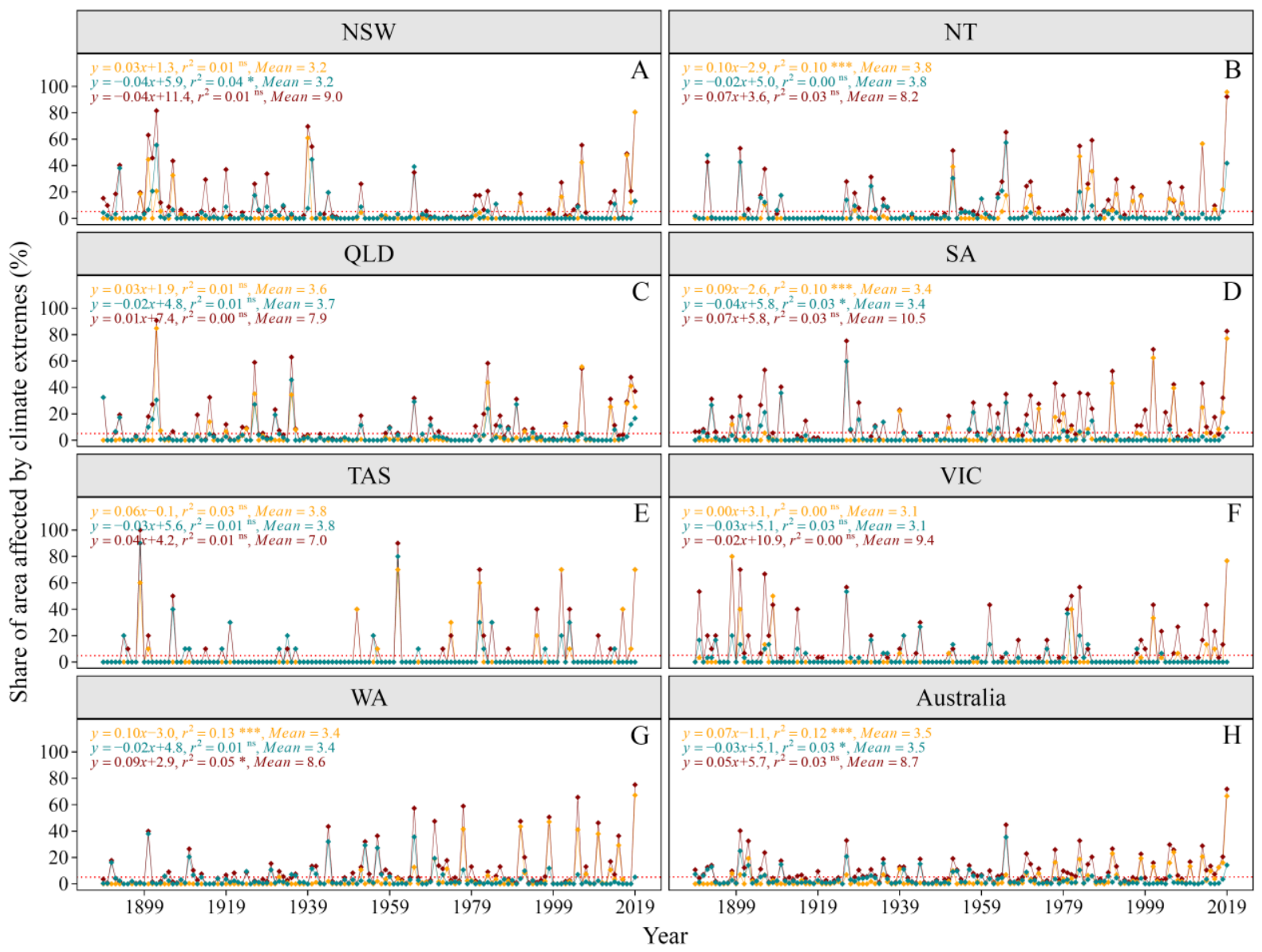

Figure S21. Area affected by summer hot, dry and compound hot-and-dry (CHD) extreme events over 1889-2019. NSW: New South Wales, NT: Northern Territory, QLD: Queensland, SA: South Australia, TAS: Tasmania, VIC: Victoria, WA: Western Australia. 
Hot and Dry Years

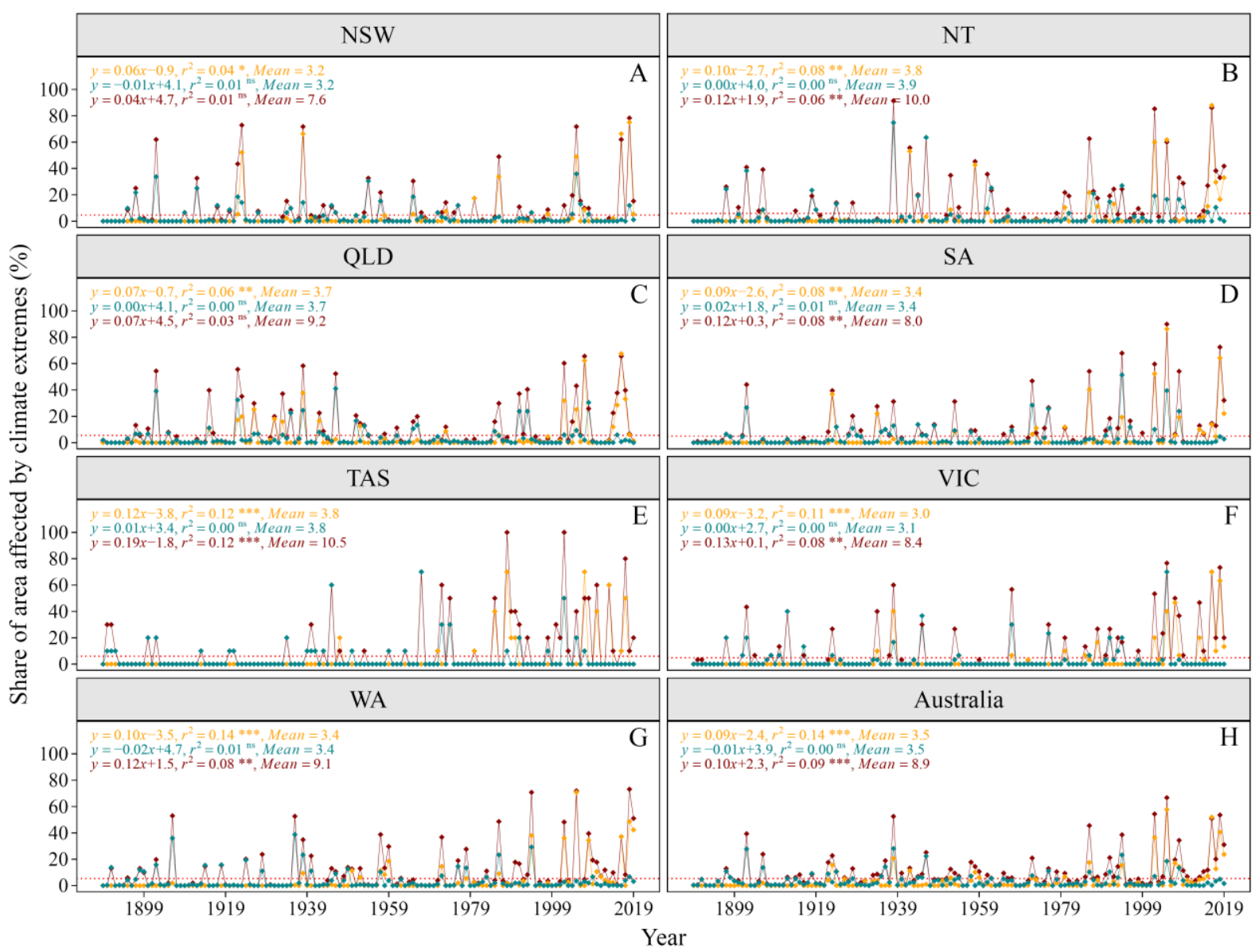

Figure S22. Area affected by autumn hot, dry and compound hot-and-dry (CHD) extreme events over 1889-2019. NSW: New South Wales, NT: Northern Territory, QLD: Queensland, SA: South Australia, TAS: Tasmania, VIC: Victoria, WA: Western Australia. 
Hot and Dry Years

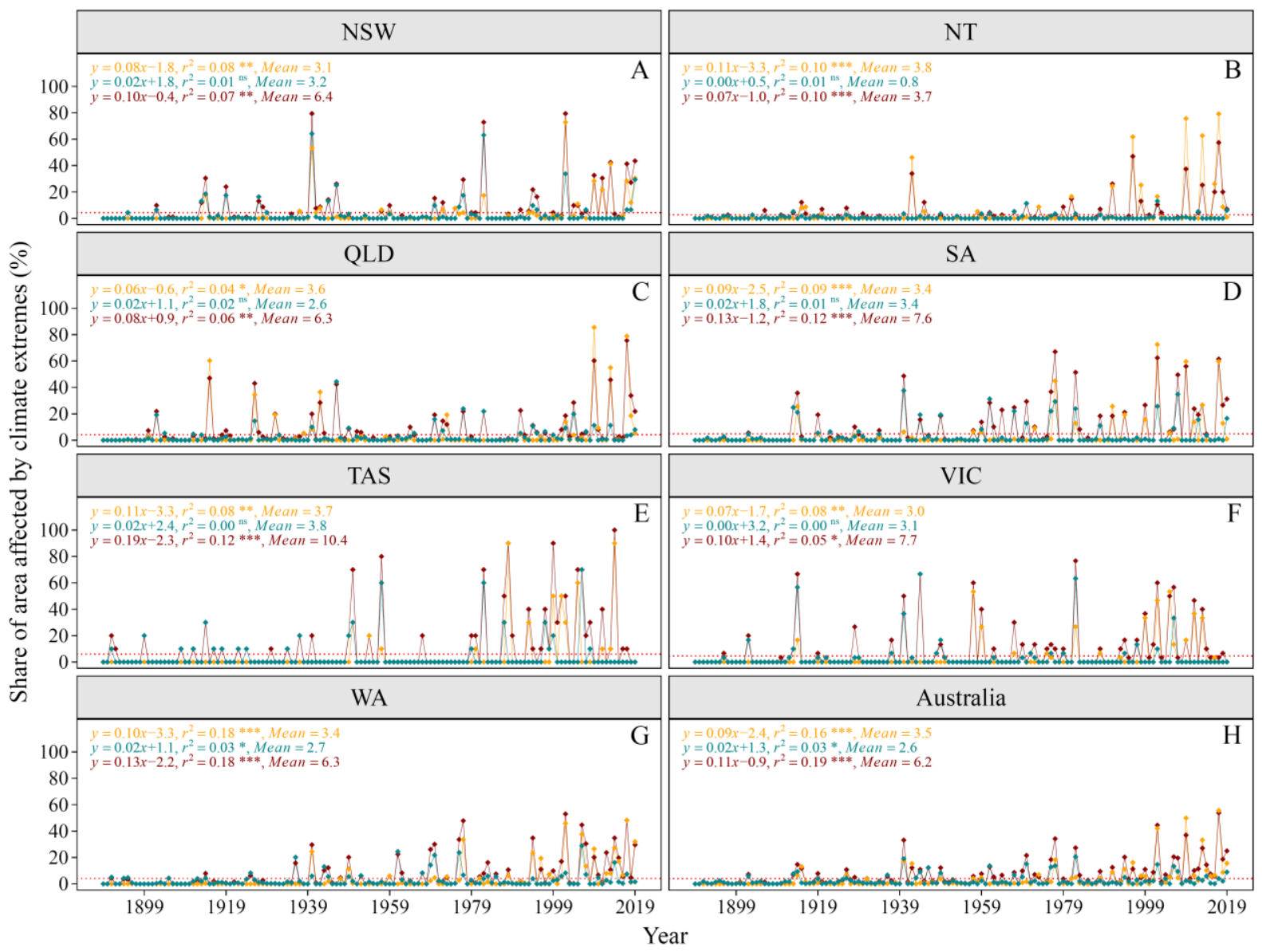

Figure S23. Area affected by winter hot, dry and compound hot-and-dry (CHD) extreme events over 1889-2019. NSW: New South Wales, NT: Northern Territory, QLD: Queensland, SA: South Australia, TAS: Tasmania, VIC: Victoria, WA: Western Australia. 
Hot and Dry Years

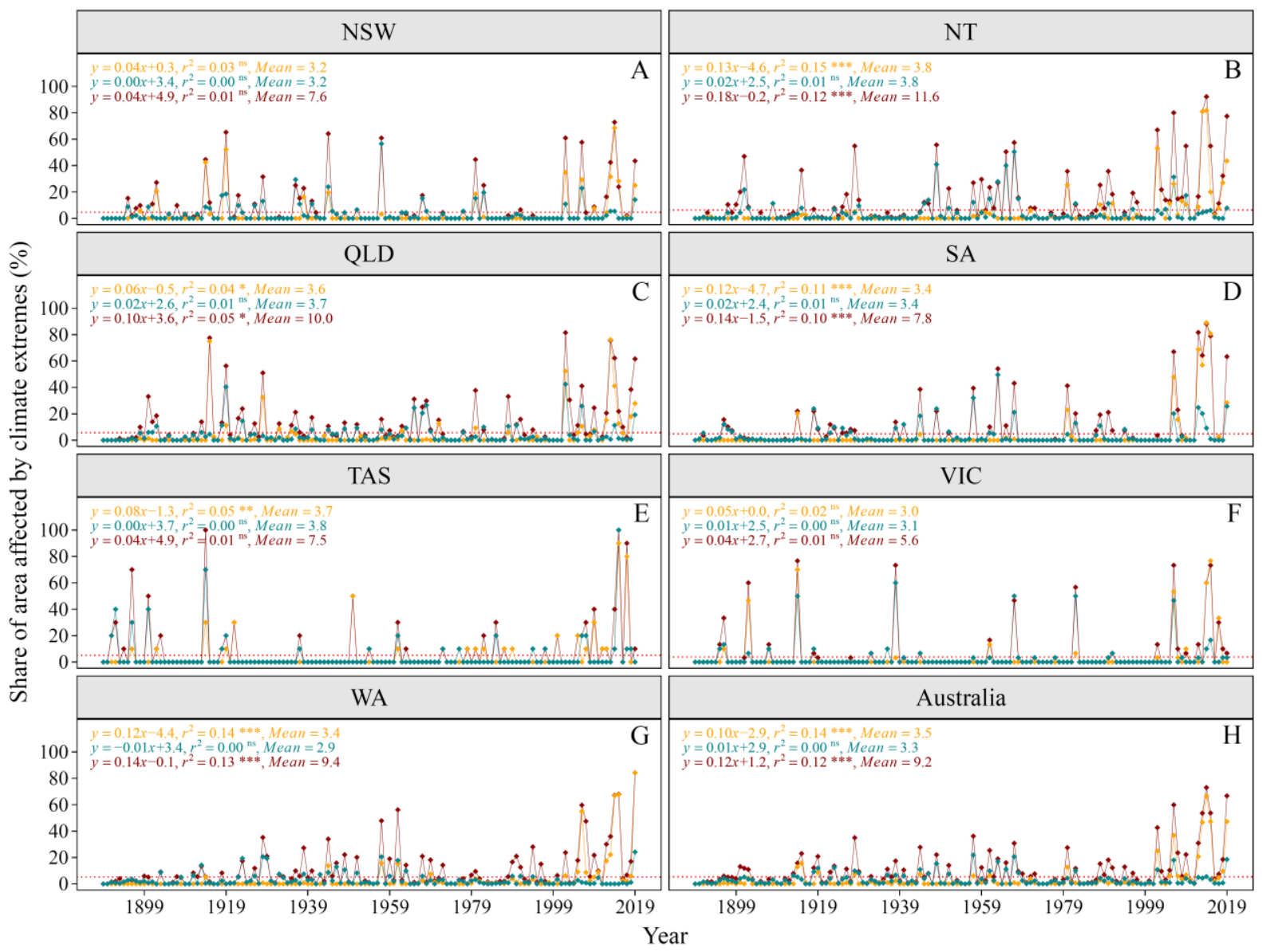

Figure S24. Area affected by spring hot, dry and compound hot-and-dry (CHD) extreme events over 1889-2019. NSW: New South Wales, NT: Northern Territory, QLD: Queensland, SA: South Australia, TAS: Tasmania, VIC: Victoria, WA: Western Australia. 


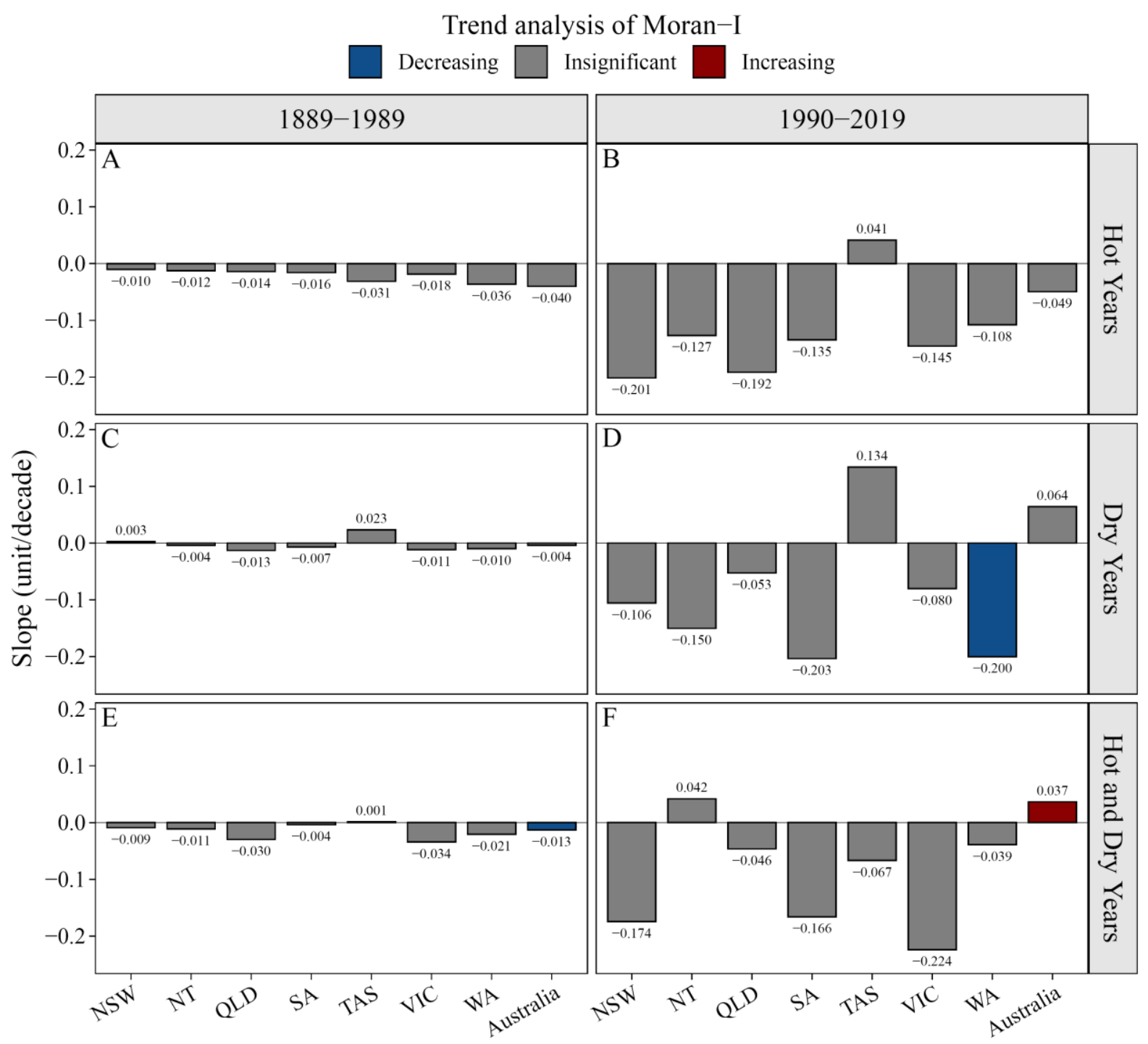

Figure S25. Trends in Moran-I values for autumn-winter hot (A,B), dry (C,D) and compound hot-and-dry (CHD; E,F) extreme events over 1889-1989 and 1990-2019. Blue and red colors show significant $(\mathrm{P}<0.05)$ decreasing and increasing trends. NSW: New South Wales, NT: Northern Territory, QLD: Queensland, SA: South Australia, TAS: Tasmania, VIC: Victoria, WA: Western Australia. 


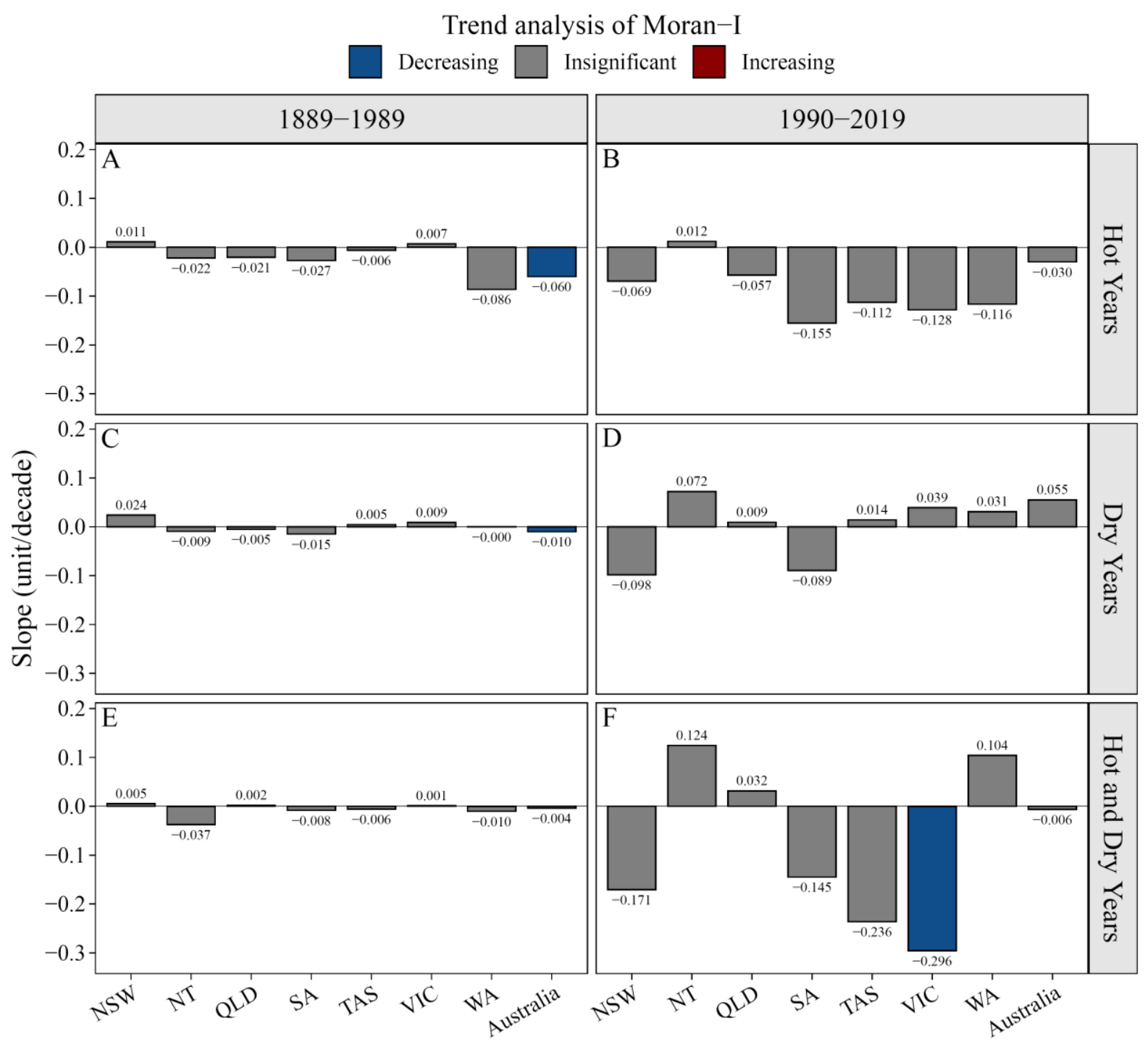

Figure S26. Trends in Moran-I values for summer hot (A,B), dry (C,D) and compound hot-and-dry (CHD; E,F) extreme events over 1889-1989 and 1990-2019. Blue and red colors show significant $(\mathrm{P}<0.05)$ decreasing and increasing trends. NSW: New South Wales, NT: Northern Territory, QLD: Queensland, SA: South Australia, TAS: Tasmania, VIC: Victoria, WA: Western Australia. 


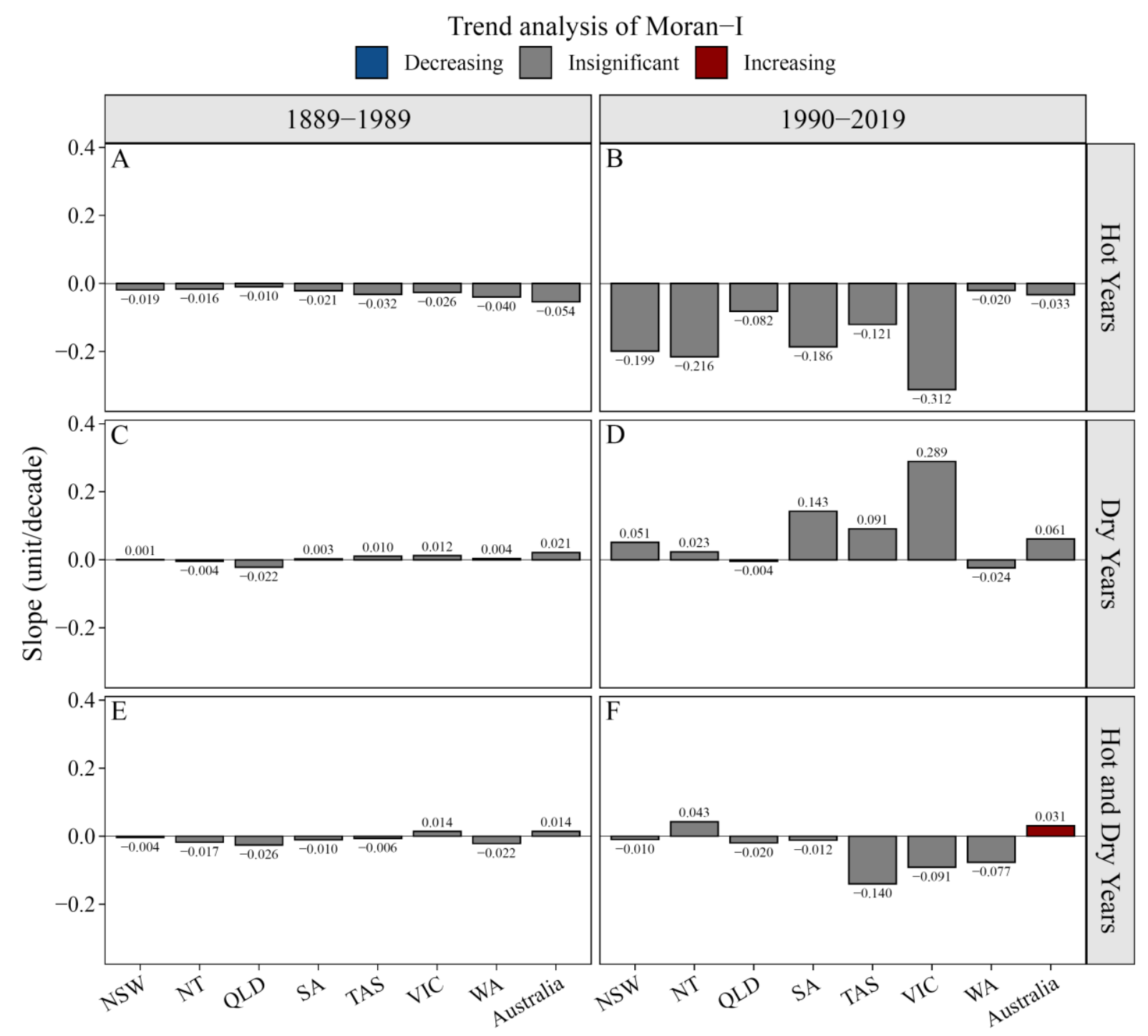

Figure S27. Trends in Moran-I values for autumn hot $(\mathbf{A}, \mathbf{B})$, dry $(\mathbf{C}, \mathbf{D})$ and compound hot-and-dry (CHD; E,F) extreme events over 1889-1989 and 1990-2019. Blue and red colors show significant $(\mathrm{P}<0.05)$ decreasing and increasing trends. NSW: New South Wales, NT: Northern Territory, QLD: Queensland, SA: South Australia, TAS: Tasmania, VIC: Victoria, WA: Western Australia. 


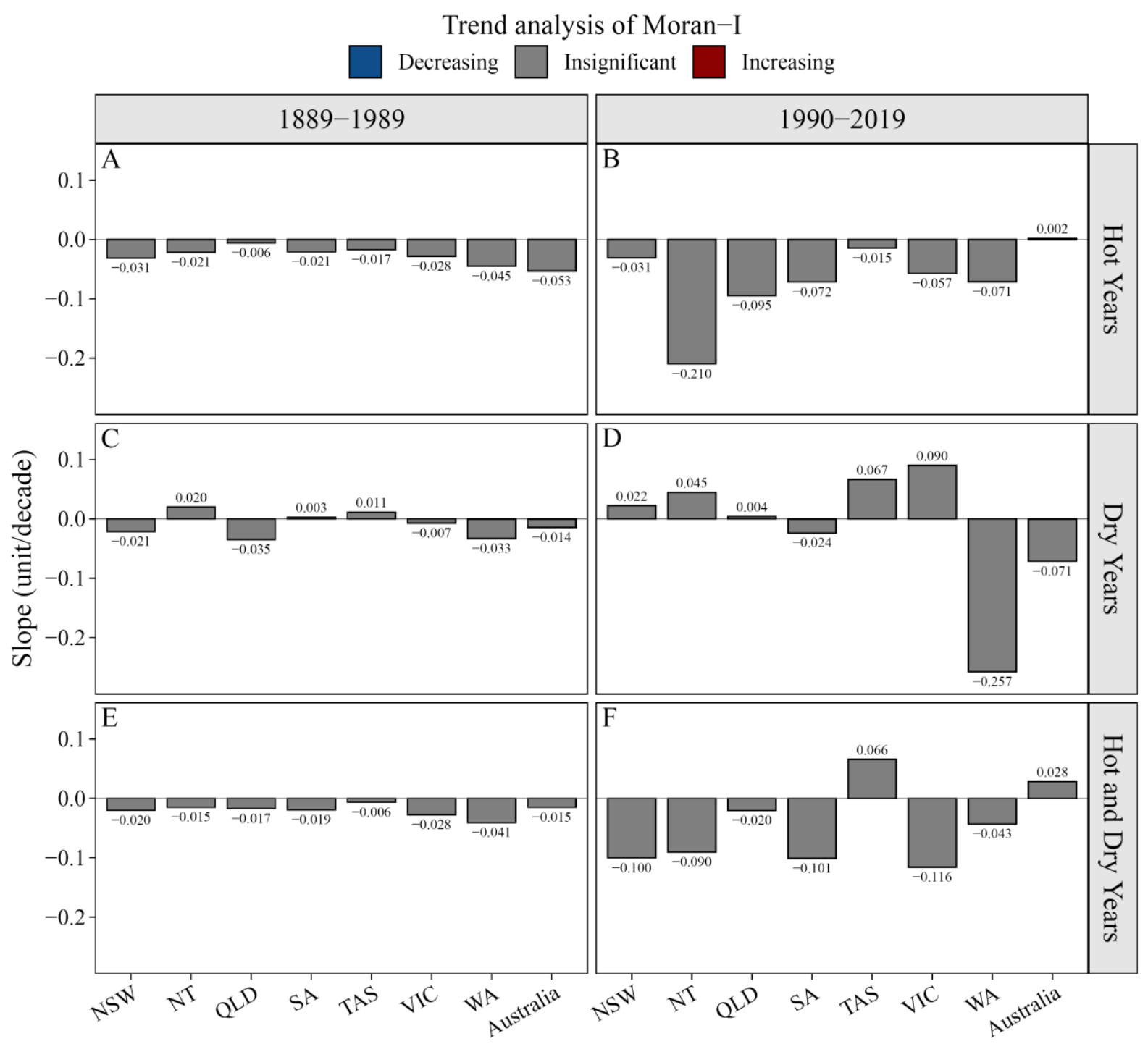

Figure S28. Trends in Moran-I values for winter hot (A,B), dry (C,D) and compound hot-and-dry (CHD; E,F) extreme events over 1889-1989 and 1990-2019. Blue and red colors show significant $(\mathrm{P}<0.05)$ decreasing and increasing trends. NSW: New South Wales, NT: Northern Territory, QLD: Queensland, SA: South Australia, TAS: Tasmania, VIC: Victoria, WA: Western Australia. 


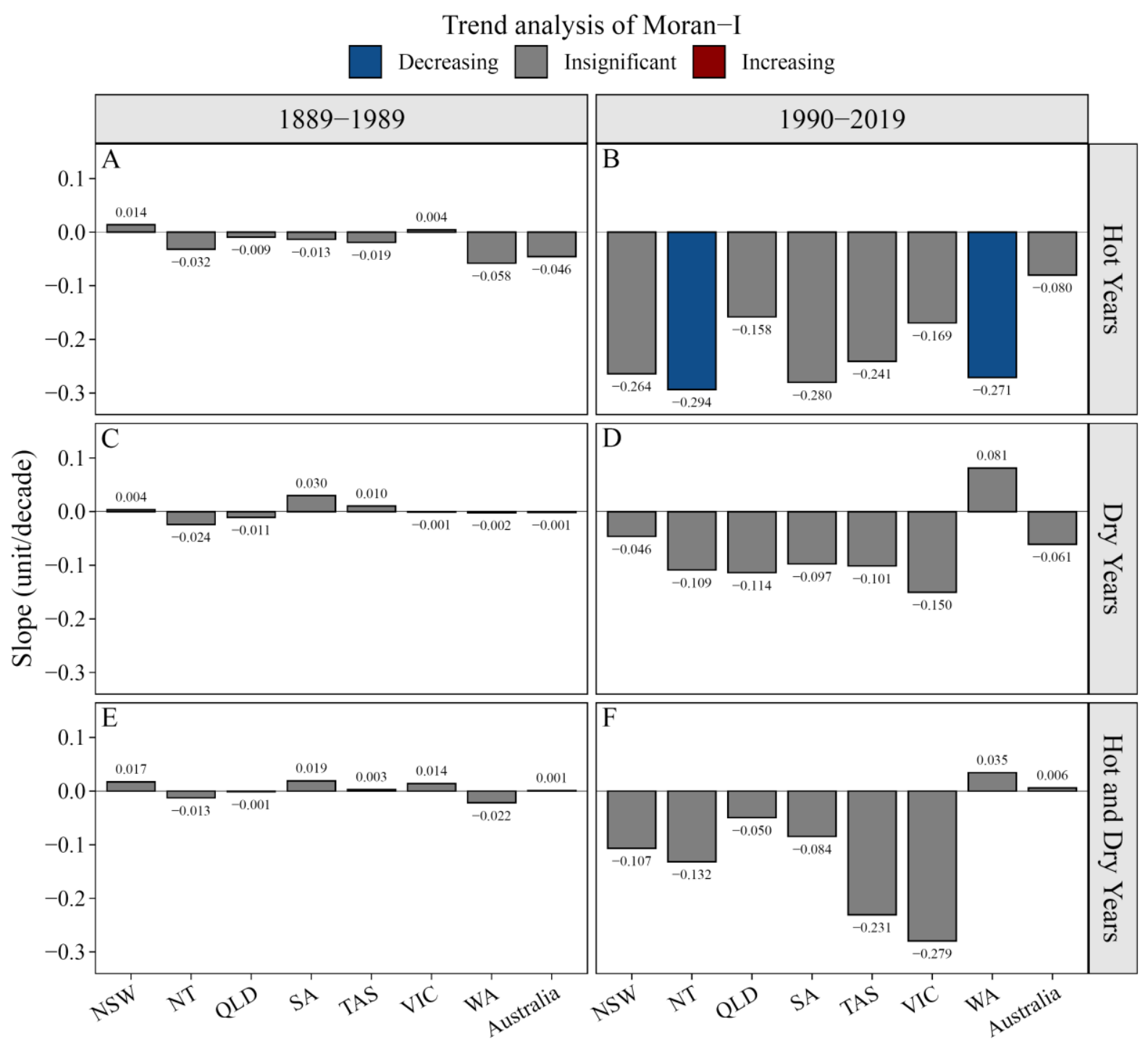

Figure S29. Trends in Moran-I values for spring hot (A,B), dry (C,D) and compound hot-and-dry (CHD; E,F) extreme events over 1889-1989 and 1990-2019. Blue and red colors show significant $(\mathrm{P}<0.05)$ decreasing and increasing trends. NSW: New South Wales, NT: Northern Territory, QLD: Queensland, SA: South Australia, TAS: Tasmania, VIC: Victoria, WA: Western Australia. 